\title{
BASLAbstracts
}

\section{ABSTRACTS FROM THE BRITISH ASSOCIATION FOR THE STUDY OF THE LIVER MEETING HELD ON 13-14 SEPTEMBER 2001 AT THE ROYAL FREE HOSPITAL, LONDON, UK}

\section{DNA IMMUNISATION FOR HBV INFECTIONS}

\author{
M.L. Michel. UREG/INSERM U163 Institut Pasteur, Paris, France
}

Chronic liver disease and hepatocellular carcinoma associated with chronic hepatitis $B$ virus (HBV) infection are among the most serious human health problems in highly endemic regions. Current therapeutic approaches to control chronic hepatitis such as interferon-alpha and lamivudine are unsatisfactory. Vaccination would be the therapeutic procedure with the lowest cost and the potentially greatest benefit. The immunogenicity of selected HBV envelope or capsid based vaccine formulations for the induction or the broadening of $T$ and $\mathrm{B}$ cell responses, deficient in HBV chronic carriers, are currently under study in animal models and in clinical trials.

DNA based or genetic vaccination is an efficient new technique to stimulate specific immune responses after in vivo delivery of bacterial plasmids encoding antigens. Systemic immunisation of mice by intramuscular injection of plasmid DNA expressing HBV envelope proteins and $\mathrm{HBV}$ surface antigen $(\mathrm{HBs} A g)$ induces rapid, strong and sustained humoral and cell-mediated immune responses. Antibodies, which are initially of the $\lg M$ then $\lg G$ isotype (predominantly $\lg G 2 a$ ), recognise several of the B cell epitopes present on the S, preS2, or preS1 domains of the envelope proteins. High titres of anti-HBs are present by 4-8 weeks and persist for at least 17 months after a single DNA injection, although they can be boosted ten-fold by a second injection of DNA, or somewhat less, by injection of a recombinant $\mathrm{HBsAg}$ protein. A strong cellular immune response is induced by the DNA based immunisation with high level of CTL and CTL precursors being detected by one week and being maintained for several months. DNA vaccine also acts as its own adjuvant owing to the presence of bacterial immunostimulatory $\mathrm{CpG}$ motifs. Such sequences present in the plasmid backbone promote a Thl like pattern of cytokine production dominated by IL-12 and IFN- $\gamma$ with little secretion of Th2 cytokines.

Immunisation of mice that are both transgenic for the human HLA-A02.01 molecule and knockout for murine MHC class I molecules, with DNA encoding $\mathrm{HBsAg}$ shows that epitopes presented after in vivo processing in HLA-A2 transgenic mice are very similar to those generated in humans during HBV infection. By inducing immune responses closely related to those involved in clearing virus from the host, DNA vaccines may represent an alternative therapeutic approach for chronic HBV infection.

As a model to study the possibility of inducing an immune response in HBV chronic carriers that could control viral infection, we used transgenic mice $(\mathrm{Tg})$ that constitutively express the $\mathrm{HBsAg}$ in the liver only. These $\mathrm{Tg}$ mice secrete large amounts of $\mathrm{HBsAg}$ into the serum without antibody production and without apparent liver pathology. Using a plasmid DNA encoding the small and the middle HBV envelope protein, we were able to generate anti-HBs antibodies in these transgenic mice, which in turn induce the clearance of circulating $\mathrm{HBsAg}$. This elimination, which was persistent, is also correlated with a decrease or the disappearance of the HBV messenger RNA from the liver. Transfer experiments involving fractionated $\mathrm{HBsAg}$ primed spleen cells obtained from DNA immunised mice into Tg mice showed that both $C D 4+$ and $C D 8+T$ cells were able to control transgene expression even in the absence of antibody production. Results from $\mathrm{HBsAg-Tg}$ mice that are knockout for the $\gamma$ interferon receptor gene indicate that the regulation of the HBV envelope messenger RNA was mediated by type 1 cytokines produced by the activated $T$ lymphocytes.

These results point to the possibility of designing more effective ways for the prevention and the treatment of HBV infections.

1. Mancini $\mathbf{M}$, Hadchouel M, Davis HL, et al. 1996. DNA-mediated immunisation in a transgenic mouse model of the hepatitis B surface antigen chronic carrier state. Proc Natl Acad Sci USA 1996;93:12496.

2. Mancini M, Hadchouel M, Tiollais $\mathrm{P}$, et al. Regulation of hepatitis B virus mRNA expression in a hepatitis B surface antigen transgenic mouse model by IFN-gamma-secreting T cells after DNA-based immunisation. J Immunol 1998;161:5564.
3. Loirat D, Lemonnier FA, Michel ML. Multiepitopic HLA-A*0201-restricted immune response against hepatitis B surface antigen after DNA-based immunisation. J Immunol 2000;165:4748.

4. Malanchère-Brès E, Payette $\mathrm{PJ}$, Mancini $\mathrm{M}$, et al. CpG oligodeoxynucleotides with hepatitis B surface antigen (HBsAg) for vaccination in HBsAg-transgenic mice. J Virology 2001;75:6482-91.

5. Michel ML, Pol S, Bréchot C, et al. Immunotherapy of chronic hepatitis B by anti-HBV vaccine: from present to future. Vaccine 2001;19:2395-9.

\section{GENE THERAPY FOR HAEMOPHILIA B}

\section{Paul Fields. Great Ormond Street Hospital for Children, London, UK}

Haemophilia is an attractive target for a gene based approach. However with any new treatment for haemophilia a potential feared complication of the treatment is the development of an antibody generated inhibitory response (mediated via an MHC class II pathway) to the infused clotting factor protein in the conventional approach to treating haemophilia. This usually results in the disease being extremely difficult to treat with an increased risk of further bleeding. The situation in a gene based approach is more complex since the protein is manufactured intracellulary and may therefore invoke a cytotoxic $\mathrm{T}$ cell response (via an MHC I pathway) to the target tissue leading to its destruction'. Thus in any gene based approach it is important to consider this additional possibility. This lecture will focus around the implications of an immune response to a gene based therapy and how these may be overcome. The talk will discuss how the early preclinical data were translated into the ongoing clinical trial for a muscle directed gene based approach to treat haemophilia B. The final part of the lecture will then focus on the possibility of using liver as a target tissue, and the approach required to investigate an immune response(s) occurring via this route.

1. Fields PA, Kowalczyk DW, Arruda VR, et al. Role of vector in activation of T cell subsets in immune responses against the secreted transgene product factor IX. Mol Ther 2000; 1:225-35.

\section{GENE THERAPY OF HEPATOCELLULAR CARCINOMA AND DIGESTIVE TUMOURS}

J. Prieto, C. Qian, V. Schmitz', J. Ruiz, G. Mazzolini, I. Narvaiza, I. Melero B. Sangro. Gene Therapy Unit, Department of Internal Medicine, Clinica Universitaria, Faculty of Medicine, Universidad de Navarra, Pamplona Spain; 'University Hospital Bonn, InternalMedicine, Germany

General aspects: Gene therapy represents a new and promising therapeutic modality. The underlying principle is based on the introduction of genetic material into cells in order to generate a curative biological effect ${ }^{1,2}$. Gene therapy is not limited to hereditary diseases but can be used for a broad variety of different acquired diseases like infections, degenerative disorders and cancer. The most challenging issues for a successful application of gene therapy to human diseases concern (1) the choice of the relevant therapeutic gene, (2) the choice of promoter and regulatory sequences driving the expression of the transgene, and (3) the vector used for the delivery of the transgene into cells (that is for transduction of target cells). Promoter, regulatory elements and vector characteristics determine the transduction efficacy (that is the number of target cells expressing the transgene and the intensity of gene expression per cell), the specificity of the transduction, the time of transgene expression, the host's immune response against the vector and eventually the undesired side effects. At present important efforts are focused on the search for vectors with less toxicity and prolonged and controlled transgene expression thereby widening the potential application of gene therapy to a high spectrum of medical fields.

Despite the impressive progress in biomedical sciences during the last decades, the therapy of many liver diseases remains unsatisfactory. This applies not only to primary and metastatic liver tumours, hepatic cirrhosis, and hereditary metabolic diseases, but also to a high proportion of cases with chronic viral hepatitis that do not respond to current antiviral therapy. There is evidently an urgent need for efficient alternative therapeutic approaches and in recent years gene therapy has emerged as a new and promising method to treat human diseases. 
GENE THERAPY FOR NEOPLASTIC LIVER DISEASES

Malignant diseases of the liver rank fifth among all primary neoplastic diseases ${ }^{3,4}$. Hepatocellular carcinoma $(\mathrm{HCC})$ is the most common primary liver malignancy with rising incidence worldwide ${ }^{3-5}$. In addition to primary tumors, the liver is the most common organ where tumour metastasis occur, 5 . Both unresectable HCC and liver metastasis of digestive tumours lack effective therapy ${ }^{3,4,7}$ and new therapeutic modalities are urgently needed.

Transfer of therapeutic genes to the tumor mass or to the peritumoral tissue provides a promising new approach for cancer therapy ${ }^{8-10}$. A variety of gene therapy based anticancer strategies have been shown to be efficient in animal tumour models, including (a) replacement of tumour suppressor genes (eg, wild type p53), (b) antisense strategies to inhibit oncogene expression, (c) drug sensitisation by transduction of tumour cells with suicide genes (eg, herpes simplex virus thymidine kinase), (d) genetic immunotherapy to stimulate the host's antitumoral immune response leg, immunostimulatory cytokines, chemokines, co-stimulatory molecules, combination of cytokines and chemokines, genetic vaccination), and (d) transfer of genes which interfere with the biological programme of tumour growth (eg, antiangiogenic substances).

\section{DRUG SENSITISATION (SUICIDE GENES)}

This therapy consists on the transfer of a gene encoding a foreign enzyme which converts a nontoxic prodrug into a lethal drug compound. The herpes simplex virus thymidine kinase (HSV-tk) is the best characterised suicide gene.

Expression of functional enzyme HSV-tk in transduced (tumour) cells induces the conversion of the non-toxic prodrug ganciclovir (GCV) into a toxic phosphorylated compound which terminates DNA synthesis and inhibits DNA polymerase" ${ }^{11}$. A characteristic trait of the suicide genes is the so-called bystander effect caused by the diffusion of the toxic drug metabolite from the transduced cells to the surrounding tissue thus increasing the number tumoural cells destroyed by the procedure. Because of this effect, significant tumour regression can be achieved even when only a limited percentage of neoplastic cells has been transduced ${ }^{12,13}$. The bystander effect also derives from the necrosis of tumoural tissue which induces local inflammation, attraction of dendritic cells and stimulation of antitumoural immunity. Thus a synergistic antitumoral effect has been observed between suicide gene based therapy and gene transfer of immunostimulatory molecules ${ }^{14}$

Several studies have demonstrated the efficacy of the HSV-tk/GCV system for the treatment of $\mathrm{HCC}^{12,15,16}$ and metastatic colorectal cancer $(C R C)^{17,18}$. One of the main obstacles limiting the application of this therapy is related to toxic side effects affecting non-tumoural tissue ${ }^{16,19}$. These side effects can be reduced by injecting the vector locally inside the tumour or by the use of tumour-specific promoters (such as alphafetoprotein promoter for HCC) to limit HSV-tk expression to tumor tissue $^{20}$.

\section{GENETIC IMMUNOTHERAPY}

Hosts immunity frequently fails to eliminate malignant tumour tissue either due to the lack of recognisable tumour antigens or to the inability of tumour antigens to stimulate an effective immune response $e^{21,22}$. Defective antitumor immunity can be attributed partly to the lack of expression of MF\{C molecules by the tumour cells and also to the secretion of immunosuppressive factors (such as TGF-beta or VEGF) by the tumour ${ }^{21}$. Gene transfer of cytokines which are important in the regulation of the immune system can overcome the immune tolerance against tumoural antigens thus facilitating tumour rejection. Many different cytokines (IL-2, IL-4, IL-6, IL-7; IL-I2, [NF-y, TNF-a, GM-CSF) have been used to modulate the host's immune response by either ex vivo or in vivo gene transfer ${ }^{23-26}$. IL-12 is among the most potent cytokines at stimulating anti-tumour immunity. IL-12 acts by (a) induction of a TH I type of response, (b) activation of natural killer cells and cytotoxic T lymphocytes, (c) enhanced expression of adhesion molecules on endothelial cells thus facilitating the traffic of lymphocytes to the tumour, (d) induction of a potent antiangiogenic effect.

In an orthotopic HCC model in Buffalo rats we have shown that intratumoral administration of recombinant adenovirus encoding IL-12 (AdIL-12) caused complete tumour eradication in most of animals and increased long term survival ${ }^{26}$. Interestingly when two tumors were implanted in the same liver, treatment of only one of them resulted in regression of both. This effect has been attributed to the fact that a proportion of the adenovirus injected into a neoplastic nodule escapes to the general circulation and (because of the strong adenoviral hepatotropism) infects the whole liver. The IL-I 2 produced by the tumour and by hepatocytes surrounding the neoplastic nodules strongly activates NK cells, induces specific antitumoral immunity and enhanced expression of adhesion molecules in the tumoural vessels and displays a powerful antiangiogenic effect with resulting tumor regression ${ }^{26}$.
Adll-1 2 given by intra-hapatic arterial route has also been shown to be efficient in the treatment of a very aggressive model of multifocal $\mathrm{HCC}$ in rats (DENAinduced $\mathrm{HCC}$ ) causing a significant reduction of tumour burden and prolongation of survival ${ }^{26}$. Adll-12 was also found to induce potent antitumoral effects in animal models of metastatic colon cancer mode ${ }^{27}$.

Although IL-12 is a potent antitumoral substance its use is also liable to cause systemic toxic effects mainly derived from the ability of this cytokine to induce IFN-y production. Because of the risk of toxicity, it is advisable not to use high doses of Adll-12 to treat neoplasms. In order to enhance the antitumoral activity of IL-12 while reducing the risk of toxicity we have tested the therapeutic effect of a suboptimal dose of Adll-12 in combination with an adenovirus expressing the chemokine IP-10 (AdIP-I 0). The rationale was to attract immunoeffector cells to the neoplasm through IP-10 and to activate the attracted lymphocytes with IL-12. We found that this combined therapy allows to reduce the dose of AdIL-1228. without loss of antitumoural efficacy but with less risk of toxicity. Since activation of dendritic cells (DC) (the most efficient antigen presenting cells) is critical for the induction of antitumoral immunity, another possible way to enhance the antitumoral effect of low doses of IL-12 is to infect DC with AdIL-I2 ex vivo and to inject these engineered $D C$ into the tumour ${ }^{29}$. In animal models of colon cancer this strategy has proved to be extremely potent at eliminating tumoral lesions and at eliciting antitumoral immune responses.

Stimulation of DC is widely dependent on activation by costimulatory molecules like B7 and CD4O ligand (CD4OL) $)^{30,31}$. We observed that adenovirus-mediated gene transfer of $\mathrm{CD} 4 \mathrm{OL}$ (AdCD4OL) completely abolished the tumourigenicity of ex vivo infected rat HCC cells [75] and that intratumoral injection of AdCD4OL into established intrahepatic $\mathrm{HCC}$ tumour nodules in rats resulted in tumor regression and prolongation of survival.

Treatment of rat $\mathrm{HCC}$ with AdCD4OL induced protective antitumor immunity and was devoid of significant toxicity ${ }^{31,32}$.

\section{OUTLOOK}

Gene therapy has emerged as a powerful and very plastic tool to govern biological functions in diseased tissues. Animal models of human diseases and pilot clinical studies clearly show that there is a future for genes to be used as curative drugs. Much remain to he done in various fields pertaining gene therapy: (a) development of new vectors with improved transduction efficiency, transgene capacity, toxicity profile and duration of expression, (b) improvement of systems to control gene expression, (c) identification of the ideal therapeutic gene or combination of genes to treat each specific medical condition amenable to gene therapy, (d) testing of different routes and procedures for vector administration, (e) establishement of a regulatory policy to ensure both safety and functionality, and ( $f$ ) development of innovative methods of large scale industrial production to allow cheap dispensation of these new drugs. The field is new but wide open. No doubt it will represent an historical step in the progress of medical therapy.

\section{ACKNOWLEDGEMENTS}

This work has been performed with the help q/ grants from: $W$ Huarte, I. r/idal, IVI Mendez, Arhurua Aspiunza, Fundacion Echebano, Fundacion Areces and CICYT grant (SAF98-0146, SAF990039, and SAF99-0084). VS was partly supported by VER UM Foundation, Germany.

1. Miller AD. Human gene therapy comes of age. Nature 1992;357:45560

2. Mulligan RC. The basic science of gene therapy. Science 1993;260:92632

3. Okuda K. Hepatocellular carcinoma. J Hepatol 2000;32 (suppl I):225-37.

4. Lau WY. Primary Liver Tumors. Scm Surg Oncol 2000;19:135-44

5. Choti MA, Bulkley GB. Management of Metastatic Disease. In: Schiff ER, Sorrell MF, Maddrey WC. Schiff's Disease oft/ic liver. Philadelphia: Lippincott-Raven, 1999.

6. McCarter MD and Fong Y. Metastatic Liver Tumors. Scm Surg Oncol 2000; 19:177-88

7. Lai EC, Fan ST, Lo CM, et al. Hepatic resection for hepatocellular carcinoma. An audit of 343 patients. Ann Surg 1995;221:291-8.

8. Qian C, Drozdzik M, Caselmann WH, et al. The potential of gene therapy in the treatment of hepatocellular carcinoma. J Hepatol 2000:32:344-51.

9. Ruiz J, Qian C, Drozdzik M, et al. Gene therapy of viral hepatitis and hepatocellular carcinoma. J Viral Hepat 1999;6: 17-34.

10. Heidemann DAM, Gerritsen WR, Craanen ME. Gene Therapy for gastrointestinal tract cancer: a review. Scandl Gastroenterol 2000;232(suppl):93-100.

11. Moolten FL. Drug sensitivity ("suicide") genes for selective cancer chemotherapy. Cancer Gene Ther 1994;1:279-87.

12. Qian C, Bilbao R, Brufla O, et al. Induction of sensitivity to ganciclovir in human hepatocellular carcinoma cells by adenovirus-mediated gene transfer of herpes simplex virus thymidine kinase. Hepatology $1995 ; 22 ; 118-$ 23. 
13. Bi WL, Parysek LM, Warnick $R$, et al. In vivo evidence that metabolic cooperation is responsible for the bystander effect observed with HSV tk retroviral gene therapy. Hum Gene Ther 1993;4:725-31.

14. Drozdzik M, Qian C, Xie X, et al. Combined gene therapy with suicide gene and interleukin-12 is more efficient than therapy with one gene alone in a murine model of hepatocellular carcinoma. J Hepatol 2000;32:279_ 86.

15. Kuriyama S, Nakatani T, Masui K, et al. Evaluation of prodrugs ability to induce effective ablation of cells transduced with viral thymidine kinase gene. Anticancer Res 1996;16:2623-8

16. Qian C, Lodate $M$, Bilbao R, et al. Gene transfer and therapy with adenoviral vector in rats with diethylnitrosamine-induced hepatocel lular carcinoma. Hum Gene Ther 1997;8:349-58.

17. Hayashi S, Emi N, Yokoyama I, et al. Effect of gene therapy with the herpes simplex virus-thymidine kinase gene on hepatic metastasis in murine colon cancer. Surg Today. 1997;27:40-3

18. Hayashi S, Emi N, Yokoyama I, et al. Inhibition of establishment of hepatic metastasis in mice by combination gene therapy using both herpes simplex virus-thymidine kinase and granulocyte macrophage-colony stimulating factor genes in murine colon cancer. Cancer Gene Ther 1997:4:339-44.

19. Brand K, Arnold W, Bartels T, et al. Liver-associated toxicity of the HSV-tk/ GCV approach and adenoviral vectors. Cancer Gene Ther 1997;4:9-16.

20. Kaneko S, Hallenbeck $P$, Kotani $T$, et al. Adenovirus-mediated gene therapy of hepatocellular carcinoma using cancer-specific gene expression. Cancer Res 1995:55:5283-7,

21. Roth C, Rochlitz C, Kourilsky P. Immune response against tumors. Adv Immunol 1994;57:281-35I.

22. Gabrilovich DI, Chen HL, Girgis KR, et al. Production of vascular endothelial growth factor by human tumors inhibits the functional maturation of dendritic cells. Nature Med 1996;2:1096-1103.

23. Musiani $\mathbf{P}$, Modesti A, Giovarella $M$, et al. Cytokine, tumor-cell death and immunogenicity: a question of choice. Immunol Today 1997;18:32-6.

24. Schmidt-Wolf G, Schmidt-Wolf GH. Cytokines and gene therapy. Immunol Today 1995;16:173-5.

25. Colombo $\mathbf{M}$, Forni $G$. Cytokine gene transfer in tumor inhibition and tumor therapy: where are we now? Immunol Today 1994;15:48-51

26. Barajas M, Mazzolini G, Genové G, et al. Gene therapy of orthotopic hepatocellular carcinoma in rats using adenovirus coding for interleukin-12 (IL-12) Hepatology 2001;33:52-61.

27. Brunda MJ, Luistro L, Warner RR, et al. Antitumor and antimetastatic activity of interleukin 12 against murine tumors. J Exp Ivled 1993;178:122330

28. Narvaiza I, Mazzolini G, Barajas M, et al. Intratumoral coinjection of two adenoviruses, one encoding the chemokine IFN-gamma-inducible protein-IO and another encoding $\mid \mathrm{L}-12$, results in marked antitumoral synergy. J Immunol 2000;164:31 12-22.

29. Mazzolini G, Qian C, Narvaiza l, et al. Adenoviral gene transfer of interleukin 12 into tumors synergizes with adoptive T cell therapy both at the induction and effector level. Hum Gene Ther 2000;11:113-25

30. Sun Y, Qian C, Peng D, et al. Gene transfer to liver cancer cells of B7-I plus interleukin 12 changesimmunoeffector mechanisms and suppresses helper $T$ cell type lcytokine production induced by interleukin 12 alone. Hum Gene Ther 2000;11:127-38.

31. Schmitz V, Barajas $M$, Wang $L$, et al. Adenovirus mediated CD4O ligand gene therapy in a rat model of orthotopic hepatocellular carcinoma. Manuscript submitted, 2001

32. Schmitz V, Barajas M, Sun Y, et al. Gene Therapy of colon carcinomas (CC) and hepatocellular carcinomas (HCC) by adenovirus-mediated in vivo gene transfer of CD4O ligand. Mol Ther 2000;1:S268.

\section{CHIMERAPLASTY: THE ROLLS ROYCE OF GENE THERAPY}

G. Dickson', I.R. Graham', A. Manzano ${ }^{1,2}$, A.D. Tagalaki², Z. Mohri², G. Sperber ${ }^{2}$, V. Hill', S. Beatti' ${ }^{2}$ S. Schepelmann², J.S. Owen². 'Centre for Biomedical Research, School of Biological Sciences, Royal Holloway College, University of London, Surrey TW2O OEX, UK; ${ }^{2}$ Centre for Hepatology, Department of Medicine, Royal Free and University College Medical School, Royal Free Campus, London NW3 2PF, UK

Synthetic RNA-DNA oligonucleotides (chimeraplasts) are capable of targeting and directing the correction of point mutations, including genomic sequences in cultured mammalian and plant cells and in whole animals. The technique of chimeraplasty has immense potential, both for human medicine and in a wide range of biotechnology applications'. Wide variations in conversion frequencies are reported, from $0.1 \%$ in a mammalian cell-free extract to $40 \%$ in the liver of rats, targeting the hemophilia B locus ${ }^{2}$ and from using the same chimeraplast in different epithelial cell types ${ }^{3}$ suggesting that the protein machinery for mismatch repair, at present still ill-defined, may have disparate efficiencies in different cells or systems.

Chimeraplasty in our laboratories is focussed on genes linked to atherosclerosis. We have reported ${ }^{4}$, that the defective apolipoprotein (apo) E allele, $\sim 2$ (C- ${ }^{*}$; ; Argi 58Cys), can be converted to the fullyfunctional c3 allele at a level of $-35 \%$ in recombinant Chinese hamster ovary $(\mathrm{CHO})$ cells. This correction was verified by PCR-RFLP at genomic and mRNA levels, and by isoelectric focussing (IEF) analysis of secreted proteins. Moreover, by prolonged passaging and cloning of cells, we have shown that the corrected allele is stably inherited. In addition, intraperitoneal administration of chimeraplasts in doublytransgenic apoE'/Human apoE2 mice has been shown to yield E2 to E3 gene conversion in liver tissue in vivo, with partial correction of hypercholesterolaemic plasma phenotype. More recently, we have used chimeraplasty to introduce the apoE mutations i.e. converting apoE3 to apoE2 in human HEK-293 and HepG2 hepatoblastoma cell lines, and have also corrected the c4 allele, a risk factor for Alzheimer's disease ${ }^{5}$, in $\mathrm{CHO}$ cells expressing human apoE4 cDNA and in EBV-transformed lymphocytes from homozygous patients.

Our experience targeting another anti-atherogenic gene, $A P O A I$, is also promising. Here, we use gain-of-function chimeraplasty to change amino acid 173 or 151 from arginine to cysteine; this allows apoAl molecules to dimerize causing, in heterozygous carriers, the natural atheroprotective phenotypes, apoAlMilaflo and apoAlp r , respectively, ${ }^{6,7}$. Thus, employing a 1 st-generation 68-mer chimeraplast we have successfully converted wild-type apoAl to apoAlp n in human HepG2 cells. As yet, conversion to apoAlMi aflo has proved refractory in HepG2 cells, although limited correction was achieved in recombinant $\mathrm{CHO}$ cells.

Clearly, while significant work is required to develop chimeraplasty as a clinical therapeutic option, the ability to target and correct SNP mutations in liver in situ to direct gene correction or gene enhancement, is a promising and attractive approach towards gene therapy for a range liver metabolic diseases.

1. Rice MC, Czymmek K, Kmiec EB. Nat Biotechnol 2001:19:321-6.

2. Kren BT, Bandyopadhyay P, Steer CJ. Nature Med 1998;4:285-90.

3. Santana E, Peritz AE, Lyer S, et al. J Invest Dermatol 1998;111:1 172-7.

4. Tagalakis AD, Graham LR, Riddell DR, et al. J Biol Chem $2001 ; 276: 13226-30$

5. Dartigue JF, Letenneur L. Curr Opin Neurol 2000:13:385-9.

6. Calabresi L. et al. J Biol Chem 1994;269:32168-74.

7. Bruckert E. et al. Atherosclerosis 1997;128:121-8.

\section{RALPH WRIGHT LECTURE. LIVER-DIRECTED CELL THERAPY}

S. Gupta Department of Medicine, Marion Bessin Liver Research Center, Comprehensive Cancer Research Center, and General Clinical Research Center, Albert Einstein College of Medicine, 1300 Morris Park Avenue, Bronx, NY 10461; sanivgupta@pol.net

The ability to repopulate the liver with transplanted cells will help develop novel therapies. A variety of recent animal studies have begun to advance insights into mechanisms regulating liver repopulation. Although transplanted hepatocytes integrate in the liver parenchyma and function normally throughout the life of rodents, transplanted cells do not proliferate significantly in the normal, unperturbed liver. Transplanted cell proliferation is activated when survival of native hepatocytes is perturbed. Under suitable situations, the liver can be repopulated extensively with transplanted hepatocytes. Moreover, transplanted hepatocytes can repopulate the liver of animals with chronic liver disease. Hepatocyte transplantation will thus apply to chronic liver disease, where structural and cellular perturbations alter hepatic function, inherited genetic disorders with extra-hepatic target organs, such as kernicterus due to congenital jaundice, encephalopathy due to hyperammonemia, and additional conditions, such as familial hypercholesterolemia, which is associated with severe atherosclerosis. Replacement of deficient liver function after orthotopic liver transplantation (OLT) in these conditions suggested that hepatocyte transplantation will be successful. Furthermore, if transplanted cells proliferated in the host liver extensively, people could be treated with relatively small numbers of hepatocytes from a single liver. This implies that cells from a single donor liver could be used to treat many patients. Proliferation of transplanted cells could potentially prolong survival in acute liver failure and offer a bridge toward OLT in less difficult circumstances; perhaps, OLT could be avoided altogether if the native liver regenerated in the additional time provided by hepatocyte transplantation. Therefore, an ability to repopulate the liver with cells offers exciting new opportunities for correcting genetic disorders and for treating liver failure. Use of several animal models has begun to establish the framework for therapeutic liver repopulation. Among presently unresolved issues are ways to repopulate the normal liver in an optimal fashion, as well as development of alternative sources for human cells in view of the scarcity of donor livers. Significant efforts are being devoted to these issues. Use of liver stem cells could be one potential way to alleviate organ shortages and advance applications of cell therapy. It is now established that the liver contains progenitor cells capable of differentiating into hepatocytes. Similarly, stem cells derived from other organs, such as 
bone marrow, can differentiate into mature hepatocytes. Finally, pluripotential human embryonic stem cells have also been isolated. Progenitor cells are capable of proliferating extensively in culture and are often amenable to highly efficient gene transfer. These advances indicate that liver-directed cell therapy offers exciting possibilities for novel therapies.

\section{SELECTED REFERENCES}

Animal studies

1. Gupta S, Aragona E, Vemuru RP, et al. Permanent engraftment and function of hepatocytes delivered to the liver: implications for gene therapy and liver repopulation. Hepatology 1991;14:144-9.

2. Rhim JA, Sandgren EP, Degen JL, et al. Replacement of diseased mouse liver by hepatic cell transplantation. Science 1994;263:1149-52.

3. Selden C, Calnan D, Morgan N, et al. Histidinemia in mice: A metabolic defect treated using a novel approach to hepatocellular transplantation. Hepatology 1995;21:1405-12.

4. Overturf K, Muhsen A-D, Tanguay R, et al. Hepatocytes corrected by gene therapy are selected in vivo in a murine model of hereditary tyrosinemia type 1. Nat Genet 1996;12:266-73.

5. Gupta S, Rajvanshi P, Sokhi R, et al. Position-specific gene expression in the liver lobule is directed by the microenvironment and not by the previous cell differentiation state. J Biol Chem 1999:274:2157-65.

6. Gupta S, Rajvanshi P, Sokhi RP, et al. Entry and integration of transplanted hepatocytes in liver plates occur by disruption of hepatic sinusoidal endothelium. Hepatology 1999;29:509-19.

7. Guha C, Sharma A, Gupta S, et al. Amelioration of radiation-induced liver damage in partially hepatectomized rats by hepatocyte transplantation. Cancer Res 1999;59:5871-4.

8. Petersen BE, Bowen WC, Patrene KD, et al. Bone marrow as a potential source of hepatic oval cells. Science 1999;284:1168-70.

9. Theise ND, Badve S, Saxena R, et al. Derivation of hepatocytes from bone marrow cells in mice after radiation-induced myeloablation. Hepatology 2000;31:235-40.

10. Lagasse E, Connors H, Al-Dhalimy M, et al. Purified hematopoietic stem cells can differentiate into hepatocytes in vivo. Nat Med 2000;6: 1229-34.

11. Dabeva MD, Petkov PM Sandhu J, et al Proliferation and differentiation of fetal liver epithelial progenitor cells after transplantation into adult rat liver. Am J Pathol 2000;156:2017-31.

12. Mitchell C, Mignon A, Guidotti JE, et al. Therapeutic liver repopulation in a mouse model of hypercholesterolemia. Hum Mol Genet 2000;9:1597_ 602.

13. Gagandeep S, Sokhi R, Slehria S, et al. Hepatocyte transplantation improves survival in mice with liver toxicity induced by hepatic overexpression of Mad 1 transcription factor. Molec Ther 2000; 1:358-65.

14. Braun KM, Degen JL, Sandgren EP. Hepatocyte transplantation in a model of toxin-induced liver disease: variable therapeutic effect during replacement of damaged parenchyma by donor cells. Nat Med 2000;6:320-6

15. Kobayashi N, Fujiwara T, Westerman KA, et al. Prevention of acute liver failure in rats with reversibly immortalized human hepatocytes. Science 2000;287: 1258-62.

16. De Vree JM, Ottenhoff R, Bosma PJ, et al. Correction of liver disease by hepatocyte transplantation in a mouse model of progressive familial intrahepatic cholestasis. Gastroenterology 2000;1 19:1720-30

17. Irani AN, Malhi H, Slehria S, et al. Correction of liver disease following transplantation of normal hepatocytes in LEC rats modeling Wilson's disease. Mol Ther 2001;3:302-9. Clinical studies

18. Mito M, Kusano M, Kauwara Y. Hepatocyte transplantation in man. Transp Proc 1992;24:3052-3.

19. Grossman M, Rader DJ, Muller DWM, et al. A pilot study of ex vivo gene therapy for homozygous familiar hypercholesterolaemia. Nature Med $1995 ; 1: 1148-54$

20. Strom SC, Fisher RA, Thompson MT, et al. Hepatocyte transplantation as a bridge to orthotopic liver transplantation in terminal liver failure. Transplantation 1997:63.559-69.

21. Fox IJ, Chowdhury JR, Kaufman SS, et al. Treatment of the Crigler-Naijar syndrome type I with hepatocyte transplantation. New Engl J Med 1998;338:1422-6

22. Bilir BM, Guinette D, Karrer F, et al. Hepatocyte transplantation in acute liver failure. Liver Transp/ Surg 2000;6:32-40. Recent review

23. Malhi H, Gupta S. Hepatocyte transplantation: New horizons and challenges. J Hep Bil Pancr Surg 2001;8:40-50.

\section{CLINICAL ASPECTS OF PORTAL HYPERTENSION}

\section{K.A. Burroughs.}

Although there have been 4 international meetings over 15 years, to standardise definitions in the field of portal hypertension, and as a consequence, improve the methodological quality of clinical trials, Z there are still areas in which the optimal therapeutic strategy is not known.

In acute variceal bleeding, little has been studied in relation to therapies not directly related to stopping bleeding-for example, blood volume restitution and use of clotting factors. An exception is the use of prophylactic antibiotics. It has now been shown that a reduced mortality is achieved by use of prophylactic antibiotics. One trial and one prospective study have also shown improvement in the failure rate to control variceal bleeding associated with use of antibiotics ${ }^{3}$ or absence of infection ${ }^{4}$. A hypothesis has been generated on the premise that infection via endotoxaemia could trigger variceal bleeding $^{5}$. Clearly infection and/or use of antibiotics are now important variables to document in randomised controlled trials in acute variceal bleeding.

Timing of administration of vasoactive drugs is a controversial area. Administration before hospital admission has shown survival benefit in grade C patients with terlipressin. However, whether this is directly related to control of bleeding, or perhaps more interestingly effects on the systemic and renal circulations needs to be determined.

Administering vasoactive drugs before diagnostic endoscopy and combining this with therapeutic endoscopy at diagnostic endoscopic improves control of bleeding but does not affect mortality ${ }^{6}$. In terms of strategies to control bleeding it is the most effective, so the lack of effect on mortality is a paradox. This leads to two possibilities: that failure to control of bleeding is not biologically related to death, contrary to observational studies ${ }^{7}$, or that the definition of control of bleeding in randomised studies is not reflecting a clinically significant end point ${ }^{8}$. In comparison with sclerotherapy there is no advantage of any specific drug ${ }^{6}$. There is no advantage of acute ligation versus injection ${ }^{6}$ : the double intubation required for ligation (following diagnostic endoscopy), might be offset by easier use of ligation acutely compared to injection, but this has not been formally assessed. Convention dictates that if more than 2 therapeutic endoscopic sessions are needed to attempt to control bleeding from oesophagcal varices, then this is a failure of endoscopic therapy. There are no randomised trials to determine the best therapy for this subgroup of patients.

For fundal variceal bleeding, tissue adhesive, $1 \%$ thrombin, and TIPS are all more effective than sclerotherapy. Optimal strategy depends on the availability of skilled operators, locally or regionally.

In rebleeding, it has been established that beta-blockade used empirically to a maximum tolerated dosage is as effective as sclerotherapy ${ }^{6}$ How beta-blockade compares with ligation remains to be established, but the first two trials suggest equivalence ${ }^{9,10}$. The main problem is the number of patients who have contraindications or who are intolerant of beta-blockers. Banding is the alternative as it is superior to sclerotherapy.

The use of haemodynamic targets as surrogates of therapeutic response to therapy is still being validated. A $20 \%$ reduction of HVPG from baseline and/or fall to $<12 \mathrm{mmHg}$ have been proposed ${ }^{11,12}$ Non-responders have rebled in two separate cohorts ${ }^{11,12}$ but not others $^{10,13}$. Remeasurement has been performed at 3 months ${ }^{11,12}$ and this misses a large proportion who rebleed within a few weeks ${ }^{10.13}$ The applicability and validity, haemodynamic targets should be tested in randomised studies. Isosorbide mononitrate potentiates the effect of propranolol on portal pressure reduction with conversion of "non-responders" to responders. This effect is mediated by reduction of intrahepatic resistance by relaxation of activated stellate cells - that is, myofibroblasts. However, therapeutic advantage of combination therapy versus non-selective beta-blockers alone has not been shown conclusively. Isosorbide mononitrate used alone may be dangerous and cannot be recommended. Lastly, failure of secondary prevention-a single episode of clinically significant rebleeding ${ }^{14}$ has recently been redefined. Subsequent therapy has not been evaluated in randomised studies.

Primary prophylaxis is also a clinical scenario in which non-selective beta-blockers arc the first choice treatment ${ }^{6}$. Although their benefit has only been shown in patients with large varices - that is, with moderate or severe risk of first bleeding, numerically, there are as many who bleed with small varices as large ones ${ }^{15}$. Progression of liver disease will increase the risk of bleeding in those who have small varices $^{15}$, to a level similar or higher than that for patients with large varices and compensated liver disease. Propranolol is the second cheapest generic drug, and safe. A strategy of treating all patients with varices, once diagnosed, can be justified. Whether banding should be used for those intolerant to beta-blockers or with contraindications, needs to be proven in those with large varices. It is expensive, although it would be limited to a small group of patients.

Prevention of varices would be a good clinic objective, but to date there is no proof that this can be done with non-selective beta-blockers.

1. Burroughs AK. Assessment of value of consensus definitions in acute variceal bleeding Lancet 2001:357:1147-8.

2. Kjaergard LL, Nikiova D, Gluud C. Randomized clinical trials in hepatology: predictors of quality. Hepatology 1999;30:1134-8

3. Bernard D, Nguyen KE, Opolon P, et al. Antibiotic prophylaxis for the prevention of bacterial infections in cirrhotic patients with gastrointestinal bleeding-a meta-analysis. Hepatology 1999;29:1655-51.

4. Goulis J, Armonis A, Patch D, et al. Bacterial infection is independently 
associated with failure to control bleeding in cirrhotic patients with gastrointestinal haemorrhage. Hepatology 1998;27:1207-12.

5. Goulis J, Patch D, Burroughs AK. Bacterial infection in the pathogenesis of variceal biceding. Lancet 1999;353:139-42.

6. Goulis J, Burroughs AK. Portal hypertensive bleeding: prevention and treatment. In: Evidence Based Gastroenterology and Hepatology. Eds McDonald J, Burroughs AK, Feagan B. London: BM Books 1999;389_ 426 .

7. Ben-Ari Z, Cardin F, McCormick PA, et al. A predictive model for failure to control bleeding during acute variceal haemorrhage. J Hepatol 1999:31:443-50.

8. Burroughs AK, Patch D. Therapeutic benefit of vasoactive drugs for acute variceal bleeding: a real pharmacological effect or a side effect of defnitions in trials. Hepatology 1996;22:737-9.

9. Minyana J, Gallego A, Vera J, et al. Endoscopic ligation versus nadalol plus isosorbide mononitrate for the prevention of variceal rebleeding. A prospective and randomized trial [abstract]. Hepatology 1999;30:215A.

10. Patch D, Goulis J, Gerunda G, et al. A randomized controlled trial comparing wedge pressure guided medical therapy against variceal banding in the secondary prevention of variceal haemorrhage [abstract]. J Hepatol 2000:32:34

11. Feu F, Garcia-Pagan J C, Bosch J, et al. Relation between portal pressure response to pharmacotherapy and risk of recurrent variceal haemorrhage in patients with cirrhosis. Lancet 1995;346:1056-9.

12. Villanueva $\mathbf{C}$, Balanzo J, Novella MT, et al. Nadalol plus isosorbide mononitrate compared with sclerotherapy for the prevention of variceal rebleeding. N Engl J Med 1996;334:1624-9

13. McCormick ??, Patch D, Greenslade L, et al. Clinical versus haemodynamic response to drugs in portal hypertension. J Hepatol 1998;28:1015-19.

14. Burroughs AK, Bosch J, Garcia-Tsao G, et al. Definition of key events: let's try again. In Portal Hypertension III. Proceedings of the Thrid Baveno International Consensus Workshop of Definitions, Methodology and Therapeutic Strategics. Ed, De Franchis R. Oxford: Blackwell Science 2001:13-21.

15. Pagliano L, D'Amico, G, Pasta L, et al. Portal hypertension in cirrhosis: natural history. In Bosch J, Groszmann R (eds). Portal hypertension, pathophysiology and treatment. Cambridge, MA: Blackwell Scientific 1994:7292.

\section{PATHOGENESIS AND MANAGEMENT OF RENAL IMPAIRMENT IN CIRRHOSIS}

V. Arroyo. Liver Unit, Institute of Digestive Diseases, Hospital Clinic, Barcelona, Spain

Renal impairment is a frequent complication of advanced cirrhosis. The initial renal function abnormality occurring during the natural course of the disease is sodium retention. It plays a major role in the pathogenesis of ascites. The mechanism of sodium retention is a homeostatic activation of vasoconstrictor and antinatriuretic systems (renin-angiotensin-aldosterone system, sympathetic nervous system, and other still unknown sodium retaining mechanisms) to maintain arterial pressure within normal or near normal limits. A splanchnic arterial vasodilation secondary to portal hypertension is the initial event of all these abnormalities. Subsequently during the course of the disease, patients develop water retention as a consequence of a marked reduction of the renal ability to excrete free water. This abnormality is secondary to a non-osmotic hypersecretion of antidiuretic hormone and leads to dilutional hyponatremia. Antidiuretic hormone is less sensitive than the sympathetic nervous system and reninangiotensin system to changes in effective arterial blood volume and this is the reason of the later development of hyponatremia. Finally, the third and chronologically the latest renal function abnormality is hepatorenal syndrome. It represents the extreme expression of the circulatory dysfunction of cirrhosis. It develops in the setting of a marked reduction in peripheral vascular resistance, arterial hypotension and extreme activation of the endogenous vasoconstrictors systems. Intrarenal mechanisms (impaired renal synthesis of vasodilators and increased renal production of vasoconstrictors), in addition to the activation of the renin-angiotensin system and sympathetic nervous system lead to renal vasoconstriction, renal hypoperfusion and reduced GFR. Renal failure in hepatorenal syndrome may follow a rapidly progressive course (type I hepatorenal syndrome) or a steady course (type II hepatorenal syndrome). Type I hepatorenal syndrome usually occurs in patients who already have type II hepatorenal syndrome and is preceded by a complication that acts as a precipitating mechanism, mainly spontaneous bacterial peritonitis. The prognosis of type I hepatorenal syndrome is extremely poor (most patients dye within days or weeks after the onset of renal failure)

Treatment of sodium retention in cirrhosis is based on the administration of diuretics (furosemide and spironolactone). In a very near future water retention and dilutional hyponatremia will be treated by aquaretic drugs. These agents are antagonists of the renal receptors of antidiuretic hormone (V2 receptors) and produce a water diuresis (increase in urine volume without changing urinary solute excretion).
Hepatorenal syndrome can be reversed by the long term (1-2 weeks) administration of vasoconstrictors (terlipressin, norepinephrine or midodrine) associated to plasma volume expansion with albumin or by the insertion of a transjugular intrahepatic portocaval shunt. There is evidence reversal of hepatorenal syndrome may be associated with an increase in survival.

1. Schrier RW, Arroyo V, Bernardi M, et al. Peripheral arterial vasodilation hypothesis: a proposal for the initiation of renal sodium and water retention in cirrhosis. Hepatology 1988;8:1151-7.

2. Arroyo V , Ginès $P$, Gerbes $A$, et al. Definition and diagnostic criteria of refractory ascites and hepatorenal syndrome in cirrhosis. Hepatology 1996:23: 164-76

3. Ginés $\mathbf{P}$, Jiménez W. Aquaretic agents. New potentially useful drugs for the treatment of water retention and hyponatremia in cirrhosis. J Hepatol 1996;24:506-12.

4. Guevara $M$, Ginès P, Fernández-Esparrach $G$, et al. Reversibility of hepatorenal syndrome by prolonged administration of ornipressin and plasma volume expansion. Hepatology 1998;27:35-41

5. Uriz J, Ginès $P$, Cárdenas $A$, et al. Terlipressin plus albumin infusion: an effective and safe therapy of hepatorenal syndrome. J Hepato/ 2000;33:43-

6. Angeli P, Volpin R, Gerunda G, et al. Reversal of type I hepatorenal syndrome with the administration of midodrine and octreotide. Hepatology 1999;29:1690-7.

7. Gulberg V, Bilzer M, Gerbes AL. Ornipressin for treatment of hepatorenal syndrome (HRS) type I: Results of long-term therapy or retreatment. Hepatology 1999;30:870-5

8. Guevara $M$, Ginès $P$, Bandi JC, et al. Transjugular intrahepatic portosystemic shunt in hepatorenal syndrome. Effect on renal function and vasoactive systems. Hepatology 1998;27:416-22.

9. Brensing KA, Textor J, Perz J, et al. Long term outcome after transjugular intrahepatic portosystemic stent-shunt in non-transplant cirrhotics with hepatorenal syndrome: a phase II study. Gut 2000;47:288-95

\section{O8 PORTAL HYPERTENSION: FROM BENCH TO BEDSIDE}

D. Rockey. Duke University Medical Center, North Carolina, USA

The response to recurrent injury, in liver and in other organs is one of wound healing. Chronic injury and wound healing in the liver ultimately lead to hepatic fibrosis and cirrhosis. One of the most important clinical sequelae of cirrhosis is portal hypertension, which is associated with significant morbidity and mortality. Although the pathophysiologic basis of portal hypertension is multifactorial, the most prominent aspect is an increased intrahepatic resistance to blood flow, which in turn is the result of both fixed and dynamically modulable vascular elements. Recent data point to several key factors in the altered vascular response that occurs in cirrhosis. For example, during liver injury and cirrhosis, resident smooth muscle-like perisinusoidal cells termed hepatic stellate cells within the hepatic sinusoid (analogous to the capillary in the systemic circulation) undergo transformation from a quiescent to an "activated" state. This process is characterized by de novo expression of smooth muscle proteins including smooth muscle isoforms of each actin and myosin. Moreover, these abundant contractile proteins impart on stellate cells enhanced contractility, elicited in particular by the endothelins, a group of 21 amino acid peptides known primarily for their vasoactive properties. Moreover, in injured liver, endothelin-1 (ET-1) is produced in increased quantities by stellate cells themselves; this paracrine loop involving ET-1 in the context of highly contractile (vasoregulatory) stellate cells results in increased resistance to blood flow typical of portal hypertension.

The dynamic nature of blood flow regulation emphasizes the importance of interplay between vasoconstrictive and vasodilatory compounds. Since ET-1, a potent vasoactive peptide, is overproduced during liver injury and contributes to increased intrahepatic resistance via contraction of stellate cells, we postulated that nitric oxide (NO), a key molecule in normal vascular homeostasis, could balance the effect of ET-1 in liver, serving as an important relaxing factor for stellate cells. Although this indeed appears to be the case in the normal liver, in the injured liver, we and others have found that endothelium-derived NO (ie, that produced by endothelial cell NO synthase) is not produced in increased quantities such that it counterbalances ET-1, but rather that endothelium-derived $\mathrm{NO}$ production is reduced. These data suggest that the increased intrahepatic resistance to blood flow typical of cirrhosis is the result of an endothelialopathy in which reduced intrahepatic NO plays an important role. Given the clear dysregulation of ET-1 and NO in the hepatic microvascular unit after injury, we have proposed to address these defects by inhibiting ET-1 production and/or replenishing $\mathrm{NO}$ in the cirrhotic liver in specific cellular compartments. 


\section{WHY WE DO TIPSS}

P.C. Hayes. Liver Unit, Department of Internal Medicine, Royal Infirmary of Edinburgh, UK

With the introduction of transjugular intrahepatic portosystemic stent shunts (TIPSS) over 10 years ago there is now considerable worldwide experience with this technique, particularly with regard to its use to control acute variceal haemorrhage, the prevention of rebleeding from oesophageal varices, bleeding from gastric varices, and treatment of refractory ascites. There have been numerous meta-analyses and commentaries about the place of TIPSS in comparison with other treatments, weighing up factors such as survival, rebleeding, encephalopathy and cost. The perceived relative importance of these factors has resulted in considerable variation in experts recommendations.

For the first 10 years or so after its introduction, TIPSS insertion was seen as the technique confined to a few specialist services. However over the last few years the number of hospitals capable of undertaking this procedure appears to have increased greatly. It is commonplace now, for example, for patients who have end-stage liver disease and are being referred for transplantation to have a TIPSS in situ. Experience in undertaking and managing patients with TIPSS is becoming more widespread. It is likely that the development of stents less likely to thrombose will increase attractiveness of the procedure. It should be appreciated that for the different purported indications for TIPSS, the weight of evidence of benefit varies and requires individual evaluation. The most controversial area at present is its use, in a large population of patients, for refractory ascites. Its use in this and other situations will be discussed.

1. Jalan R, Lui HF, Redhead DN, et al. TIPSS 10 years on. Gut 2000;46:57881

2. Papatheodoridis GV, Goulis J, Leandro G, et al. Transjugular intrahepatic portosystemic shunt compared with endoscopic treatment for prevention of variceal rebleeding: a meta-analysis. Hepatology 1999;30:612-22.

3. Russo MW, Zacks SL, Sandler RS, et al. Cost-effectiveness analysis of transjugular intrahepatic portosystemic shunt (TIPS) versus endoscopic therapy for the prevention of recurrent esophageal variceal bleeding. Hepatology 2000;31:358-63.

4. Garcia-Villarreal L, Martinez-Lagares F, Sierra A, et al. Hepatology $1999 ; 29: 27-32$

\section{WHY WE TIPS SPARINGLY}

\section{J. O'Grady. Institute of Liver Studies, King's College Hospital}

TIPS was developed as an alternative to surgical shunt procedures at a time when the indications for surgical shunts were becoming very selective. This was in part a reflection of the impact liver transplantation was having on the management of end-stage liver disease and portal hypertension. However, it also reflected the untoward complications of shunting-hepatic decompensation, encephalopathy, and shunt occlusion. My mentor, Professor Roger Williams, predicted at that time that TIPS was likely to encounter exactly the same outcome profile and he would appear to have been correct. The data are now clear in showing that TIPS occlude regularly, have unacceptable encephalopathy rates, and do not prolong life. The question must therefore be asked why some institutions have dramatically increased shunting procedures in the TIPS era.

Does TIPS extend the indications for shunting beyond those accepted for surgical shunts? I believe not. Patients who were considered too ill for surgical shunts and considered unlikely to survive the anaesthetic are also too ill for TIPS. Sicker patients deteriorate after TIPS in the same manner as if they had anaesthesia and consequently it cannot be argued that TIPS extends the role of shunting in Child's B and $C$ patients. Similarly, TIPS does not replace other excepted therapies in the management of portal hypertension-for example, regular band ligation in the management of oesophageal varices.

TIPS does have a role in modern hepatology, but it is the same role that surgical shunts had in the pre-TIPS era. The clear indications for TIPS are:

- uncontrolled bleeding from gastric varices

- selected cases with uncontrolled bleeding from oesophageal varices

- intractable ascites or hydrothorax in Child's A patients

- Budd-Chiari syndrome.

The use of TIPS in other settings as a definitive therapeutic process is difficult to justify on the basis of side effects and survival rates. It is more difficult to assess the role of TIPS as a bridge to transplantation in these settings, as the eventual outcome is mainly determined by the transplant itself. However, the modern intra-operative management of portal hypertension means that portal hypertension only poses a challenge to the surgeon in exceptional cases. TIPS is a nice tool but with all "tool" analogies it is important to remember the wise words involving mallets and hammers!

\section{BRITISH LIVER TRUST LECTURE. NOTES FROM A BILE-OLOGIST-MECHANISMS OF CHOLESTASIS}

J.L. Boyer. Liver Center, Yale University School of Medicine, New Haven, $C T$, USA

Most of the transport proteins that determine the formation of bile have been cloned from rodent and human liver in the last few years. utations in several of these transporters (FIC1, MDR3, BSEP) result in cholestatic liver disease in infancy. A brief review of these developments will be presented by way of background.

We have been interested in how these transport proteins are regulated in acquired forms of cholestatic liver injury. Previous studies indicate that several models of cholestasis including common bile duct obstruction in rodents, ethinyl estradiol treatment, and endotoxin administration result in down regulation of the sodium taurocholate co-transporting polypeptide (Ntcp) while the expression of the hepatic bile salt export pump (Bsep) is relatively well maintained ${ }^{1-3}$. These adaptive responses in transport proteins in liver may help to limit the accumulation of bile salts and lessen tissue injury. However, little is known about the effects of cholestasis on the expression of other bile salt transporters including the multidrug resistance associated protein, Mrp3, in liver ${ }^{4-6}$ and cholangiocytes ${ }^{6,7}$, as well as lsbt in cholangiocytes and kidney ${ }^{8}$. The kidney expresses both Isbt and Mrp2 on the luminal membrane of the proximal tubule 9 and Mrp2 is known to be capable of transporting sulfated bile salts ${ }^{10}$. The expression of these transporters has now been in hepatocytes, cholangiocytes and kidney, following common bile duct ligation (CBDL) in the rat. RNA protection assays, indirect immunofluorescence and confocal microscopy and Western blot analysis were used to assess changes in expression of these transporters. Following CBDL, serum bile salts rose and then declined to lower levels suggesting an adaptive response. In contrast, urinary bile salt excretion rose progressively over a two-week period. Following CBDL, Mrp3, which is normally localised only to the basolateral membrane of cholangiocytes and to a single layer of hepatocytes surrounding the central vein, significantly increased and by 14 days all hepatocytes demonstrated basolateral membrane labeling. At the same time canalicular Mrp2 staining was significantly diminished. Proliferating bile ducts continued to demonstrate positive staining for Mrp3. After two weeks of bile duct obstruction, Isbt mRNA and protein expression in total liver increased to $300 \%$ and $200 \%$ of control values, respectively, as a result of bile duct proliferation. Concurrently, Isbt mRNA and protein in the kidney had fallen to $46 \%$ and $37 \%$ of controls, respectively, and sodium dependent uptake of ${ }^{3} \mathrm{H}$-taurocholate in brush border membrane vesicles was decreased. In contrast, Mrp2 protein expression in the kidney increased by twofold. Immunofluorescent studies confirmed the changes in Isbt and Mrp2 in the liver and kidney. These observations demonstrate that Mrp3 in hepatocytes and cholangiocytes and Isbt and Mrp2 in kidney and cholangiocytes undergo adaptive regulation following cholestatic liver injury. As Mrp3 is capable of transporting toxic bile acids", up-regulation of Mrp3 in hepatocytes may compensate for the downregulation of Mrp2 as well as provide a pathway for removal of bile salts from the cholangiocytes back to the systemic circulation. Changes in expression of renal Isbt may decrease renal bile salt reabsorption. Altogether, these adaptive responses in the expression of bile salt transporters in hepatocytes, cholangiocytes, and kidney as well as intestine may facilitate alternative extrahepatic pathways for bile salt excretion during cholestasis, thereby limiting the hepatotoxic effect of the accumulating bile salt pool. The role of nuclear hormone receptors in the regulation of these adaptive changes is now being examined.

1. Trauner M, Meier PJ, Boyer JL. Molecular pathogenesis of cholestasis. N Eng J Med 1998:339:1217-27.

2. Trauner M, Meier PJ, Boyer JL. Molecular regulation of hepatocellular transport systems in cholestasis. J Hepatol 1999;31:165-78.

3. Lee $\mathbf{J}$, Boyer JL. Molecular alterations in hepatocyte transport mechanisms in acquired cholestatic liver disorders. Semin Liver Dis 2000;20:373-84.

4. Hirohashi $T$, Suzuki $H$, Ito $K$, et al. Hepatic expression of multidrug resistance-associated protein-like proteins maintained in Eisai hyperbilirubinemic rats. Mol Pharmacol 1998;53:1068-75

5. Ogawa K, Suzuki H, Hirohashi T, et al. Characterization of inducible nature of MRP3 in rat liver. Am J Physiol Gastrointest Liver Physiol 2000:278:G438-G446.

6. Soroka CJ, Lee JM, Azzaroli F, et al. Cellular localization and up-regulation 
of multidrug resistance-associated protein 3 in hepatocytes and cholangiocytes during obstructive cholestasis in rat liver. Hepatology 2001;33:78391.

7. Kool M, van der Linden $M$, deHaas $M$, et al. MRP3, an organic anion transporter able to transport anti-cancer drugs. Proc Nat Acad Sci 1999:96:6914-19.

8. Lee JM, Azzaroli F, Gigliozzi A, et al. Adaptive regulation of the ileal sodium-dependent bile salt transporter (ISBT), and the multispecific organic anion transporter (MRP2), in kidney and cholangiocytes in chronic cholestasis-alternative pathways for bile salt excretion [abstract]. Hepatology 1999;30:417A.

9. Shneider BL, Dawson Pa, Christie DM, et al. Cloning and molecular characterization of the ontogency of a rat ileal sodium-dependent bile acid transporter. J Clin Invest 1995;95:745-62.

10. Konig J, Nies AT, Cui Y, et al. Conjugate export pumps of the multidrug resistance protein (MRP) family: localization, substrate specificity, and MRP2-mediated drug resistance. Biochim Biophys Acta 1999;1461:37794

11. Hirohashi T, Suzuki H, Takikawa H, et al. ATP-dependent transport of bile salts by rat multidrug resistance-associated protein 3 (Mrp3). J Biol Chem 2000;275:2905-10.

\section{SERUM MARKERS PREDICT LIVER FIBROSIS}

W. Rosenberg', A. Burt ${ }^{2}$, S. Hubscher ${ }^{3}$, T. Roskams ${ }^{4}$, M. Voelker ${ }^{5}$, M. Becka ${ }^{5}, M$. Arthur' for the SB-155 Investigators. 'Southampton, ${ }^{2}$ Newcastle Upon Tyne, ${ }^{3}$ Birmingham, ${ }^{4}$ Leuven, ${ }^{5}$ Bayer AG. Mailpoint 811 , Liver Group, Division of Infection, Inflammation and Repair, University of Southampton, Southampton SO53 1ER, UK

Background: The established method for diagnosing hepatic fibrosis is histological analysis of a liver biopsy. Biopsy can be painful and hazardous making frequent, repeated sampling unacceptable. Inaccuracies may arise through sampling error, inadequacies of histological scoring systems and inter-observer variation in interpretation of biopsies. Accurate monitoring of disease and the development of antifibrotic agents are hampered by dependence on liver biopsies to assess outcome. The search for an alternative to liver histology has led us to develop highly sensitive immunoassays for serum levels of a panel of mediators of liver fibrosis and their degradation products.

Methods: In an international multicentre study we have investigated the relationship between serum levels of ten markers measured using sensitive automated immunoassays, and liver fibrosis, assessed by histological examination of liver biopsies in 921 subjects undergoing liver biopsy for the investigation of liver disease at 13 centres. Local and 3 central pathologists used the Ishak and Schever histological scoring systems. Algorithms employing the most discriminant serum markers were used to investigate the relationship between serum markers and liver histology. We report the agreement between pathologists; the Negative Predictive Value (NPV) for fibrosis, agreement with histology (kappa) and discriminatory accuracy for the serum markers.

Results: Agreement between pathologists ranged from kappa $=0.462-0.970$. Serum markers were compared to biopsy scores graded as "mild" (Schever 0-1; Ishak 0-2) and "moderate/ severe" (Schever 2-4; Ishak 3-6) fibrosis to distinguish clinically important categories. For Schever the NPV for fibrosis $=82 \%$, kappa= $0.35-0.39$; the area under the curve (AUC) of receiver operating characteristic (ROC) plots was 0.86. For Ishak the NPV for fibrosis $=82 \%$, and kappa $=0.3-0.4 ; \mathrm{AUC}$ for $\mathrm{ROC}=0.86$.

Conclusions: An algorithm of serum markers of liver fibrosis can predict the extent of fibrosis on liver biopsy at a level comparable to independent pathologists. This will be a useful tool to identify the presence or development of clinically significant liver fibrosis. The utility of these assays will be determined in the longitudinal follow up of our study over 2 years.

\section{CHARACTERISATION OF HEPATIC FIBROSIS BY GENETIC PROFILING OF IN VITRO ACTIVATED HUMAN STELLATE CELLS}

F Walker', E.J. Murray', G. Price', D.A. Mann ${ }^{3}$, R.C. Benyon ${ }^{3}$, M.J. Arthur ${ }^{3}$, S.E. Wilkinson', K.M. Bottomley'2, L. Wise ${ }^{2}$, J.S. Nixon', J.P. Iredale ${ }^{3}$. 1 Biology Group and 'Bioinformatics, Roche Discovery Welwyn, Welwyn Garden City, Herts AL7 3AY, UK; ${ }^{3}$ Liver Fibrosis Research Group, Division of Infection Inflammation and Repair, University of Southampton, Southampton General Hospital, Southampton, SO 16 6YD, UK

Hepatic fibrosis is a progressive debilitating disease which if left unchecked leads to cirrhosis and liver failure. To date, transplantation remains the only clinical treatment. The molecular mechanisms which lead to fibrosis represent an area of intensive study and it is now clear that hepatic stellate cells (HSCs) play a pivotal role in this process. As a first step to developing an effective anti-fibrotic chemotherapy, we have undertaken a global genetic analysis of HSC activation using Affymetrix GeneChip® HG-U95A, which represents up to 11000 characterised human genes.

We have analysed pairwise, matched HSCs either freshly isolated (designated as "quiescent"), or activated by culture on plastic in the presence of $16 \%$ serum, from three independent healthy human liver samples at $n=>4$ for each condition. All three datasets show uniform host control gene expression and hybridisation controls. Our three datasets exhibit a consistent number of expressed genes (4000-5000 active in both quiescent and activated HSCs). In addition, 2200 genes are consistently modulated upon activation, of which 1000 genes are upregulated and $~ 1200$ are downregulated. Furthermore, 900 gene modulations $(-40 \%)$ are common to all three samples which is extremely high agreement when compared to other gene profiling studies using established or transformed cell lines.

Finally, further analysis shows that $\sim 400$ genes are consistently and significantly upregulated during HSC activation. Many of the collagen genes are represented in the upregulated genes as expected for a model for fibrosis. Other identified genes which are modulated include those for cell motility, growth factors/receptors, TGF signalling, ECM remodelling, and those genes which are established markers for activation - for example, $\alpha$-smooth muscle actin.

We intend using these datasets to target pathways for therapeutic intervention to help prevent hepatic fibrosis caused, for example by chronic HCV infection. Such an anti-fibrotic therapy, allied to an anti$\mathrm{HCV}$ viral therapy, would meet an urgent clinical need.

\section{ADULT LIVING DONOR LIVER TRANSPLANTATION: INITIAL UK EXPERIENCE}

R. Williams ${ }^{1,2}$, A. Alisa', J. Karani ${ }^{1,3}$, M. Rela ${ }^{1,3}$, N. Heaton ${ }^{1,3}$. 'Liver Unit Cromwell Hospital, ${ }^{2}$ Institute Of Hepatology, University College London Hospitals; ${ }^{3}$ Institute of Liver Studies, King's College Hospital

Adult-to-adult living donor liver transplantation (aLDLT) can be dramatically successful for both recipient and donor and over the past two years, the procedure has been widely adopted in the USA and mainland Europe, fuelled by increasing waiting lists for cadaver organs. The present report describes the first experience in the UK with the procedure when used for overseas patients who have the lowest priority for cadaver organ allocation. Thirteen patients were transplanted over the period November 1998 to April 2001. Ages ranged from 22-65 years. The indication for transplantation was end stage cirrhosis from HCV/HBV (10 cases) with single instances of cryptogenic cirrhosis, secondary biliary cirrhosis, and alcoholic liver disease. The grafts were left lobe in the first two and right lobe in subsequent 11 recipients as donated by 7 sons/daughters and 6 brothers/sisters. Over the same period of time, 5 potential recipients were excluded on account of medical unsuitability and four donors - in 3 because of severe fatty change, and 1 on account of a previously undetected cryptogenic cirrhosis on liver biopsy. For 10 of the 13 recipients the outcome was considered satisfactory, although 3 of the 10 had major post transplant complications relating to small for size syndrome (1), a biliary leak (1) and occlusion of segmental hepatic artery (1). Two of the 3 unsuccessful cases had had extensive surgery previously which constituted a major risk factor. The donors experienced minor bile leaks and other complications but only 1 caused concern with an acute diabetic ketoacidosis which resolved over 24 hours. Liver function tests in the donor had returned to normal by the 7-14 day. Serial liver volume measurements by CT imaging also showed rapid regeneration with return to $80 \%-90 \%$ of pre-donation size by $4-6$ weeks. In the recipient regeneration occurred more slowly but all 10 cases had reached the calculated standard liver volume for their size by 3 months. The main ethical issues relate to selection criteria for the recipient and the measures needed to protect the donors whose safety, in the light of 3 reported donor deaths, is of paramount concern.

\section{SNPS ASSOCIATED WITH GENETIC SUSCEPTIBILITY TO ALD AND NASH/NAFLD: SAME AGAIN PLEASE!}

S. Saksena, J. Jacob, J.B. Leathart, A.K. Daly, C.P. Day. Centre for Liver Research, Medical School, University of Newcastle upon Tyne, Framlington Place, Newcastle upon Tyne NE2 4HH, UK

Non-alcoholic fatty liver disease (NAFLD) describes a spectrum of liver disease ranging from simple steatosis, through non-alcoholic steatohepatitis (NASH) to fat with cirrhosis. NAFLD is histologically 
identical to alcoholic liver disease (ALD) but occurs without heavy drinking and is associated with obesity and type 2 diabetes. The reason why only a minority of individuals with these risk factors develop NAFLD are unclear, but genetic factors may play a role. We have reported associations between ALD and single nucleotide polymorphisms (SNPs) in genes encoding CTLA-4, the IL-4 receptor and IL-10 and we hypothesised that these SNPs may also be associated with the risk of NAFLD.

We genotyped 62 patients with NAFLD for the the exon 1 CTLA-4 SNP, the Q576R IL-4 receptor SNP and the -627 IL-10 SNP. NAFLD was diagnosed in the presence of: an ALT>2xULN for >6months, ultrasound evidence of steatosis, drinking $<20$ units/week, and exclusion of other liver diseases. Histological confirmation was obtained in $75 \%$ patients. Results were compared with 200 local healthy controls and previously reported genotypes of $>250$ patients with ALD.

The distribution of the CTLA-4 and IL-4R genotypes in NAFLD was different from controls and similar to ALD. 76\% NAFLD had at least 1 copy of the CTLA-4 G allele vs $47 \%$ controls (OR 3.6 [1.8-7.0]) and $67 \%$ ALD (NS). $50 \%$ NAFLD had at least 1 copy of the IL-4R rare allele versus $27 \%$ controls (OR 2.0 [1.1-3.7] and 47\% ALD (NS). The frequency of the IL-10 SNP was identical in NAFLD and controls $137 \%$ $\checkmark 33 \%)$ and less than ALD $151 \%, 0.57$ [0.3-1.0]

Susceptibility to NAFLD and ALD is associated with functional SNPs in the genes encoding CTLA-4 and IL4-R. This may reflect a role for these gene products in disease pathogenesis or may be due to linkage with other SNPs. The similar genetic associations for these 2 diseases provide further evidence that they share a common pathogenesis.

\section{TIMP-1 AND -2 INHIBIT APOPTOSIS OF HUMAN AND RAT HEPATIC STELLATE CELLS IN VITRO}

F. Murphy, R. Issa, H. Hussain, S. Ratnarajah, C. Benyon, J.P. Iredale. Liver Group, Cell \& Molecular Medicine, Southampton General Hospital, Southampton, Hampshire SO16 6YD, UK

Introduction: The activated hepatic stellate cell (HSC) is cardinal in liver fibrosis. Activated HSC also express tissue inhibitors of metalloproteinases (TIMPs). During spontaneous recovery from liver fibrosis there is a decrease of TIMP expression, an increase in collagenase activity and apoptosis of HSC. This has highlighted the potential role of TIMP-1 and -2 in HSC survival.

Aims: To determine the effect of TIMP-1 and TIMP-2 on human and rat HSC proliferation and apoptosis.

Methods: Extracted rat and human HSC were cultured on plastic in the presence of serum until activated. The proliferative and apoptotic responses of HSC were quantified by tritiated thymidine incorporation, acridine orange staining, Caspase-3 activity and TUNEL staining before and after treatment with TIMP-1, TIMP-2, a synthetic MMP inhibitor (MMPI-1) and neutralising antibodies to TIMPs and a non-immune lgG. Western blotting for $\mathrm{Bcl}-2$ was also studied.

Results: Neither TIMP-1 nor TIMP-2 had effect on proliferation of rat HSC. Assessment of nuclear morphology following acridine orange staining showed that a $4 \mathrm{hr}$ incubation with TIMP-1 or TIMP-2 significantly reduced apoptosis of human and rat HSC induced by cycloheximide in a dose dependent manner $(n=5, p<0.0001)$ at a range of $1-200 \mathrm{ng} / \mathrm{ml}$. A similar pro-survival effect was observed for apoptosis induced by absolute serum deprivation and nerve growth factor stimulation. Neutralising antibodies to TIMP-1 and TIMP-2 increased apoptosis in rat HSC compared to a non-immune lgG control. The synthetic matrix metalloproteinase inhibitor MMPI-1 (1-30uM) also had dose dependent protective effect, suggesting that the anti-apoptotic effects in HSC may be dependent on matrix metalloproteinase inhibition. The anti-apoptotic effect of TIMP-1 and -2 in each model was confirmed by assay for Caspase-3 activity and TUNEL staining. Western blotting showed that TIMP-1 increased Bcl-2 levels in HSC.

Conclusion: TIMP-1 and TIMP-2 inhibit apoptosis of human and rat hepatic stellate cells.

\section{ORTHOTOPIC LIVER TRANSPLANT FOR THE TREATMENT OF METASTATIC NEUROENDOCRINE TUMOURS- ANALYSIS OF ALL UK PATIENTS}

A. Jamil', S. Taylor-Robinson ${ }^{2}$, C. Millson ${ }^{3}$ A. Gimson ${ }^{4}$, J. Buckels ${ }^{5}$, M. Hudson ${ }^{6}$, M. Caplin 7 , J.K. Ramage 1,8, R.Williams. ${ }^{8}$ 'North Hampshire Hospital, Basingstoke; ${ }^{2}$ Hammersmith Hospital; ${ }^{3}$ Leeds University Hospital; ${ }^{4}$ Addenbrookes Hospital; ${ }^{5}$ Birmingham Liver Unit; ${ }^{6}$ Newcastle Liver Unit; ${ }^{7}$ Royal Free Hospital; ${ }^{8}$ Kings College Hospital and the UKNET group

Orthotopic liver transplant (OLT) is a scarce and expensive resource and its use in metastatic malignant disease is controversial. Data from individual centres have been published in small numbers with inconclusive results. Data were collected from all transplant units in UK to assess patient survival and rates of recurrence of neuroendocrine tumours (NETs) post OLT

Methods: Questionnaires were mailed to transplant centres in UK and also to all members of the UK NET group to ensure no patients were excluded. All transplant centres replied and data was gathered on all patients known to have had OLT for any NET.

Patients: 29 patients were analysed with a mean age at transplant of 51.3 years (range 32.4-65.4)

Main hormones secreted were 5HIAA (9 pts), insulin (3), VIP(1) Gastrin (1), PP (1), AlphaFP(1), PTHRP (1), non-secreting (12). Sites of primary were: lleum (7), Pancreas (1 1), colorectal (3), lung (3), adrenal (1), not found/not known (4). The main reasons for transplant were: Pain/Pressure (7) Hormone control (8), potential cure (8).

Follow-up: 22 of the patients have been followed up for at least 5 years. Median survival overall was: 32 months (range 0.73-197). For the group of patients with secreting carcinoid tumours median survival was 33.7 months (range 3.4-161.4). Disease free survival was $48 \%$ at $1 \mathrm{yr}$ and $13.3 \% 5 \mathrm{yrs}$. Crude survival rates were $79 \%$ at 1 year and $24 \%$ at 5 years. Eight patients are still alive. The longest survivor is still alive and recurrence free 196 months post transplant (Pancreatic Polypeptide secreting tumour).

Conclusions: This study has the longest follow up of any series of OLT in this condition. There are occasional long term survivors of OLT for NET, but there are no obvious predictive factors in terms of hormone output or primary site. Disease can be palliated initially by this treatment but long term results question the use of this scarce resource except in very unusual circumstances.

\section{MESO-PORTAL BYPASS (MPB) IN INFANTS AND CHILDREN: POTENTIAL CURE FOR EXTRAHEPATIC PORTAL HYPERTENSION (EHPH)}

I. Gehrke, P. John', H. Noujaim, S.V. Beath, P. McKiernan, J.B. Otte'2, D.A Kelly, J. de Ville de Goyet. Liver Unit and 'Dept of Radiology, Birmingham Children's Hospital, UK; ${ }^{2}$ Dept of Paediatric Surgery, Clin. Univ. de St Luc, Université Catholique de Louvain Brussels, Belgium

Introduction: EHPH due to Portal Vein (PV) thrombosis (T) is a common cause of bleeding during childhood. Conventional treatment is symptomatic with sclerotherapy/banding of oesophageal varices and porto-systemic shunting is offered only if bleeding cannot be controlled. More recently direct liver re-vascularisation (d-vasc) has been proposed by creating a MPB (between superior mesenteric vein (SMV) and intrahepatic left (ihL) PV in cases where the latter is patent $(86 \%$ of cases in our experience).

Aim: To evaluate the outcome of patients treated with MPB

Methods: All patients with EHPH who underwent MPB were reviewed.

Results: From 1990-May2001, 52 MPB were performed on 48 patients $(29 M / 19 F)$. Aetiology was idiopathic $n=27$, umbilical catheterisation/infection $n=11$, following liver transplantation $n=9$, following abdominal surgery $n=1$. Prior to MPB $16.6 \% \quad(n=8)$ presented with hypersplenism and $79.1 \%(n=38)$ with recent $G 1$ bleeding (including $n=4$ with refractory bleeding requiring emergency surgery). Median age and weight at operation were $8.5 y$ $(0.44-16.7)$ and $26.6 \mathrm{~kg}(5.9-60)$ respectively. Complications developed in $n=7$ (MPB stenosis $n=2$, MPB thrombosis $n=5$ ) due to technically favourising factors (use of allografts bypasses from unrelated donors $n=3$, bypass from small-for-size internal jugular vein $n=1$, goretex bypass $n=1, S M V$ thrombophlebitis $n=1$, poor ihLPV branching $n=1$ ), out of whom $n=4$ benefited from successful re-operation (F/U 30-74 mo), 2 patients remain stable with EHPH after MPB thrombosis and 1 patient with trisomy 9 , refractory ascites and failed MPB due to SMV thrombophlebitis died 12 mo post-MPB. Patient's internal jugular vein was used in 39 MPB with a $97 \%$ patency rate. Overall $94 \%(n=45)$ of patients are currently well with a patent MPB on US Doppler, no signs of EHPH and no episode of bleeding (median $\mathrm{F} / \mathrm{U}=18$, range 1-93 mo). In these patients US Doppler showed a rapid increase in diameter and flow velocity of intrahepatic PV radicals, disappearance of cavernoma and significant reduction of spleen size. Following MPB growth velocity has improved in many patients.

Conclusion: This series shows that curative treatment for EHPH can be achieved by MPB in $94 \%$ of patients and up to $97 \%$ when the patient's own internal jugular vein is used. Because direct re-vascularisation of the liver precludes any risk of encephalopathy or other effects related to porto-systemic shunting, the MPB may be considered early in the management of patients with EHPH. 


\section{THERE MUST BE A THIRD LOCUS FOR LOW $\gamma G T$ PFIC}

S. Strautnieks', J. Byrne', Alex Knisely', Laura Bull ${ }^{3}$, Irene Jankowska ${ }^{4}$, Joanna Pawlowska ${ }^{4}$, Nelson Freimer ${ }^{3}$, Etienne Sokal ${ }^{5}$, Giorgina MieliVergani ${ }^{1,2}$, Richard Thompson 1,2. 'Department of Child Health, Guy's, King's and St Thomas' School of Medicine, London; ${ }^{2}$ Institute of Liver Studies, King's College Hospital, London; ${ }^{3}$ Liver Centre Laboratory and Department of Medicine, San Francisco General Hospital, San Francisco, CA, USA; ${ }^{4}$ Children's Memorial Institute, Warsaw, Poland; UCSF, San Francisco, CA, USA: ${ }^{5}$ University Catholique Louvain, Louvain, Belgium

The progressive familial intrahepatic cholestases (PFIC) are a heterogeneous group of autosomal recessive conditions. The common features are presentation in early childhood of a subsequently progressive cholestasis leading to end stage liver disease by the second decade of life. The diagnosis can be made genetically with the two most common forms, BSEP deficiency and FICl deficiency, being characterised by normal levels of $\gamma$-glutamyl transpeptidase. These are caused by mutations in $A B C B 11$ and $A T P 8 B 1$. These genes encode the bile salt export pump (BSEP) and FIC proteins, and are on chromosomes $18 \mathrm{q} 21$ and $2 \mathrm{q} 24-31$ respectively.

Over 200 families with PFIC have entered the screening programme. Of these approximately one quarter are consanguineous or have several affected children and hence were suitable for haplotype segregation analysis to determine if they mapped to chromosomes 2 or 18. In consanguineous families, the assumption is that an affected child has inherited two copies of the same mutation from an ancestor and will at the same time have inherited two copies of the surrounding chromosomal region. Closely linked markers will therefore be homozygous. In families with several affected children, the chromosomal inheritance pattern in affected and unaffected children was determined.

Five key microsatellite marker loci (D2S156, D2S2380, D2S354, $D 2 S 124$, and $D 2 S 111$ ) flanking $A B C B 11$ and 3 intragenic loci (BSEP1, BSEP2, BSEP3) were used for haplotype construction on chromosome 2. Two intragenic markers (FICG1, FICG2) and 4 other loci (D18S858, D18S41, D18S977, D18S849), flanking ATP8B1, were typed on chromosome 18. Of 34 consanguineous or multiply affected families examined $12(35 \%)$ are consistent with linkage to chromosome $2,9(26 \%)$ to chromosome 18 and 3 are uninformative. $10(29 \%)$ do not link to either. This strongly suggests the presence of a third locus for low $\gamma$-GT PFIC.

\section{LYMPHOCYTE ADHESION MEDIATED BY THE HEPATIC ENDOTHELIAL ADHESION RECEPTOR VASCULAR ADHESION PROTEIN-1 IS DEPENDENT ON ITS SEMICARBIZIDE AMINE OXIDASE ACTIVITY}

P.F. Lalor', S. Edwards', M. Salmi', S. Jalkanen², D.H. Adams'. 'Liver Research Laboratories, MRC Centre for Immune Regulation, University of Birmingham and ${ }^{2}$ University of Turku

The endothelial adhesion molecule vascular adhesion protein-1 is constitutively expressed in human liver where it mediates lymphocyte adhesion to hepatic endothelium. Cloning of VAP-1 revealed it to be a semicarbizide sensitive amine oxidase (SSAO). We have reported that VAP-1 is shed form the hepatic vascular bed in a soluble form which accounts for nearly all circulating monoamine oxidase activity in human serum. In the present study we investigated whether the adhesive function of VAP-1 is dependent on its enzyme activity. We show that VAP-1 is constitutively expressed on human hepatic sinusoidal endothelium and use monolayers of these cells in flow-based adhesion assays to demonstrate that VAP-1 supports adhesion and transmigration of lymphocytes under flow. Blocking VAP-1 with antibodies reduced lymphocyte adhesion by $50 \%$ and significantly reduced the proportion of adherent lymphocytes that transmigrated on TNF- $\alpha$, TNF- $\beta$ or LPS-activated endothelium. Remarkably, inhibition of the amine oxidase activity of VAP-1 by treating the endothelium with either 1-10 $\mu \mathrm{M}$ hydroxylamine (a broad monoamine oxidase inhibitor) or 200-500 $\mu \mathrm{M}$ semicarbizide (a specific SSAO inhibitor) for 20 mins prior to perfusion of lymphocytes reduced both adhesion and transmigration to a similar level seen with blocking $\mathrm{mAb}$. Thus the enzymatic and adhesive properties of VAP-1 appear to be intimately linked.

Conclusions: (1) This is the first report of an enzyme regulating lymphocyte transendothelial migration and suggests that VAP-1 belongs to a novel class of adhesion proteins. (2) Our ability to block the adhesive function of VAP-1 by inhibiting SSAO activity suggests that small molecule inhibitors of VAP-1 enzyme activity may be developed as novel anti-inflammatory therapies in liver disease.

\section{ANTIOXIDANTS VERSUS CORTICOSTEROIDS IN THE TREATMENT OF SEVERE ALCOHOLIC HEPATITIS: A RANDOMISED TRIAL}

M.G. Phillips, H. Curtis, B. Portmann, N. Donaldson, A. Bomford, J.G. O'Grady. Institute of Liver Studies, King's College Hospital, London, UK.

Background: Corticosteroids are the only widely used therapy for severe alcoholic hepatitis $(\mathrm{AH})$ which has a hospital mortality of up to $65 \%$. However, corticosteroids are not universally used because of perceived problems with toxicity, particularly sepsis and gastrointestinal bleeding. Recent evidence that suggests severe $\mathrm{AH}$ is driven by oxidative stress and the effects of the pro-inflammatory cytokines has generated interest in the therapeutic role of antioxidants. We undertook a randomised clinical trial to test the hypothesis that antioxidants are superior to corticosteroid-based therapy.

Study design: The trial set out to assess 30 day mortality with $80 \%$ power at the $5 \%$ significance level. Patients were randomised to either Prednisolone $30 \mathrm{mg}$ daily or an antioxidant cocktail (vitamins A, C, E, selenium, allopurinol, desferrioxamine, and $\mathrm{N}$-acetylcysteine) and intralipid as a membrane stabiliser. The disease severity at randomisation was similar for both groups (discriminant function 61 in the corticosteroid group, 60 in the antioxidant group).

Results: A planned interim analysis was undertaken after 95 patients were studied. Histological confirmation of $\mathrm{AH}$ was available in $72 \%$ and $74 \%$ of these had cirrhosis. The 30 day mortality was $30.2 \%$ for patients on corticosteroids and $45.8 \%$ for patients on antioxidants $(p=0.04)$. Statistical analysis revealed that the odds of dying were 2.5 times greater for patients on antioxidants, confirming significant inferiority of this treatment modality. On entry to the trial the two groups were comparable for the main clinical parameters affecting mortality.

Conclusion: Interim statistical analysis demonstrating inferiority of antioxidants called for the termination of the trial. In the absence of any apparent evidence suggesting antioxidant toxicity, we conclude that these data support the use of prednisolone in severe AH. The potential for additional benefit form antioxidants cannot be excluded.

\section{TH-1 CYTOKINE POLYMORPHISMS AND OUTCOME OF HEPATITIS C VIRUS INFECTION}

E. Yamada', J. Mitchell', A.G. Demaine', M.E. Cramp'2. 'Dept of Molecular Medicine, Plymouth Postgraduate Medical School, University of Plymouth, UK; ${ }^{2}$ Gastroenterology Unit, Derriford Hospital, Plymouth, UK

Background: Hepatitis C virus (HCV) infection becomes chronic infection with persistent viraemia in $85 \%$ of cases. Virus-specific T helper (Th)-1 cell responses have been shown to be important in spontaneous and treatment related viral clearance. This study investigated the relationship between polymorphisms found in the promoter regions of the IL-12 p35 and p40 subunit genes, and the CA repeats in the first intron of the IFN- $\gamma$ gene, and disease outcome plus treatment response in $\mathrm{HCV}$ infection.

Samples and Methods: DNA samples were extracted from peripheral blood mononuclear cells of $140 \mathrm{HCV}$ infected patients and 77 normal uninfected controls. From the 140 patients, 54 spontaneously cleared viraemia whereas 86 were chronically infected with positive HCV RNA. Of those 86,48 had received IFN- $\alpha$ based anti-viral treatment, and 12 had a sustained response, 20 relapsed following an initial treatment response, and 16 did not respond to the treatment. Polymerase chain reaction (PCR) followed by restriction fragment length polymorphism was performed to identify single basepair substitutions in the IL-12 p35 and p40 genes, and the CA repeats in the IFN- $\gamma$ gene were detected by polyacrylamide gel electrophoresis

Results: Polymorphisms in the promoter regions of the IL-12 p35 and p40 genes were rare in HCV infected patients as in controls, and no association found between these polymorphisms and disease outcome. Polymorphic variations were detected in the CA repeats of the IFN- $\gamma$ gene. The high IFN- $\gamma$ producing $122 \mathrm{bp}$ (12 CA repeats) allele was found significantly less frequently in both chronically infected patients with positive HCV RNA (55 out of 86, $p=0.019$ ) and treatment non-responders ( 8 out of $16, p=0.01$ ) compared with controls (62 out of 77)

Conclusion: The demonstration of a reduced carrier frequency of the high IFN- $\gamma$ producing $122 \mathrm{bp}$ allele in chronically infected patients with positive HCV RNA and in treatment non-responders supports the important role of IFN- $\gamma$ and Th-1 response in control and clearance of $\mathrm{HCV}$ infection. 


\section{MOLECULAR ADSORBENTS RECIRCULATING SYSTEM: EARLY CLINICAL EXPERIENCE}

R. Jalan', C. Steiner', 'D. Kapoor', ${ }^{2}$ A. Alisa², S. Sen, R. Williams ${ }^{1,2}$. 1,2Institute of Hepatology, University College London Hospitals, and ${ }^{2}$ Cromwell Hospital, London

Background: Molecular Adsorbents Recirculating System (MARS) is a liver support device based on the use of a hollow fibre dialysis module in which the patient's blood is dialyzed across an albumin impregnated membrane while maintaining a flow of $20 \%$ albumin in the extracapillary compartment. The aims of this study were to assess the safety, efficacy and feasibility of using this system in patients with liver failure in conjunction with haemofiltration rather than haemodialysis.

Methods: 7 patients with acute-on-chronic liver failure [ACLF, alcoholic hepatitis-6, 4 Type 1 hepatorenal syndrome (HRS)], and 2 with acute liver failure (ALF, fulfilled criteria for liver transplantation, LT), were treated with $4.9 \pm 2.7$ (range 1 to 9) sessions with MARS, each lasting 10.7 \pm 6.1 (range 1 to 24) hours. They were evaluated clinically, biochemically, haematologically and haemodynamically before and after the treatment period. Using the MELD scoring system, the estimated 3 months survival in the ACLF group was $14 \%$.

Results: 4 of the 7 patients with ACLF ( 1 with HRS) were discharged from the hospital and are alive with a median follow up of 6 (range 0.03-7) months. Of the 2 patients with ALF, 1 died while the other was successfully bridged to LT after 9 days. Cardiac output was reduced $(9.7 \pm 0.3$ to $7.8 \pm 0.3 \mathrm{~L} / \mathrm{min})$ and the SVR $(914 \pm 88$ to $1178 \pm 29)$ and MAP $(71 \pm 24$ to $79 \pm 12 \mathrm{~mm} \mathrm{Hg})$ increased. There was a significant improvement in bilirubin $(415 \pm 192$ to $258 \pm 131 \mu \mathrm{mol} / \mathrm{L}$, $\mathrm{p}=0.005)$, creatinine $(175 \pm 77$ to $101 \pm 65 \mathrm{\mu mol} / \mathrm{L}, \quad \mathrm{p}=0.02)$, ammonia $(223( \pm 14.2)$ to $167( \pm 17.2) \mathrm{umol} / \mathrm{L}, \mathrm{p}<0.02)$, Maddrey's index $(102.1 \pm 51.29$ to $56.8 \pm 50.85, p=0.01)$ as well grade of encephalopathy $(2.7 \pm 0.71$ to $1.3 \pm 1.41, p=0.002)$. Serum electrolytes did not change significantly. No haemolysis or effects on platelets was observed. One patient experienced transient arrhythmias.

Conclusion: This study shows that MARS is safe to use with haemofiltration and with evidence of improvement in liver, renal and brain function in ACLF. Early data suggest the profound heamodynamic effects of MARS may mediate improved renal function and outcome in ACLF which may be mediated by the nitric oxide scavenging effect of albumin. On the basis of these results, a multicentre, randomised clinical trial has been initiated.

\section{PROGRESSIVE LIVER PATHOLOGY IN LONG TERM SURVIVORS OF PAEDIATRIC LIVER TRANSPLANTATION}

H. Evans', P.J. McKiernan, S.V. Beath, J. de Ville de Goyet, S.G. Hubscher', D.A. Kelly. Birmingham Children's Hospital and 'The University of Birmingham, UK

Introduction: Five year survival following paediatric liver transplantation (OLT) is $>85 \%$ but the long term histological outcome of allografts is unknown. We previously reported that at 5 years post OLT, $77 \%$ of liver biopsies were abnormal, with $48 \%$ demonstrating graft hepatitis of unknown aetiology'

Aim: To evaluate graft histology at 1, 5, and 10 years post OLT and correlate with liver biochemistry and autoantibody (Abs) results to determine potential predictive and aetiological factors. Methods: A retrospective review of histology from protocol biopsies at 1, 5, and 10 years post OLT was performed and compared with standard liver biochemistry and immunological markers (ANA (1 in 25), SMA (1 in 40), LKM (1 in 40) and AMA (1 in 40) and immunoglobulins). Logistic regression was used to identify factors which correlated with abnormal histology.
Results: 159 children (78M; 81F) underwent OLT and had graft survival of $=5$ years. Immunosuppression was cyclosporin, corticosteroids and azathioprine, with cyclosporin monotherapy after 12 months. Histological data were available from 124 (61M; 63F) (78\%) patients:

At 1 yr post OLT, abnormal liver biochemistry correlated with abnormal allograft histology, but not at 5 and 10 years. There was a statistically significant increase in graft hepatitis and fibrosis/cirrhosis at 5 and 10 years $(p<0.05)$. There was a correlation between graft hepatitis and positive autoantibodies at 5 and 10 years $(p<0.03)$ but hypergammaglobulinaemia was present in only 4 children at 5 years.

Conclusions: The incidence of abnormal graft histology increased progressively between 1 and 10 years At 1 year post OLT, abnormal liver biochemistry correlated with abnormal allograft histology, but not at 5 and 10 years post OLT. Liver biochemistry was not predictive of graft hepatitis. The development of graft hepatitis was associated with positive ANA and SMA, being positive in all children by 10 years. The aetiology of graft hepatitis has yet to be explained but may have an immunological basis.

1. HM Evans, et al. Histology of liver allografts five years following paediatric liver transplantation [abstract]. Hepatology 2000;32 (suppl II):227A.

\section{QUANTITATIVE AND QUALITATIVE CHANGES IN HCV-SPECIFIC LIVER INFILTRATING T-CELLS PARALLEL THE PROGRESSION OF LIVER DAMAGE IN CHRONIC HEPATITIS C}

I. Mullerova, E. Rigopoulou, P. Haigh, H. Cooksley, R. Williams, N.V. Naoumov. Institute of Hepatology, University College London, UK

The immune mechanisms underlying viral persistence and progression of liver damage in chronic HCV infection remain unknown. The aim of the present study was to determine the frequency and functional characteristics of HCV-specific CD4+ and CD8+ T cells in the liver and circulation at different stages of chronic hepatitis $C$.

Methods: Peripheral blood mononuclear cells (PBMC) and liver infiltrating lymphocytes (LIL) were isolated from 35 patients with chronic hepatitis C (all HCV RNA positive). According to the grade (G) and stage (S) of liver histology, the patients were divided into mild $(G \leqslant 3$, $\mathrm{S} 0-1, \mathrm{n}=10)$; moderate $(\mathrm{G} \geqslant 4, \mathrm{~S} 2-4, \mathrm{n}=10)$ and severe $(\mathrm{G} \geqslant 6, \mathrm{~S}$ $5-6, n=15)$ hepatitis. The frequency of HCV-specific IFN- $\gamma$ and IL-10 producing $\mathrm{CD} 4+$ and $\mathrm{CD} 8+\mathrm{T}$ cells in both compartments were enumerated by Elispot assays using $\mathrm{HCV}$ antigens or peptides, respectively. The CD4/CD8 T cell subset in both compartments was determined by flow cytometry.

Results: There was an inverse relationship between the frequency of IFN- $\gamma$ and IL-10 producing, HCV-specific T cells in both compartments with the progression of liver disease. Patients with severe hepatitis $C$ had significantly lower numbers of HCV-specific CD4+ $(p=0.0006)$ and CD8+ T cells $(p=0.003)$ producing IFN- $\gamma$, both in liver and circulation. In contrast, the number of HCV specific CD4+ and CD8+ T cells producing IL-10 was 7-10 times higher in patients with cirrhosis that in patients with mild hepatitis $C$.

HCV-specific $T$ cells represented a minority of liver infiltrating lymphocytes, particularly at the stage of moderate and severe hepatitis. The CD4/CD8 ratio in LIL was reversed from $0.53 \pm 0.1$ in mild disease to $1.2 \pm 0.1$ in advanced disease, indicating an increasing predominance of CD4+ T lymphocytes.

Conclusion: These results provide direct evidence for the contrasting cytokine profile of virus-specific $T$ cell responses in the liver and circulation in relation to the stage of chronic hepatitis $C$. The imbalance of $\mathrm{T}$ cell type 1 /type 2 reactivity to $\mathrm{HCV}$, in parallel with disease progression, may explain the poor antiviral treatment response in patients with more advanced fibrosis.

\begin{tabular}{|c|c|c|c|c|c|c|}
\hline \multicolumn{7}{|c|}{ Abstract 24} \\
\hline & \multicolumn{2}{|c|}{1 year $(n=111)$} & \multicolumn{2}{|c|}{5 years $(n=124)$} & \multicolumn{2}{|c|}{10 years $(n=32)$} \\
\hline & $\begin{array}{l}\text { Histology } \\
\text { No (\%) }\end{array}$ & $\begin{array}{l}\text { Pos Abs } \\
\text { No (\%) }\end{array}$ & $\begin{array}{l}\text { Histology } \\
\text { No (\%) }\end{array}$ & $\begin{array}{l}\text { Pos Abs } \\
\text { No }(\%)\end{array}$ & $\begin{array}{l}\text { Histology } \\
\text { No (\%) }\end{array}$ & $\begin{array}{l}\text { Pos Abs } \\
\text { No (\%) }\end{array}$ \\
\hline Normal & $65(59)$ & 0 & $35(28)$ & 0 & $6(19)$ & 0 \\
\hline Hepatitis & $26(23)$ & $7(27)$ & 41 (33) & $34(83)$ & $12(38)$ & $12(100)$ \\
\hline Hep \& fib & $5(5)$ & $1(20)$ & 21 (17) & 15 (71) & $5(16)$ & $4(80)$ \\
\hline Fibrosis & 3 (3) & 0 & $18(15)$ & $4(22)$ & 7 (22) & $4(57)$ \\
\hline Rejection & $8(7)$ & 0 & $6(5)$ & $1(17)$ & $2(6)$ & $1(50)$ \\
\hline Other & $4(4)$ & 0 & $3(2)$ & $1(33)$ & 0 & 0 \\
\hline
\end{tabular}




\section{LIVER FIBROSIS IS DRAMATICALLY REDUCED IN CARBON TETRACHLORIDE INJURED JUND KNOCKOUT MICE}

D.E. Smart', J.B. Weitzman', M.J.P. Arthur' D.A. Mann'. 'Liver Group, Division of Infection, Inflammation and Repair, University of Southampton, Southampton, SO16 6YD, UK; ${ }^{2}$ Institute Pasteur, Paris, France

Jun protooncogenes (c-Jun, JunB and JunD) are key components of the dimeric transcription factor AP- 1 and act as regulators of many cell functions characteristic of the activated phenotype of HSC leg, proliferation, apoptosis, matrix synthesis and turnover, expression of cytokines etc). In vitro and in vivo studies from our laboratory have shown that JunD expression is induced during HSC activation and is the predominant Jun family protein expressed in these cells ${ }^{1,2}$. We have recently described how JunD is required for high level activity of the tissue inhibitor of metalloproteinases-1 (TIMP-1) and interleukin-6 (IL-6) gene promoters in activated rat $\mathrm{HSC}^{2}$. These data prompted us to explore the possibility that JunD can function as a transcription regulator of liver fibrogenesis. JunD $\%$ mice have recently been described and other than defects in spermatogenesis are apparently normal ${ }^{3}$. Adult male JunD $\%$ and wild type control mice (3 animals per group) were given an intraperitoneal injection of a 1:4 mix of $\mathrm{CCl}_{4}$ : olive oil $(25 \mu)$ $\mathrm{CCl}_{4} / 100 \mathrm{~g}$ body weight) twice weekly over a period of 8 weeks to induce chronic liver injury. Liver sections from culled mice were then analysed histochemically for the extent of fibrosis and collagen deposition. The results showed that JunD $\%$ mice have a dramatically attenuated phenotype, with a substantially reduced level of fibrosis relative to that observed in wild type mice. Reduced levels of collagen deposition and numbers of activated hepatic stellate cells relative to these parameters in controls was observed in all 3 JunD $\%$ mice. We conclude that JunD is a regulator of the expression of profibrogenic genes in activated HSC and plays a critical role in the fibrogenic process in vivo. JunD should therefore now be considered as an important target for drug design.

1. Bahr MJ, et al. Hepatology 1999;29:839-48.

2. Smart DE, et al. J Biol Chem 2001 (In press).

3. Thepot D, et al. Development 2000;127:143-53.

\section{HEPATITIS B VIRUS GENOTYPES AND RESPONSE TO INTERFERON ALPHA TREATMENT IN CHRONIC HEPATITIS B}

J. Hou ${ }^{1,3}$, R. Schilling', H.L.A. Janssen² , J. Chen ${ }^{3}$, D. Liư ${ }^{3}$, R . Heijtink², K. Luo $^{3}$ G.K.K. Lau ${ }^{4}$, R. Williams' S. W. Schalm², N.V. Naoumov' I Institute of Hepatology, University College London, UK; ${ }^{2}$ Erasmus University Hospital, Rotterdam, The Netherlands; ${ }^{3}$ Department of Infectious Disease, Nanfang Hospital, Guangzhou, China; ${ }^{4}$ Department of Medicine, Queen Mary Hospital, Hong Kong, China

The impact of different HBV genotypes on the response to interferonalpha (IFN- $\alpha$ ) treatment is not known. We investigated the relationship between HBV genotypes, their ability to develop mutations in the core promoter (CP) and preC/ $\mathrm{C}$ gene with the outcome of IFN- $\alpha$ treatment in a homogeneous group of 148 patients with $\mathrm{HBeAg}(+)$ chronic hepatitis B (103 from Europe and 45 from China).

Methods: HBV genotypes were identified by Innolipa assay (Innogenetics, Belgium). The DNA sequence of the $C P$, preC-region and the entire $\mathrm{C}$-gene was determined both at baseline and at the end of treatment.

Results: In European patients the most common genotypes were A $46 / 103(45 \%)$ and D 35/103 (34\%), while Chinese patients were infected with either genotype C 29/45 (64\%) or B 16/45 (36\%). The response to IFN treatment was higher in genotype $A$ vs $D$ and in genotype $C$ vs $B$. CP-mutations (CPM) were significantly more frequent at baseline in responders $(p=0.005)$ with further increase at the end of treatment, while the preC-stop mutation (PCM) was equally distributed between responders and non-responders. The development of CPM was dependent on the genotype: $A(48 \%)$ vs $D(12 \%)$ and in genotype $C(42 \%)$ vs $B(21 \%)$. In contrast, the PCM was more often in genotype D $43 \%$ vs $A(7 \%)$ and in genotype $B(65 \%)$ vs $C(33 \%)$. Furthermore, the response to treatment was associated with a lower variation in the C-gene to generate $2.4 \pm 2.0$ amino acid (aa) changes per patient in responders vs $4.1 \pm 2.4 \mathrm{aa} /$ patient in non-responders $(p=0.007)$. Genotype A had the lowest $C$-gene variation $1.7 \pm 1.9 \mathrm{aa} /$ patient, compared to D 4.0 $\pm 2.3(p=0.0004) ; B 3.7 \pm 2.1 \quad(p=0.007)$ or $C$ $3.3 \pm 2.5(p=0.002)$

Conclusion: The response to IFN- $\alpha$ treatment differs between HBV genotypes, depending on the molecular characteristics of the Core promoter and Core gene variability. The higher response to treatment, observed in HBV genotype $A$, is related to its greater tendency to develop core promoter mutations and less variations in the nucleocapsid protein.

\section{DEFINITION OF IMMUNODOMINANT B CELL EPITOPES ON SOLUBLE LIVER ANTIGEN (SLA) AND THEIR IMPLICATION FOR MOLECULAR MIMICRY}

D.-P. Bogdanos', F. Rodrigues', U.C. Sharma', Y. Ma', G. Mieli-Vergani², D. Vergani'. 'Institute of Hepatology, University College London, UK; ${ }^{2}$ Department of Child Health, King's College Hospital, London, UK

Background: Soluble liver antigen (SLA)/UGA suppressor † RNA associated antigenic protein, a major target antigen in autoimmune hepatitis, is a $50 \mathrm{kDa}$ cytosolic protein composed of 441 amino acid, the sequence of which has been recently established.

Aims: To define the B cell epitopes on SLA and to investigate whether they are targets of cross-reactive immune responses with microorganisms.

Methods: Reactivity to 54 icosameric peptides overlapping by 12 aa, spanning the entire sequence of SLA, was tested in 5 anti-SLA seropositive AlH patients with high titres of anti-SLA by radioligand assay (Hepatology 2000;32(suppl):310A), ELISA (Euroimmun UK Ltd and immunoblot.

Results: Three antigenic regions were defined located towards the SLA C-terminus, 2 of them novel $(281-308,321-348)$ and one previously described (aa 385-441). This latter was found to contain 2 antigenic sub-regions separated by an invariably non-reactive sequence (393-412), a discontinuity probably reflecting the conformational nature of this epitopic region. The fine specificity of SLA 385-441 was investigated with 15-mer peptides overlapping by 3 aa and the focus of reactivity was localized to aa $412-441$. Since this region was found to share $>70 \%$ similarity with 9 microbial antigens, the relevant microbial peptides were tested for reactivity. Only the urease alpha subunit (aa 225-239) of Helicobacter pylori was cross-reactive as confirmed by competition ELISAs. Interestingly, SLA/H pylori peptide crossreactive patients had serological evidence of $H$ pylori infection (Euroimmun, UK)

Conclusion: Our results provide for the first time a complete linear $B$ cell epitope map of SLA, a major antigen in $\mathrm{AlH}$, and implicate $H$ pylori in the generation of autoimmunity through a mechanism of molecular mimicry.

\section{NOTCH RECEPTOR AND LIGAND EXPRESSION IN DEVELOPING HUMAN LIVER}

D.M. Flynn, S. Nijiar, S.G.Hubscher, J. de Ville, D.A. Kelly, M.D. Kilby A.J. Strain, H.A.Crosby. Liver Research Laboratories, Queen Elizabeth Hospital, Women's Hospital and Birmingham Childrens' Hospital, Birmingham, UK

Introduction: The Notch signaling pathways is important in normal development and cell specification in many organisms. Jagged 1, a notch receptor ligand, is present in developing liver and implicated in the abnormal development of the biliary tree in Alagille syndrome. Receptor expression is not known.

Aim: To examine and compare Notch ligand and receptor expression in human fetal and paediatric liver

Methods: RT-PCR for Jagged 1, Jagged2, Delta and Notch 1-4 was performed in fetal $(n=10)$, normal $(n=5)$ and diseased liver $(n=10)$. Immunostaining of frozen sections of fetal ( $n=4 ; 10-16$ weeks) normal ( $n=7 ; 4-12$ years) and diseased $(n=11 ; 9$ months -5 years) liver was performed using antibodies to Notch 1-4, Jagged 1 and cytokeratin 19 (CK19).

Results: Jagged 1 and Notch 1-4 mRNA was detectable by RT-PCR at all ages, except in fetal liver where Notch3 was restricted to 10-16weeks gestation. Jagged2 and Delta were not expressed. Immunostaining fetal liver showed Jagged 1 expression on ductal plate and vascular endothelium, and Notch3 on adjacent portal tract mesenchyme. In normal liver, Notch 1-4 stained endothelial cells. Notch2 and 3 also stained occasional biliary epithelial cells and Jagged 1 colocalised with CK19 on BEC. In disease Notch2 additionally stained stromal cells in portal tracts and cirrhotic fibrous septa, Notch3 also stained stromal and occasional ductular cells, and Jagged 1 colocalised with CK 19 on ductular cells.

Conclusion: Notch 1-4 are expressed in human liver. Notch3 shows restricted expression in fetal liver adjacent to the Jagged 1 expressing ductal plate. In diseases associated with marginal ductular reaction its expression is increased in close proximity to Jagged expressing ductular cells. This suggests that Notch3 and Jagged 1 may 
be required for normal development of bile ducts and become reactivated in diseases associated with abnormal ductular reaction.

\section{PROSPECTIVE STUDY OF OBSTETRIC CHOLESTASIS IN SOUTH WALES}

C.L. Ch'ng', M. Morgan', J.G.C. Kingham'. 'Department of Gastroenterology and ${ }^{2}$ Obstetrics, Singleton Hospital, Swansea, UK

Aims: A prospective study of the incidence, clinical and biochemical features, management and outcome of obstetric cholestasis $(O C)$ in a defined population in South Wales, UK.

Methods: All pregnancies in an obstetric unit serving 270000 were screened for OC between March 1999 and February 2001. OC was diagnosed based on pruritus, abnormal liver tests and exclusion of other hepatobiliary diseases.

Results: 36 episodes (in 35 patients) of OC were identified among 7000 pregnancies-incidence $0.5 \%$. Age ranged from $16-45$ years (Median 29). There were five twin and one triplet pregnancies. Fourteen were primiparae while 21 had had 1 to 5 previous pregnancies, five of which were complicated by $O C$ with two associated stillbirth. Three had family history of OC. All were symptomatic: pruritus in 36, vomiting in four, diarrhoea in three and severe malaise in two. Two patients suffered hyperemesis earlier in their pregnancy and two preeclampsia. Symptoms started between 22 and 39 weeks gestation (median 34). Fifteen had proven urinary tract infection either just before or after diagnosis of OC 35 had elevated AST (19-519. median $164 \mathrm{U} / \mathrm{ll}$ ). Serum bile acids raised in 29 of 31 tested (8-179; median 48 umol/I). $\gamma$ GT was modestly elevated (6-292 U/I) in only eleven episodes while bilirubin was raised in thirteen (6-34 $\mathrm{\mu mol} / \mathrm{l})$. Leucocytosis was seen in 21 patients. The interval from diagnosis of OC to delivery ranged from 1 to 44 days (median 6). Ursodeoxycholic acid was given to nine patients with improvement in symptoms in 6 and biochemistry in 7. Induction of labour or Caesarean section was undertaken in 27 because of OC. There was no maternal or fetal death but 13 of 43 babies required admission to SCBU. Symptoms and abnormal liver function resolved rapidly after delivery.

Conclusion: $O C$ is common in South Wales complicating 1 in 200 pregnancies. It is characterised by elevated transaminases rather than cholestasis on routine biochemistry. Serum bile acids were almost invariably raised. Jaundice is neither a necessary nor a common component of OC. Combined medical and obstetric care with early delivery minimises maternal and fetal morbidity.

\section{A SMALL SYNTHETIC PEPTIDE FOR GENE DELIVERY VIA THE SERPINE ENZYME COMPLEX RECEPTOR}

S. Patel, X. Zhang, C. Collins, J.W. Fabre. Department of Clinical Sciences, Institute of Liver Studies, Guy's, King's and St Thomas' School of Medicine, King's College Hospital, Bessemer Road, London, UK

The serpin-enzyme complex receptor (SECR) has previously been successfully targeted for gene delivery using synthetic peptide ligands covalently linked in fluid phase to commercially available polylysine preparations $(\sim 10 \mathrm{kD}$ to $54 \mathrm{kD})$. Our main objective in this study was to improve this approach by the use of small, bifunctional, and easily standardised synthetic peptides. Two peptides designated polylysine anti-trypsin 1 (PAT1) ( $\mathrm{K}_{16}$ FNKPFVFLI) and PAT2 ( $\mathrm{K}_{16}$ CSIPPEVKFNKPFVFLI) were evaluated for gene delivery to the HUH7 human hepatocyte cell line. The $\mathrm{K}_{16}$ moiety binds DNA electrostatically, while the FVFLM motif of human $\alpha 1$-antitrypsin targets the SECR. Both PAT1 and PAT2 bind to and condense DNA into small particles as shown by laser-scattering techniques. However, only PAT2 is effective for gene delivery, presumably an account of the greater distance between the $\mathrm{K}_{16}$ chain and the FVFLM motif. Gene delivery by PAT2/DNA complexes is chloroquine dependent, can be blocked completely by free ligand (CSIPPEVKFNKPFVFLI), and is highly efficient (eg, approximately 5 -fold more effective than lipofectamine). At physiological salt concentrations, PAT2/DNA complexes formed at $4 \mu \mathrm{g} / \mathrm{ml}$ of DNA are $\sim 350 \mathrm{~nm}$ in diameter and highly effective for gene transfer, but at $100 \mu \mathrm{g} / \mathrm{ml}$ of DNA the complexes are aggregated (diameter $>4 \mu \mathrm{m}$ ) and inactive. Our finding that a small (33 amino acid) bifunctional synthetic peptide represents an efficient and readily standardised DNA vector for the SECR is of potential importance for gene therapy of the liver, as this receptor is strongly expressed by hepatocytes.

\section{THE CHEMOKINE CXCL16 AND ITS RECEPTOR CXCR6 ARE IMPORTANT FOR POSITIONING OF T CELLS WITHIN THE LIVER}

M. Heydtmann', S.G. Hübscher', M. Briskin², D.H. Adams'. 'Birmingham University, Birmingham, UK; ${ }^{2}$ Millenium Inc., Boston, MA, USA

Background \& Aims: The outcome of HCV infection is dependent in part on chemokines, which recruit and position lymphocytes in the infected liver. The novel chemokine CXCL16 is unusual in that it exists in a transmembrane as well as a soluble form. This provides a potential mechanism for localization to particular structures. We studied the role of this chemokine and its specific receptor CXCR6 in lymphocyte recruitment and retention in the liver in HCV.

Materials \& Methods: Lymphocytes were isolated from liver removed at transplantation and from paired peripheral blood samples. Primary cultures of cholangiocytes, hepatocytes and sinusoidal endothelial cells were established. CXCR6 and CXCL16 expression was studied by flow cytometry and immunocytochemistry and confocal microscopy. Lymphocyte adhesion to cholangiocytes monolayers was analysed in static adhesion assays.

Results: CXCR6 was expressed by the majority of $\mathrm{CD} 8^{+} \mathrm{T}$ cells and CD56 ${ }^{+}$cells in the liver. Less than $50 \%$ circulating Tcells were CXCR6+ in normals but this increased significantly in $\mathrm{HCV}$ patients. In the liver CXCR6 ${ }^{+}$lymphocytes were found in association with $\mathrm{CXCL16}$ in inflammatory areas. Cultured cholangiocytes and hepatocytes stained strongly for CXCL16 with cholangiocytes showing a strong membranous pattern whereas endothelial staining was weak and confined to the cytoplasm. Inhibition of either CXCL16 or its receptor CXCR6 with specific mAb reduced lymphocyte adhesion to monolayers of cholangiocytes by $56.7 \%$ and $49 \%$ respectively. This inhibition was similar to that seen with blocking CD18/ICAM-1.

SUMMARY:

(1) A high proportion of liver infiltrating effector cells express CXCR6.

(2) CXCL16 is concentrated on epithelial cells particularly cholangiocytes in a trans-membrane form supporting lymphocyte adhesion.

Conclusions: This is the first demonstration of lymphocyte adhesion supported by a CXC chemokine. CXCL16 expression by cholangiocytes suggests a role in attracting and retaining effector cells to promote bile duct damage in inflammatory liver disease.

\section{CHANGES IN NEUROPSYCHOLOGICAL FUNCTION FOLLOWING HYPERAMMONEMIA INDUCED BY A SIMULATED BLEED IS MEDIATED BY INCREASE IN BRAIN WATER}

R. Jalan', S. Balata ${ }^{2}$ S. Olde Damink ${ }^{4}$, K. Ferguson ${ }^{3}$ I. Marshall, ${ }^{3}$ D. Kapoor', P.C. Hayes ${ }^{2}$, N.E.P. Deutz', R. Williams', J. Wardlaw'3. 'Institute of Hepatology, University College London, UK; ${ }^{2}$ Liver Unit, Royal Infirmary, Edinburgh, UK; ${ }^{3}$ Dept of Neuroradiology, Western General Hospital, Edinburgh, UK; ${ }^{4}$ Dept of Surgery, Maastricht University, the Netherlands

Hypothesis and Aims: This study was designed to explore the hypothesis that hyperammonemia induced by oral administration of an amino acid (aa) solution mimicking the haemoglobin molecule would produce neuropsychological deterioration by increasing brain glutamine and brain water.

Methods: The study was performed in 3 parts and measurements were made prior to and 4 hours after administration of the aa solution or placebo. Part 1. Battery of neuropsychological function was measured in 32 cirrhotic patients (age: $56( \pm 6), 18$ males, Child $A: 11, B: 16, C: 5$; alcoholic liver disease: 26 patients) who were randomised to either a bolus administration of $75 \mathrm{gm}$ of the aa solution or placebo. Part 2. In the first 16 patients randomised in this study proton magnetic resonance scan of the brain using short echo time spectroscopy $(36 \mathrm{~ms})$ was performed. Peak area ratios for were fitted using the MRUI software. Part 3. In 6 other patients, magnetisation transfer ratio (MTR) study was performed in a transverse plane in 4 different regions and averaged (before and 4 hours after aa solution). Venous blood was collected for the measurement of ammonia and aa.

Results: Significantly greater increase was observed in ammonia ( $\mu \mathrm{mol} / \mathrm{L})(81 \pm 8$ to $121 \pm 11 ; 81 \pm 9$ to $89 \pm 8 ; \mathrm{p}<0.01)$ and brain glutamine.glutamate/ $\mathrm{Cr}$ ratio $(2.0( \pm 0.8)$ to $2.8(1.2) ; 2.4( \pm 0.8)$ to $2.6( \pm 0.7)$ and deterioration in neuropsychological function in patients treated with the aa solution compared with placebo. All aa levels increased except isoleucine levels which decreased significantly in the aa group $(76( \pm 3.1)$ to $28( \pm 2.8) \mu \mathrm{mol} / \mathrm{L}, p<0.01)$. MTR decreased significantly from $30( \pm 2.9)$ to $23( \pm 4) ; p<0.01)$ after the aa solution. 
Conclusions: The results of this study show for the first time that induced hyperammonemia due to a simulated upper gastrointestinal bleed produces neuropsychological deterioration by increasing brain water.

\section{CO-ORDINATED REGULATION OF TIMP-1 AND ITS TRANSCRIPTIONAL REGULATOR UTE-1 BINDING PROTEIN (UTE-1BP) AS A FEATURE OF THE ACTIVATED PHENOTYPE OF HEPATIC STELLATE CELLS (HSC)}

R. Ruddell, N. Mungalsingh, M.J.P. Arthur, D.A. Mann. Liver Research Group, Division of Infection, Inflammation, Allergy and Repair, University of Southampton, Southampton General Hospital, Southampton, SO16 6YD, UK

The major source for the elevated level of hepatic TIMP-1 expression in the injured liver is de novo synthesis by activated HSC. We have recently described a new regulator of TIMP-1 gene transcription called UTE- 1 ' . A UTE-1 binding site in the TIMP-1 promoter is essential for transcriptional activity in activated HSC and interacts with an as yet uncharacterised $30 \mathrm{kDa}$ nuclear protein that is induced during HSC activation. The aims of the current study were to determine if induction of UTE-1 activity is closely linked to the phenotypic state of HSC and determine if UTE-1 activity and TIMP-1 mRNA expression are coordinately regulated in the activated HSC. It has previously been demonstrated that culturing freshly isolated HSC on Matrigel suppresses culture-induced activation while culture of pre-activated HSC on Matrigel can reverse morphological and biochemical features of HSC activation. In the present study we show that induction of TIMP-1 mRNA expression and UTE-1 DNA binding activity are both completely repressed when freshly isolated rat HSC are cultured on a thin layer of Matrigel. We also show that when pre-activated rat HSC are passaged onto Matrigel coated plastic there is a rapid (within 3 hours of plating) and progressive inhibition of TIMP-1 mRNA expression, TIMP-1 promoter activity and UTE-1 DNA binding activity. These effects were not reproduced when activated HSC were cultured on individual matrix components including the major components of Matrigel (Laminin and Collagen IV). In summary, the expression of TIMP-1 and activity of its key transcriptional regulator UTE-1 are co-ordinately regulated during HSC activation and are intimately linked to the phenotype of the HSC. UTE-1 is therefore a potential target for developing therapeutics aimed at reducing TIMP-1 expression in the fibrotic liver.

1. Trim JE, et al. J Biol Chem 2000;275:6657-63.

\section{NO ASSOCIATION BETWEEN FUNCTIONAL SNPS IN THE ENDOTOXIN RECEPTORS CD14 AND TLR4 AND ALCOHOLIC LIVER DISEASE: IS ENDOTOXIN IMPORTANT IN HUMAN DISEASE?}

J.B. Leathart*, C.P. Day, A.K. Daly. Centre for Liver Research, Medical School, University of Newcastle upon Tyne, Framlington Place, Newcastle upon Tyne NE2 4HH, UK

The reasons why only a minority of heavy drinkers develop advanced alcoholic liver disease (ALD) remain unclear but twin studies suggest that genetic factors play a role. Studies confined largely to animal models of ALD suggest that increased gut permeability to endotoxin leading to release of pro-inflammatory cytokines from Kupffer cells is important in disease pathogenesis. The effects of endotoxin on Kupffer cells are mediated by two receptors, CDI 4 and toll-like receptor- 4 (TLR4) and mouse strains deficient in either receptor are protected against the development of ALD. Single nucleotide polymorphisms (SNPs) have been described in CDI4 and TLR4 that have been associated with increased levels of CDI4 and hypo-responsiveness to endotoxin respectively and the CDI4 SNP has recently been associated with advanced ALD in a Finnish population

We therefore determined the frequency of the CD14 -159 C $\rightarrow T$ promoter SNP and the TLR4 Asp 299 Gly SNP in 279 patients with biopsy-proven advanced ALD (cirrhosis/fibrosis), 126 heavy drinkers with normal liver function tests/ultrasound or steatosis only on biopsy and 111 healthy controls. There was no difference in allele frequencies or genotype between the groups for either SNP. For the CD 14 SNP, 71\% of ALD patients had at least one T allele compared to $76 \%$ of heavy drinkers and $76 \%$ controls. For the TLR4 SNP, $12 \%$ of ALD patients and 13\% of heavy drinkers were heterozygous for the rare allele.

These results showing no association between apparently functional SNPs in the two Kupffer cell endotoxin receptors cast considerable doubt on the role of endotoxin-mediated Kupffer cell activation in the pathogenesis of ALD in humans. 1. Hepatology 2001;33:1 148-53.

\section{A DNA VACCINE FOR HCV}

E.A. Sanders, D. Xhu, M. Spellerberg, K. King, F. Stevenson, W.M. Rosenberg. Infection, Inflammation and Repair, University of Southampton, Southampton General Hospital, Tremona Road, Southampton, UK

Introduction: Hepatitis $C$ is a major public health problem infecting approximately $3 \%$ of the world's population. The majority of those acutely infected remain infected for life with only $15 \%$ clearing the virus spontaneously. Effective treatment for chronic hepatitis $\mathrm{C}(\mathrm{CHC})$ is available but leads to a sustained viral clearance in only $40 \%$ of individuals and is associated with a high frequency of adverse events and is expensive. Clearance of acute HCV is associated with vigorous and multispecific CD4+ and CD8+ T cell responses to the virus. This information is encouraging when considering the possibility of designing effective preventative and therapeutic vaccines. We have adapted an augmentation strategy which has already been successfully used against lymphoma and myeloma.

Aim: To design an effective DNA vaccine against HCV using a fusion of the gene encoding Tetanus toxin to a fragment of the E2 region of $\mathrm{HCV}$.

Materials and Methods: A truncated E2 sequence was cloned into a DNA expression vector incorporating Fragment $C$. In vitro expression of HCVE2-FrC was demonstrated in COS cells and rabbit reticulocytes. Five $\mathrm{C} 57$ /black mice were vaccinated by intramuscular injection of 50 pg of DNA, on three occasions three weeks apart. Antibody responses to $\mathrm{E} 2$ and $\mathrm{FrC}$ were assessed by ELISA.

Results: In vitro expression of FrC-E2 and the E2 construct was successfully demonstrated in COS cells and rabbit reticulocytes. Despite the deletion of the hydrophobic region of the HCV E2 sequence protein secretion was not observed. Detectable levels of HCV E2 antibody were demonstrable in $5 / 5$ vaccinated mice post vaccination with HCVE2-FrC construct and HCVE2 gene sequence alone.

Conclusions: Humoral responses were elicited with both the HCVE2 and the HCVE2-FrC construct. Further studies are in progress to ascertain whether the humoral response is induced more rapidly with the $\mathrm{FrC}$ containing construct and also to determine the ability of this novel DNA vaccination strategy to augment $C D 4+$ and $C D 8+T$ lymphocyte responses.

\section{HEPATITIS C IMPAIRS CELL CYCLE PROGRESSION- IMPLICATIONS FOR HEPATIC REGENERATION}

A.E. Marshall, S.M. Rushbrook, L.S. Morris', A. Freeman', K. Bird', I.S Scott', N. Coleman', G. Alexander. Departments of Medicine and 'Molecular Pathology, University of Cambridge, Hills Road, Cambridge, CB2 2QQ, UK

Background: The mechanisms by which hepatitis $C$ virus (HCV) causes chronic liver disease, cirrhosis and hepatocellular carcinoma ( $\mathrm{HCC}$ ) are unknown. $\mathrm{HCV}$ core protein and nonstructural protein 5A (NS5A) are known to affect cell cycle regulation in vitro. Progression through the cell cycle is dependent on serial activation of cyclin dependant kinases (cdk) in association with cyclins. Inhibition of cdks occurs via p21, p27, p57, and INK4 proteins (p16, p15, p18, p19) and prevents cell cycle progression. Ectopic expression of p21 can cause G1 or G2 arrest.

Methods: Using immunohistochemistry, we have examined liver biopsies from 50 patients with chronic $\mathrm{HCV}$ at all stages of disease for the presence of cell cycle markers. Minichromosome maintainance protein 2 (MCM2), a sensitive and specific marker expressed throughout the cell cycle, cyclin DI in Gl phase, cyclin A in S, cyclin BI in $\mathrm{G} 2$ and phosphohistone $\mathrm{H} 3$ in mitosis and $\mathrm{p} 21$. HCC and colonic carcinoma served as positive controls and normal liver as a negative control

Results: Throughout the spectrum of disease, MCM2 expression was increased and correlated with the stage of fibrosis (stage 0 , 3-14\%; stage 5, 5-40\%, p<0.0001, highest level, 59\%). Cyclin D1 expression was similar to and did not exceed MCM2. In contrast, hepatocyte expression of markers for the later stages of the cell cycle was very low: $0.4-1.6 \%$ expressed cyclin $A,<0.1 \%$ expressed cyclin B1 and $0.36-0.5 \%$ expressed phosphohistone H3. p2 1 expression was present in up to $60 \%$ of hepatocytes and was closely associated with MCM2 expression.

Conclusion: These data indicate that a significant proportion of hepatocytes have entered the cell cycle, but are arrested at Gl/S. Changes are seen in all stages of disease, therefore is it likely to be a 
consequence of viral infection. As p21 and MCM2 expression are linked, HCV may induce p21. HCV may therefore impair hepatic regeneration.

\section{GENETIC DIFFERENCES IN INTERLEUKIN 10 PRODUCTION DO NOT INFLUENCE THE SEVERITY OF CHRONIC HEPATITIS C}

W.G.H. Abbott', E. Rigopoulou', P. Haigh', H. Cooksley', I. Mullerova', M. Novelli' ${ }^{2}$ A. Winstanley', R. Williams' N.V. Naoumov' 'Institute of Hepatology and ${ }^{2}$ Dept of Pathology, University College London, UK

The cellular and molecular mechanisms responsible for inter-individual differences in severity of chronic hepatitis $\mathrm{C}(\mathrm{CHC})$ have not been defined. Interleukin 10 (IL-10) is an anti-inflammatory cytokine that down-regulates anti-viral immune responses. Understanding the role of IL-10 in chronic hepatitis C (CHC) may be of value for designing new treatment strategies.

Aim: To determine whether genetic polymorphisms in the IL-10 promoter and/or the ability to produce IL-10 influence HCV-specific T cell reactivity and the severity of $\mathrm{CHC}$.

Methods: 113 consecutive patients with $\mathrm{CHC}$ were characterised for an IL-10 promoter polymorphism (either GCC, ACC, or ATA), for concanavalin $\mathrm{A}$ (Con A) stimulated IL-10 production from PBMC, and for $\mathrm{T}$ cell proliferation to HCV core, NS3, NS4, and NS5 antigens. The grade and stage of liver histology was correlated with these parameters and also with clinical variables.

Results: A mild grade of $\mathrm{CHC}$ was associated with high T cell proliferation to core $(p=0.06)$, NS3 $(p=0.05)$ and NS4 $(p=0.05)$ antigens, young age $(p=0.002)$ and intravenous drug use (IVDU) $(p=0.004)$. There were no associations between the grade of $\mathrm{CHC}$ and either Con A stimulated IL-10 production, IL-10 promoter haplotype, sex, alcohol intake, or HCV genotype. Age and IVDU were independently associated with the grade of $\mathrm{CHC}$ on multivariate analysis $(p=0.0006)$. An early stage of $\mathrm{CHC}$ was associated with young age $(p=0.0001)$, short duration of $\mathrm{HCV}$ infection $(p=0.01)$ and low grade of $\mathrm{CHC}(\mathrm{p}=0.0002)$, but not with IL-10 promoter haplotype, Con A stimulated IL-10 production, T cell proliferation, sex alcohol intake or HCV genotype. On multivariate analysis, age and the grade of $\mathrm{CHC}$ were independently associated with the stage of $\mathrm{CHC}(\mathrm{p}=0.0001)$. There were no associations between HCV-specific $T$ cell reactivity and either Con A stimulated IL-10 production or IL-10 promoter haplotype.

Conclusions: Inter-individual differences in Con A stimulated IL-10 production and functional genetic polymorphisms in the IL-10 promoter have no influence on the severity of chronic hepatitis $C$.

\section{VITRONECTIN INDUCES MIGRATION OF ACTIVATED T LYMPHOCYTES: A MECHANISM FOR LYMPHOCYTE INFILTRATION OF HEPATIC TUMOURS}

S. Edwards, P.F. Lalor, D.H. Adams. Liver Laboratories, Queen Elizabeth Hospital, Birmingham, UK

Background: The mechanisms by which lymphocytes infiltrate hepatic tumours are poorly understood. The extracellular matrix glycoprotein vitronectin is a major component of the stroma of hepatic tumours and might thus play a role in the recruitment and retention of infiltrating leukocytes. In order to address this hypothesis, we examined the ability of vitronectin to support migration of activated peripheral blood T cells (PBT) and tumour infiltrating lymphocytes (TIL) isolated from hepatic colorectal cancer metastases. In addition we investigated the possibility that this interaction was mediated by the integrin $\alpha_{\mathrm{\gamma}} \beta_{3}$

Methods: TIL and PBL migration to vitronectin $(2-0.00002 \mu \mathrm{g} / \mathrm{ml})$ was assessed using an in vitro chemotaxis assay and activated T cells expanded in culture for up to 14 days. Vitronectin was presented in soluble and immobilised states. Expression of $\alpha_{\mathrm{v}} \beta_{3}$ integrin on T cells was determined by flow cytometry. The ability of vitronectin to support adhesion of TIL to tumour tissue was assessed by tissue binding and static adhesion assays.

Results: (1) TIL from hepatic tumours and activated PBT migrated to vitronectin in both its soluble and immobilised states. This migration to vitronectin was not mediated by the integrin $\alpha_{v} \beta 3$ which was absent from the migrating T cells. (2) TIL bound to tumour tissue in vitro and this was blocked by an antibody against vitronectin but the blocking $\alpha \beta_{3}$ antibody LM609 was ineffective.

Summary: (1) Vitronectin can support, chemotaxis, haptotaxis and adhesion of activated T cells. (2) T cells infiltrating liver tumours show negligible $\alpha_{v} \beta_{3}$ dependent migration or adhesion suggesting that TIL employ an alternative vitronectin receptor.

Conclusions: Vitronectin is a potent pro-migratory factor for activated $\mathrm{T}$ cells. It may be particularly important for regulating lymphocyte migration and retention through the extracellular matrix in hepatic tumours or during fibrogensis.

\section{REGULATION OF ADAMS IN HEPATIC STELLATE CELLS BY SOLUBLE GROWTH FACTORS: EVIDENCE FOR A ROLE FOR ADAMTS-1 IN FIBROGENESIS}

M.J. Lorite, D.J. Bevitt', J. Benitez, N. McKie', C.P. Day. Centre for Liver Research and 'Dept of Rheumatology, Medical School, Framlington Place, Newcastle upon Tyne, UK

We have previously reported that a new group of matrix metalloproteinase (MMP)-related enzymes known as ADAMs (A Disintegrin And Metalloproteinase) are present in hepatic stellate cells (HSC). We have cloned several ADAM family members from primary HSC whose properties suggest their potential role in fibrogenesis including: ADAM10 (a type IV collagenase in vitro), ADAM17 (a TNF $\alpha$ convertase), ADAMTS-1 and TS-5 (proteoglycanases capable of releasing bound growth factors from the ECM). To seek further evidence for a role of these proteins in fibrogenesis we have examined the regulation of ADAM10, ADAM17 and ADAMTS1 by soluble factors with established profibrogenic (PDGF, TGF $\alpha$ or antifibrogenic (IL-

10) effects. For comparison the effects of these factors on MMP2 and TIMPI were also determined.

HSCs were isolated from male rats by pronase/collagenase digestion/density gradient centrifugation. Experiments were performed on 2 week old passage 1 cells. Growth factors were present for $1 \mathrm{~h}$ after $24 \mathrm{~h}$ in serum free medium. mRNA was quantified by Northern blotting using labelled PCR products from our cloning experiments. PDGF up-regulated the expression of ADAMTS-1 ADAM10, ADAM17 and TIMP-1 in a dose-dependent manner and down-regulated MMP2 expression. IL-10 down-regulated the expression of ADAMTS-1 and ADAM10. TGF $\alpha$ had no consistent effect on any ADAM.

These data support a role for ADAMs proteins in liver fibrogenesis either by (i) releasing TGF $\alpha$ from decorin in the ECM (ADAMTS-1); (ii) Degrading type IV collagen (ADAM10) and/or activatinf TNF? (ADAM17).

\section{CD40 MEDIATED MECHANISMS OF LIVER} INFLAMMATION: THE EFFECTS OF CD4O LIGATION ON CHEMOKINE SECRETION AND ADHESION MOLECULE EXPRESSION IN PRIMARY HUMAN INTRAHEPATIC SINUSOIDAL ENDOTHELIAL CELLS AND BILIARY EPITHELIAL CELLS

C. Russell, S. Randhawa, D. Adams, S. Afford. Liver Research Laboratories, MRC Centre for Immune Regulation, The University of Birmingham Institute of Clinical Science, The Queen Elizabeth Hospital, Edgbaston, Birmingham B15 2TH, UK

Background: CD40 a member of the TNF receptor superfamily is widely expressed on many cell types including intrahepatic endothelium (IEC), biliary epithelium (BEC) and hepatocytes during inflammatory liver disease. On hepatocytes, CD40 expression has been associated with amplification of Fas mediated apoptosis. The functional significance of CD40 on other liver cells remains unknown although reports suggest that it may be involved in regulation of leukocyte recruitment via modulation of chemokine secretion and adhesion molecule expression.

Aims: The purpose of this study was to compare chemokine secretion and adhesion molecule expression by IEC and BEC before and after stimulation with CD40 ligand (CD4OL).

Methods: Briefly, IEC or BEC from human liver tissue were isolated and cultured according to standard protocols. Cells were stimulated with soluble recombinant CD4OL (up to $1 \mathrm{ug} / \mathrm{ml}$ ) or $10 \mathrm{ng} / \mathrm{ml} \mathrm{TNF} \alpha$ over $24 \mathrm{hrs}$. Secretion of the chemokines IL8, ENA 78 or MCP-1 was measured in culture supernatants by ELISA. Cell surface expression of adhesion molecules ICAM-1, VCAM-1 or E-Selectin was measured by flow cytometry or cell based ELISA.

Results: (1) IEC chemokine secretion: stimulation with CD4OL increased secretion of IL 8 from $417(+/-510)$ to $1460(+/-990 \mathrm{pg} / \mathrm{ml})$ $(2 \mathrm{p}<0.005)$ and ENA 78 from $629(+/-358)$ to $1185(+/-605) \mathrm{pg} / \mathrm{ml}$ $(2 \mathrm{p}<0.013)$. MCP-1 secretion was not affected following CD4OL treatment. (2) IEC adhesion molecule expression: stimulation with CD4OL increased expression of ICAM 1 from $17.0(+/-4.4)$ to $42.8+/-7.4 \%$ 
+ve cells $(2 p<0.005)$. E-selectin increased from $2.91+/-5)$ to $11.71+/-$ $2.6 \%)+v e$ cells $(2 p<0.07)$. VCAM-1 expression was unaffected. TNF $\alpha$ consistently induced more chemokine secretion and higher levels of adhesion molecules compared with CD4OL. (3) BEC chemokine secretion: CD4OL had no effect on secretion of ENA-78, IL8 or MCP-1 whereas TNF? induced secretion of all three chemokines. (4) BEC adhesion molecule expression: CD4OL increased expression of ICAM-1 from $0.284(+/-0.027)$ to $0.439(+/-0.014)$ OD units $(n=3)$. VCAM-1 expression also increased from $0.292(+/-0.07)$ to 0.43 (+/-0.01) OD units $(n=3)$ and CD4OL stimulation was more effective than TNF $\alpha$.

Conclusions: CD40 ligation selectively enhanced IEC IL8, ENA78 secretion and ICAM-1 and E selectin expression. In BEC chemokine secretion was unaffected by CD40 ligation whereas ICAM-1 and VCAM-1 expression increased. These data provide further evidence for variation in responses between cell types following CD40 ligation, and suggest that CD40 may have a pivotal but complex role in modulation of leukocyte recruitment and retention during inflammatory liver disease.

\section{HAEMOCHROMATOSIS-ASSOCIATED HFE GENOTYPES IN BLOOD DONORS: AGE-RELATED FREQUENCY AND PHENOTYPIC EXPRESSION}

K. Palmer, V. Chambers, A. Dalton, R. Sokol, R. Pollitt, M.S. Tanner, D. Gleeson. Dept of Child Health, University of Sheffield, Trent Regional Blood Transfusion Service and Liver Unit, Sheffield Teaching Hospitals, Sheffield, UK

Background: Of UK patients with haemochromatosis, $90 \%$ are homozygous for the HFE gene mutation C282Y; another $3 \%$ are heterozygous for $\mathrm{C} 282 \mathrm{Y}$ and a second HFE gene mutation: H63D. There are limited data on the frequency and phenotypic expression of these mutations in healthy people. In such populations, genotypes associated with ill health should show age-related attrition

Methods: We studied randomly selected male blood donors $1 \leqslant 4$ units previously donated) from the Trent Region in 4 age cohorts. HFE genotyping was performed using a PCR-based BIPASA system.

Results: Table shows genotype distribution in the four cohorts. Genotype distribution was in Hardy-Weinberg equilibrium in each cohort. Wild/C282Y frequency fell slightly with increasing age (NS after Bonferroni correction): no such trend was seen for C282Y/ C282Y or $\mathrm{C} 282 \mathrm{Y} / \mathrm{H} 63 \mathrm{D}$. In C282Y/C282Y subjects, serum \% iron saturation ( $\mathrm{n}=16)$ was (median (range)) 63 (15-80); serum ferritin $(\mathrm{n}=16)$ was $215(60-2449) \mathrm{mmol} / \mathrm{L}$ and was $>500 \mathrm{\mu mol} / \mathrm{L}$ in only one; neither parameter correlated with age or number of previous units donated. In $\mathrm{C} 282 \mathrm{Y} / \mathrm{H} 63 \mathrm{D}$ subjects $(\mathrm{n}=100) \%$ iron saturation was $39(18-77)$ and ferritin, $79(4-419) \mu \mathrm{mol} / \mathrm{L}$.

\begin{tabular}{|lllll|}
\hline Abstract 42 & \multicolumn{5}{l|}{} \\
\hline Genotype & $\begin{array}{l}<30 \mathrm{yr} \\
(\mathbf{n}=1727)\end{array}$ & $\begin{array}{l}30-40 \mathrm{yr} \\
(\mathbf{n}=1154)\end{array}$ & $\begin{array}{l}40-50 \mathrm{yr} \\
(\mathbf{n}=1691)\end{array}$ & $\begin{array}{c}>50 \mathrm{yr} \\
(\mathbf{n}=898)\end{array}$ \\
\hline Wild/Wild & $61.7 \%$ & $63.8 \%$ & $63.2 \%$ & $66.6 \%$ \\
Wild/H63D & $21.4 \%$ & $22.4 \%$ & $22.2 \%$ & $21.0 \%$ \\
Wild/C282Y & $12.0 \%$ & $10.1 \%$ & $10.3 \%$ & $7.9 \%$ \\
H63D/H63D & $2.7 \%$ & $1.9 \%$ & $1.9 \%$ & $2.2 \%$ \\
C282Y/H63D & $1.9 \%$ & $1.7 \%$ & $1.8 \%$ & $1.9 \%$ \\
C282Y/C282Y & $0.23 \%$ & $0.09 \%$ & $0.53 \%$ & $0.33 \%$ \\
\hline
\end{tabular}

Conclusion: In presumably healthy UK blood donors, C282Y/ C282Y and C282Y/ H63D have overall frequencies of $0.3 \%$ and $1.8 \%$ respectively, show no apparent attrition with age and are rarely associated with $>3$ fold elevation of serum ferritin. Phenotypic expression of haemochromatosis-associated mutations is highly variable.

\section{REGULATION OF HEPATIC STELLATE CELL ACTIVATION BY INTEGRIN $\mathrm{A}_{v} \mathrm{~B}_{3}$}

X. Zhou, J.P. Iredale, R.C. Benyon. Liver Research Group, University Division of Infection, Inflammation and Repair, Southampton General Hospital, Southampton, UK

The integrins are a family of cell surface adhesion molecules that mediate cell to extracellular matrix interaction. Integrins regulate a variety of cellular functions. In liver fibrosis, hepatic stellate cells $(\mathrm{HSC})$ are the major source of extracellular matrix components. HSC activation is a key event in hepatic fibrogenesis. We have examined the role of $\alpha_{v} \beta_{3}$ integrin in regulating rat HSC activation and proliferation using the disintegrin echistatin.

Western blotting and Taqman RT-PCR showed that activated HSC express integrin $\alpha_{k} \beta_{3}$. The effects of the integrin $\alpha_{v} \beta_{3}$ antagonist echistatin, $100 \mathrm{nM}$, on HSC adhesion to various matrices was examined. This disintegrin reduced attachment of HSC to Matrigel by $4.9 \%$, to fibronectin by $62.3 \%$, to vitronectin by $69.7 \%$, to collagen I by $25.8 \%$, to plastic by $59.8 \%$, but did not inhibit adhesion to laminin. A $24 \mathrm{hr}$ treatment with echistatin, $100 \mathrm{nM}$, reduced the proliferation rate of $\mathrm{HSC}$ on plastic by $73.5 \%$ assessed using ${ }^{3} \mathrm{H}$-thymidine incorporation. Western blotting showed reduced activation of MAP kinase p42 and p44 isoforms. Echistatin treatment for $24 \mathrm{hr}$ also reduced the expression of mRNA for: TIMP-1 by $97.1 \%$; pro-collagen-1 by $72.0 \%$; $\alpha$-SMA by $15.0 \%$; CTGF by $97.4 \%$ and TGF $\beta 1$ by $93.0 \%$ when examined by Taqman RT-PCR. Decreased expression of $\alpha$-SMA was confirmed by Western blotting. Collagenolytic activity in pooled cell lysates and supernatants, and MMP-9 secretion, were increased, but MMP-2 and MT1-MMP were unchanges by echistatin treatment CAT assays showed TIMP-1 promoter expression was decreased by $68.7 \%$ after 56 hours treatment with echistatin.

These finding suggest that integrin $\alpha_{4} \beta_{3}$ plays a important role in the interaction between $\mathrm{HSC}$ and extracellular matrix which are required for $\mathrm{HSC}$ activation and proliferation.. Integrin regulation of HSC might be important under conditions of fibrogenesis in the liver where there are major qualitative and quantitative changes in the extracellular matrix including enhanced deposition of $\alpha_{4} \beta_{3}$ ligands such as fibronectin, vitronectin and thrombospondin.

\section{REOXYGENATION-INDUCED ICAM-1 EXPRESSION AFTER COLD ISCHAEMIA IN HEPG2 CELLS IS STIMULATED BY L-NAME AND INHIBITED BY NAC}

V. Hoang, B.J. Fuller, B.R. Davidson. University Department of Surgery, Royal Free \& University College Medical School, Royal Free Campus, Pond Street, London, UK

Introduction: Intercellular adhesion molecule-1 (ICAM-1) plays a critical role in hepatic ischaemia/reperfusion (I/R) injury during transplantation. There is consistent up-regulation of ICAM-1 on both hepatic parenchemal cells and endothelial cells during I/R. The mechanism that leads to the induction of ICAM-I expression during I/R is not clear but it is believed that free radicals are involved in the process. The present study was carried out to determine whether ICAM-1 expression is potentiated by free radical processes during hepatic $I / R$ using the HepG2 cell line as a model system.

Methods: Cells were made hypoxic in University of Wisconsin solution for $16 \mathrm{~h}$ at $4^{\circ} \mathrm{C}$. Reoxygenation was carried out in culture medium for $4 \mathrm{~h}$ at $37^{\circ} \mathrm{C}$. $5 \mathrm{mM}$ of $\mathrm{N}$-acetyl cysteine (NAC) or $1 \mathrm{mM}$ of $\mathrm{N}^{\mathrm{G}}$-nitro-L-aginine methyl ester (L-NAME) were added at the beginning of the reoxygenation period. ICAM-1, $\beta$-actin and glyceraldehyde phosphate dehydrogenase (GAPDH) mRNA levels were determined by Nothern blot and semiquantitative rt-PCR.

Results: ICAM-1, $\beta$-actin, and GAPDH expression were unaffected by hypoxic condition. Compared to hypoxia alone, reoxygenation stimulated ICAM-1 expression by $300 \pm 35 \% \quad(p<0.001)$. In the presence of NAC and L-NAME ICAM-1 expression was stimulated by $150 \pm 25 \%(p<0.001)$ and $465 \pm 50 \%, p<0.001$, respectively (compared to hypoxia alone). Both NAC and L-NAME had no significant effect on mRNA levels of $\beta$-actin or GAPDH

Conclusion: The results presented in this study show that ICAM-1 expression in HepG2 cells can be induced by reoxygenation after cold hypoxia. The induction of ICAM-1 expression is partially inhibited by NAC and potentiated by L-NAME suggesting that free radicals may be involved in upregulation, whilst nitric oxide may be partially protective, possibly by itself acting as a scavenger.

\section{PARTIAL SEQUENCE ANALYSIS OF INDIGENOUS} HEPATITIS E VIRUS ISOLATED IN THE UNITED KINGDOM

Y. Wang', D.F. Levine', R.P. Bendall ${ }^{3}$, C-G. Teo ${ }^{4}$, T.J. Harrison'. 'Centre for Hepatology, Royal Free and University College Medical School, University College London, London, UK; ${ }^{2}$ West Cornwall Hospital, Penzance, UK; ${ }^{3}$ Public Health Laboratory, Truro, UK; ${ }^{4}$ Hepatitis and Retrovirus Laboratory, PHLS Central Public Health Laboratory, London, UK

Introduction: Hepatitis E virus (HEV) is a major cause of water-borne epidemics and sporadic cases of acute hepatitis in various regions of 
the developing world. Initially, it was believed that HEV was not present in industrialised countries, where the occasional diagnosis of hepatitis $\mathrm{E}$ usually is associated with recent travel by the patient to an endemic area. However, it has become clear that hepatitis $\mathrm{E}$ may be acquired in the USA and Europe and, recently, indigenous cases have been reported in the UK.

Methods: We investigated a longitudinal series of five serum samples from a 61 year old man who presented with acute hepatitis and who had not travelled outside the UK. RT-PCR was carried out on serum samples using degenerate oligonucleotide primers corresponding to open reading frames (ORFs) 1 and 2 of HEV, as described previously. The nucleotide sequences of positive amplicons were determined and compared to the EMBL and Genbank databases using BLAST and homologous sequences in the databases were aligned using PILEUP.

Results and discussion: The earliest sample available, which was positive for IgM antibodies to HEV, was positive by RT-PCR using both sets of primers. The ORF1 product showed $77-88 \%$, and the ORF2 product, $79-90 \%$, nucleotide identity to HEV sequences in the nucleotide databases. In both cases, the closest match was to HEV sequences (G2) derived from a patient with acute hepatitis acquired in Greece.

Conclusions: The origin of this novel variant of HEV is unclear but evidence is increasing that hepatitis $E$ in humans is zoonotic. Although this British patient did not report contact with rats or pigs or keep a dog, it seems likely that the source of his infection was zoonotic. We believe that indigenous hepatitis $\mathrm{E}$ in the UK may be under-diagnosed and suggest that testing for antibodies to HEV is appropriate in acute, non-A-C hepatitis in the UK and other industrialised countries.

\section{LIVER TRANSPLANT FOR AMYLOID RELATED LIVER FAILURE}

A. Stangou', N. Heaton', M. Rela', J.O'Grady ' G.Mufti' ${ }^{2}$, G.Alexander ${ }^{3}$, J. Gillmore ${ }^{4}$, P. Hawkins'. 'Liver Unit and ${ }^{2}$ Haematology Department King's College Hospital, London, UK; ${ }^{3}$ Department of Medicine, University of Cambridge School of Medicine, UK; ${ }^{4}$ The National Amyloidosis Centre, Royal Free Hospital, London, UK

Background: The liver is frequently involved in systemic AL amyloidosis, and it produces genetically variant amyloid fibril precursor proteins in some of the hereditary amyloid syndromes. Hepatic failure is rare in $\mathrm{AL}$ amyloidosis, but hyperbilirubinaemia confers a median prognosis of only 3 months. No systematic studies of liver transplantation for end stage hepatic amyloidosis have been performed. We report here the evaluation, management and outcome of 12 patients with end stage hepatic amyloidosis, 10 of whom underwent orthotopic liver transplantation (OLT).

Patients and methods: Ten patients were managed in 4 UK transplant centres, and two patients were treated in two centres in the USA. Mean age was $49(16-66)$ years. All patients had hepatomegaly, 10 had jaundice and ascites, and 2 patients were already undergoing renal dialysis. The amyloid fibril type was determined by immunohistochemistry and DNA analysis, and visceral amyloid deposits were imaged and monitored with radiolabelled SAP scintigraphy.

Results: Nine patients had AL amyloidosis, and 3 had hereditary forms associated with variant fibrinogen $\mathrm{A}$ alpha chain, apolipoprotein Al and lysozyme respectively. Extrahepatic amyloid deposits were present on SAP scintigraphy in all cases. All patients underwent OLT except two with $\mathrm{AL}$ who died whilst waiting for a donor organ. The patients with fibrinogen and apolipoprotein Al amyloid who were undergoing dialysis had combined liver and kidney transplants. The diagnosis of hereditary lysozyme amyloidosis was made retrospectively in a 16 year old boy who had presented in a moribund state with spontaneous liver rupture.

Outcome: Two out of the 7 patients transplanted for AL amyloid developed renal impairment and died within 4 months, and 2 others who had both received chemotherapy prior to transplantation died at 11 and 18 months, due to multiple organ failure associated with relentless graft and extrahepatic amyloid deposition. Three of the AL patients are alive with normal graft function at 10,25, and 46 months post-OLT. Intriguingly, the longest survivor exhibited a partial remission of his subtle underlying monoclonal gammopathy following OLT without cytotoxic therapy. Each of the patients with hereditary systemic amyloidosis is extremely well 3-5 years after OLT. Amyloid fibril protein production has been halted completely in the patient with fibrinogen amyloidosis and reduced by $50 \%$ in the patient with apolipoprotein Al amyloid.

Conclusions: OLT can be life saving in patients with systemic AL amyloidosis who develop liver failure, but the universal presence of extrahepatic amyloid deposits and need for adjuvant chemotherapy present major challenges to successful outcome. The excellent outcome of OLT in each of these 3 types of hereditary systemic amyloidosis strongly supports its use for these much rarer indications.

\section{THE THERAPEUTIC POTENTIAL OF RETINOIDS FOR HEPATOCELLULAR CARCINOMA (HCC)}

B. Rana', C. Redfern', D. Manas² , M. Bassendine 1,2. 'School of Clinical Medical Sciences, University of Newcastle, UK; ${ }^{2}$ Freeman Hospital Liver Unit, Newcastle upon Tyne, UK

Primary hepatocellular cancer $(\mathrm{HCC})$ ranks fifth in frequency of malignancies in the world and is increasing in developed countries. Treatment is largely palliative and long-term survival rare. A report' that an acyclic retinoid prevents second primaries of $\mathrm{HCC}$ after resection has raised the possibility that cirrhotic patients at risk of $\mathrm{HCC}$ may benefit from chemoprevention. Recent data suggest that retinoids also show promise for the chemoprevention of other cancers. The aims of this study were to ask whether retinoids and receptor-specific retinoid analogues are effective in promoting the differentiation and apoptosis of HCC in vitro. CD437, a retinoic acid receptor $\gamma(\operatorname{RAR} \gamma)$-selective analogue, was effective at inhibiting the proliferation of Hep3B and HepG2 HCC cells by up to $75 \%$ at concentrations of $1 \mu \mathrm{M}$ and $10 \mu \mathrm{M}$. Analysis by flow cytometry suggested that the anti-proliferative effects of CD437 were due to the induction of apoptosis in these cells. The RAR $\beta / \gamma$ selective antagonists CD2665 and CD2848 did not inhibit the effects of CD437 and this suggests that RARs are not involved in mediating these properties of CD437. Fenretinide, an RAR $\beta / R A R \gamma$ selective retinoid was also effective at inhibiting proliferation but only at high $(10 \mu \mathrm{M})$ doses. Neither 9-cis, all-trans retinoic acid or an RXRselective retinoid LGD 1069 were effective at inhibiting proliferation in these HCC cell lines. Previous work ${ }^{2}$ on neuroblastoma cells has suggested that fenretinide works by both RAR-dependent and independent pathways. In summary, this study suggests that drugs acting exclusively via RARs are unlikely to be effective agents in the chemoprevention of HCC. However, the retinoid analogue CD437 has therapeutic potential in HCC, possibly acting via an RAR-independent pathway.

1. Muto Y, Moriwaki H, Ninomiya M, et al. N Engl J Med 1996;334:1561-7. 2. Lovat PE, Ranalli $M$, Annichiarrico-Petruzzelli $M$, et al. Exp Cell Res 2000;260:50-60.

\section{HEPATITIS B IMPAIRS CELL CYCLE PROGRESSION- IMPLICATIONS FOR HEPATIC REGENERATION}

S.M. Rushbrook, A.E. Marshall, L.S. Morris', I.S. Scott', K. Bird', N. Coleman', G. Alexander. Departments of Medicine and 'Molecular Pathology, University of Cambridge, Hills Road, Cambridge, CB2 2QQ, UK

Background: Hepatitis B virus infection is a major cause of chronic liver disease, cirrhosis and hepatocellular carcinoma (HCC). The underlying mechanisms are poorly understood. Hepatitis B X protein is known to affect the cell cycle in vitro. Progression through the cell cycle depends on serial activation of cyclin dependant kinases (cdks) in association with cyclins. Inhibition of cdks occurs via p21, p27, $\mathrm{p} 57$, and INK4 proteins (p16, p15, p18, p19) and prevents cell cycle progression. Ectopic expression of p21 can cause G1 or G2 arrest.

Methods: Using immunohistochemistry, we have examined liver biopsies from 36 patients at all stages of HBV related liver disease for cell cycle markers: minichromosome maintainance protein 2 (MCM2), a sensitive and specific marker expressed throughout the cell cycle, cyclin $D 1$ in $G 1$ phase, cyclin $A$ in $S$, cyclin $B 1$ in $G 2$, phosphohistone $\mathrm{H} 3$ in mitosis and $\mathrm{p} 21$. HCC and colonic carcinoma served as positive controls and normal liver as a negative control.

Results: At all stages of disease, MCM2 expression was increased, present in 2.6-56\% of hepatocytes. The level of cyclin D expression was similar to and did not exceed MCM2. However, hepatocyte expression of markers for the later stages of the cell cycle was very low: $<1.79 \%$ cyclin A positive, $<0.01 \%$ cyclin B positive, and $<0.01 \%$ phosphohistone $\mathrm{H} 3$ positive. p2 1 expression was increased in all cases, expressed by up to $31 \%$ of hepatocytes. Of $\mathrm{HBcAg}$ positive cells (likely to support active viral replication) $55-75 \%$ are in cell cycle, compared with $1-5 \%$ of $\mathrm{HBsAg}$ positive cells (likely to represent integrated viral DNA)

Conclusion: These data show that a significant proportion of hepatocytes have entered the cell cycle, but are arrested at G1/S and upregulation of $\mathrm{p} 21$ is seen. As these changes are seen across the spectrum of disease, they are likely to be caused by viral infection, and may be explained by a p2l dependent mechanism. HBV may therefore impair hepatic regeneration. 


\section{A RISE IN CEREBRAL BLOOD FLOW PRECEDES INTRACRANIAL HYPERTENSION IN PATIENTS WITH ACUTE LIVER FAILURE (ALF)}

R Jalan', S. Olde Damink', P.C. Hayes ${ }^{3}$, N.E.P. Deutz' ${ }^{2}$ A. Lee ${ }^{3} .{ }^{1}$ Institute of Hepatology, University College London, UK; ${ }^{2}$ Liver Unit, Dept of Surgery, Maastricht University, the Netherlands; ${ }^{3}$ Scottish Liver Transplantation Unit, Edinburgh, UK

Hypothesis and Aims: Ammonia is considered central in the pathogenesis of increased intracranial pressure (ICP) in ALF. Data regarding the role of altered cerebral blood flow (CBF) remain uncertain. This study tested the hypothesis that increase in ICP in patients with ALF was preceded by a rise in $\mathrm{CBF}$

Methods: 21 patients with ALF (mean age: $28( \pm 2.9)$, males: 8 , aetiology, paracetamol overdose: 18, were studied from the time they were admitted to the intensive care unit with grade III-IV hepatic encephalopathy. Cardiovascular haemodynamics, ICP and MAP were monitored invasively. CBF was measured at 8 hour intervals using the Kety-Schmidt method. Blood was sampled from an artery and jugular vein for measuring ammonia, blood gases, glucose and lactate.

Results: All patients fulfilled the criteria for poor prognosis and the median prothrombin time was 102 (range 78-132) sec, creatinine 339 (254-432); all required haemofiltration and 18 patients required inotropic support. Cerebral perfusion pressure was maintained greater than $55 \mathrm{mmHg}$. Sixty five measurements of CBF were made in these 21 patients. Depending upon the ICP at the time of insertion of the monitor, the patients could be divided into two groups. Patients in Group 1 had higher ICP, n=8, 32 (28-54) compared with Group 2 patients, $n=13,14(11-18) ; p<0.01$. ICP in the patients in Group 1 was difficult to control but 4 patients from Group 2 developed went on to have surges of high ICP. Arterial ammonia, brain ammonia extraction, $\mathrm{CBF}$ and delivery of ammonia to the brain were significantly higher in patients in Groupl compared with those in Group 2 ( $p<0.01$ each). Peaks of increased ICP in Group 2 were preceded by increase in CBF. ICP correlated directly with the CBF ( $r=0.74$, $p<0.0005)$. The jugular venous oxygen saturation did not correlate with ICP. Conclusions. The results suggest that increase in CBF is important in the pathogenesis of increased ICP. Until better methods of monitoring CBF continously is available, patients with ALF should be monitored using an ICP monitor.

\section{ANTI-TUMOUR NECROSIS FACTOR-A (TNF) IN PATIENTS WITH SEVERE ALCOHOLIC HEPATITIS (AH) IMPROVES CLINICAL OUTCOME}

S.J. Hodges', R. Jalan', N.A. Davies', D. Shawcross', A. Alisa, ${ }^{2}$ ',Williams',2. 'Institute of Hepatology, University College London Medical School and Hospitals, UK; ${ }^{2}$ Cromwell Hospital, London, UK

Background and Hypothesis: The aims of this pilot study were to evaluate the efficacy and safety of anti-TNF in severe AH and assess changes in the pro-inflammatory/antiflammatory cytokine balance.

Methods: Six male patients [54yr (40-62); Pugh 12 (11-13), 2 had Type 2 hepatorenal failure] with severe AH (confirmed by liver biopsy) were treated with $5 \mathrm{mg} / \mathrm{kg}$ (IV) of the chimeric TNF antibody (Infliximab, Schering Plough). Venous blood was collected prior and on days $3,7,14,21$, and 28 following treatment, for the measurement of inflammatory markers by ELISA.

Results: All patients were cirrhotic and had AH. Predicted 3-month survival, using the MELD scoring system, improved from $23 \%$ to $78 \%$ post therapy. 5 of the 6 patients are alive 6.5 months (1-14) after treatment. Despite, substantial improvement in liver function, 1 patient died from uncontrolled sepsis after 4 weeks. No adverse events related to the treatment were observed. Results are below, * $p<0.05$ from baseline, using ANOVA.

Measurements were made for sera levels of: IL-1 $\beta$; IL-4; IL-6; IL-8; IL-10; IL-12; TNF $\alpha$; IFN $\gamma$; IL-1RA; TNF-R 1; and TNF-R2. Differences were not found to be statistically significant for any of these modulators of inflammation in this pilot study. However, early indications suggest the modulation of inflammatory mediators.

Conclusions: All patients tolerated the anti-TNF therapy well and the increased survival suggests that this treatment is effective in $\mathrm{AH}$. However, we are not yet able to show a conclusive effect on circulating cytokine levels to explain the observed recovery of these patients. These clinical findings warrant further investigation.

\section{A POWERFUL COOPERATIVE INTERACTION BETWEEN A FUSOGENIC PEPTIDE AND LIPOFECTAMINE FOR THE ENHANCEMENT OF RECEPTOR-TARGETED, NON-VIRAL GENE DELIVERY VIA INTEGRIN RECEPTORS}

X. Zhang, L. Collins, J.W. Fabre. Department of Clinical Sciences, Institute of Liver Studies, Guy's, King's and St Thomas' School of Medicine, King's College Hospital, Bessemer Road, London, UK

Following receptor-mediated endocytosis, vector/DNA complexes require assistance to exit endocytic vesicles in order to avoid degradation in the lysosomes. Overcoming this barrier is a major challenge for the development of receptor-targeted, non-viral gene delivery. The fusogenic peptide of influenza virus haemagglutinin, lipofectamine, and chloroquine were tested singly and in combination in various doses for promoting in vitro gene transfer by an integrin-targeted, non-viral DNA vector (polylysine-molossin). Polylysine-molossin is a bifunctional synthetic peptide of 31 amino acids, consisting of an amino terminal chain of 16 lysines for electrostatic binding of DNA, and the 15 amino acid integrin-binding domain of the venom of the American pit viper, Crotalus molossus molossus. The fusogenic peptide and lipofectamine both individually promoted integrin-targeted gene delivery. However, the combined use of these agents was particularly effective, even at concentrations where neither agent singly had any effect on promoting gene delivery by polylysine-molossin. This optimal combination was effective on several cell lines and primary cell cultures. With the $\beta$ galactosidase reporter gene $60-65 \%$ of HepG2 cells and $75-80 \%$ of $\mathrm{HuH7}$ cells were positive. Surface charge of polylysine-molossin/DNA/ lipofectamine/fusogenic peptide complexes was approximately the same as that of polylysine-molossin/DNA complexes. Size distribution of complexes suggested that competitive binding of polylysinemolossin and lipofectamine to DNA influenced overall efficacy of this approach. The finding that the combined use of very low doses of two membrane destabilising agents results in high levels of receptortargeted gene delivery is potentially important for in vitro and in vivo gene therapy applications.

\section{EFFECT OF COMBINED LAMIVUDINE AND INTERFERON ALPHA TREATMENT ON THE T-CELL RESPONSE TO HBV CORE PEPTIDES IN PAEDIATRIC PATIENTS INFECTED WITH CHRONIC HEPATITIS B VIRUS}

M. Cavers', M. Aw², L. D'Antiga'2, R. Williams', A. Moorat ${ }^{3}$, M. Greensmith ${ }^{3}$, M. Atkins' ${ }^{3}$, G. Mieli-Vergani ${ }^{2}$, D. Vergani'. 'Institute of Hepatology, University College London, UK' ${ }^{2}$ Department of Child Health, King's College Hospital, London, UK; ${ }^{3}$ Glaxo-Wellcome Research and Development, Greenford, Middlesex, UK

Lamivudine treatment in adult patients with chronic hepatitis $B$ virus (CHBV) infection dramatically reduces viral antigenaemia concomitantly with an increase in a proliferative $\mathrm{CD} 4^{+} \mathrm{T}$-cell response to HBV nucleocapsid antigens and peptides (Boni et al, 1998), both changes subsiding on Lamivudine removal.

Aim: To investigate $\mathrm{CD} 4^{+} \mathrm{T}$-cell proliferative responses in paediatric patients undergoing an 8 week viral load-reducing Lamivudine treatment followed by a 44 week immunostimulatory interferon alpha treatment. Methods/patients: PBMC were obtained at 11 different time points ( 1 pre-treatment, 4 during lamivudine, 6 during IFN treatment) over the one year treatment period, from $10 \mathrm{HBeAg}^{+}$patients

\begin{tabular}{lllll} 
Abstract 50 & & & \\
\hline & Day 0 & Day 7 & Day 14 & Day 28 \\
\hline Bilirubin & $314(216-583)$ & $342(174-550)$ & $278(116-395)$ & ${ }^{*} 154(89-203)$ \\
PT & $22(16-33)$ & $19(16-29)$ & $18(15-25)$ & $18(14-25)$ \\
Maddrey & $68(40-121)$ & $57(38-109)$ & $50(36-87)$ & $* 47.5(23-64)$ \\
\hline
\end{tabular}


(aged 4-14), 7 of whom had acquired the infection vertically and 3 horizontally. Proliferation of PBMC was assessed against 20-mer synthetic HBV peptides spanning the whole core sequence, tetanus toxoid as recall antigen and phytohemagglutinin as a polyclonal T cell stimulator. HBV DNA tests were performed by hybridisation assay.

Results: after 6 months treatment HBV DNA became undetectable in only $3 / 10$ patients, decreased in 6 and remained unchanged in 1 . HBV antigen specific T-cell responses were rarely detectable, with a stimulation index exceeding 3 in only 5 patients on 25 of 600 occasions. Non-HBV specific responses were detectable throughout the study.

Conclusion: Our results suggest that HBV antigen specific CD4 $4^{+}$ T-cells have undergone clonal deletion in these patients and T-cell tolerance to HBV is not broken over 6 months of therapy.

\section{LONG TERM SURVIVAL POST EARLY LIVER TRANSPLANTATION IN ORGANIC ACIDAEMIAS}

P. Gissen', A. Chakrapani ${ }^{2}$, J.E. Wraith², J.H. Walter², J.V. Leonard ${ }^{3}$, J. Buckels', D. Mayer', J. de Ville de Goyet', S.V. Beath', D.A. Kelly', P.J. McKiernan'. 'The Liver Unit, The Birmingham Children's Hospital, UK; ${ }^{2}$ Willink Biochemical Genetics Unit, Royal Manchester Children's Hospital, UK; ${ }^{3}$ Institute of Child Health and Great Ormond Street Hospital for Children, UK

Introduction: Conventional management of early-onset methylmalonic acidaemia (MMA) and propionic acidaemia (PA) is associated with a poor outcome and thus early liver transplantation (OLT) has been proposed as a potentially "curative" treatment in order to prevent neurological damage.

Objective: To review the outcome of early OLT in the treatment of $P A$ and MMA.

Patients and Methods: Retrospective case-note review of all patients who have undergone OLT for PA and MMA in a single centre. 8 patients with early onset organic acidaemias (2MMA, $2 F, 6$ PA, 3 F) underwent OLT between 1991 and 1999. The median age at OLT was 15 months (range 7-29 months).

Results: There was a higher than average incidence of serious perioperative complications, relating to metabolic instability. 3 patients survived more than 1 year (1 MMA, 2 PA) and are now 4, 6 and 8 years post OLT (mean survival 5.7 years) with mean age of 7.5 yrs. All have improved metabolic control. 2 patients with PA have had no metabolic decompensation on a normal diet, are making developmental progress and attend mainstream schools. The surviving patient with MMA initially made developmental progress. She subsequently developed portal vein thrombosis, requiring porto-systemic shunting. This surgery was followed by persistent hyperammonaemia. One year following this, she developed basal ganglia necrosis during an episode of pneumonia, with resultant handicap.

Conclusions: Patients with organic acidaemias are a high-risk group for OLT. The potential benefits of improved quality of life, reduction in metabolic decompensation, and improved protein tolerance must be weighed against high perioperative mortality. The small number of survivors makes it difficult to assess the neurological benefits of early OLT in this group of patients, and aggressive medical management in infancy should be the priority, with recourse to OLT being an option in an appropriately selected subgroup.

\section{ROLE OF THE NOTCH/CBF-1 SIGNALLING PATHWAY IN THE REGULATION OF HEPATIC STELLATE CELL (HSC) ACTIVATION}

F. Oakley, J. Mann, D.A. Mann. Liver Research Group, Division of Infection, Inflammation and Repair, University of Southampton, Level D, Southampton General Hospital, Southampton, SO16 6YD, UK

Activation of the HSC is a pivotal event in the pathobiology of liver fibrosis and cirrhosis, hence an understanding of the biology of the HSC and the factors that regulate the phenotype of this cell is considered to be essential for the development of new anti-fibrosis therapeutics. We have previously reported that activity of the transcription factor NF-KB is persistently induced upon in vitro activation of rat $\mathrm{HSC}^{1}$. Activated HSC express 2 known (p50:p65 and p65:p65) NF-kB DNA binding complexes together with a 3rd unknown complex. In this study we identify the protein component of the 3rd inducible NF- $\mathrm{KB}$ complex as the transcription factor CBF-1. Using transfection studies, we show that CBF-1 acts as a repressor of NF-KB directed gene transcription for a subset of genes (eg, IL- 6 and IKB- $\alpha$ ) and suggest that one if its functions is to help maintain a pool of persistently active NF-KB. CBF-1 also functions in the Notch signalling pathway that plays a critical role in development and differentiation of a variety of cell types (eg, muscle and nerve). When Notch interacts with its ligands (Jagged/Delta) its intracellular domain (NotchlC) is cleaved and is transported to the nucleus where it forms a dimer with CBF-1 and converts CBF-1 into a transcriptional activator. In this study we used RT-PCR to show that rat HSC express Notch 1 and 2 . We also show that transfection of HSC with a NotchIC expression vector induces transcriptional activation of a CBF-1 reporter gene. We suggest that the Notch/CBF-1 signalling pathway may be an important regulator of the trans-differentiation of HSC to their profibrogenic phenotype and as such would be a target for drug development.

1. Elsharkawy A, et al. Hepatology 1999;30:761-9

\section{A COMPARISON OF MR SPECTROSCOPY AND HEPATIC VEIN TRANSIT TIMES USING MICROBUBBLE-ENHANCED ULTRASOUND IN CHARACTERISING SEVERITY OF LIVER DISEASE IN PATIENTS WITH HEPATITIS C.}

A.K.P. Lim ${ }^{1,2}$, N. Patel', G. Hamilton' , M.J.K. Blomley ${ }^{2}$, H.C. Thomas, D.O Cosgrove', S.D. Taylor-Robinson. 'Robert Steiner MRI Unit, ${ }^{2}$ Divisions of Imaging, and Medicine, Imperial College School of Medicine, London, UK

Purpose: ${ }^{31}$ - -magnetic resonance spectroscopy (MRS) and hepatic vein Doppler ultrasound arrival times (AT) after administration of a microbubble agent can be used as non-invasive markers for cirrhosis. Our aim was to compare the efficacy of the two tests in differentiating severity of chronic hepatitis C virus (HCV) liver disease, using histology as the gold standard.

Methods: 21 biopsy-proven HCV patients were studied prospectively. Based on their histological fibrosis (F) and necroinflammatory (NI) scores, patients were divided into mild, $n=6(F \leqslant 2 / 6, N I \leqslant 3 / 18)$; moderate/severe $n=9(F \geqslant 3 / 6, N I \geqslant 4 / 18)$ and cirrhotic, $n=6(F=6)$ disease. The \% phosphomonoester (PME) and phosphodiester (PDE) signals were measured with a ratio $\mathrm{PME} / \mathrm{PDE}<0.23$ considered normal. Measurement of tracer AT, consisted of bolus microbubbles administered intravenously. Time-intensity curves of spectral Doppler signals were then analysed from the right and middle hepatic veins. An AT of $>24 \mathrm{~s}$ was considered normal. The sensitivities and specificities were calculated for an increased PME/PDE and shortened AT correlating with disease severity.

Results: Spectra and AT were abnormal in 10 patients (47\%). In mild disease, PME/PDE was normal in 4/6, AT was normal in 6/6. In moderate/severe disease, PME/PDE was abnormal in 2/9, AT were abnormal in 4/9. In cirrhosis, AT and PME/PDE were abnormal in $4 / 6$ and $4 / 6$ respectively. Overall, PME/PDE values corresponded with AT in 17 patients $(81 \%)$ while AT, MRS and histology were in agreement in 12 patients (57\%). AT and MRS were $63 \%$ and $53 \%$ sensitive with a specificity of $100 \%$ and $63 \%$ respectively.

Conclusion: MRS and AT can differentiate mild from moderate and cirrhotic disease in $\mathrm{HCV}$-infected patients which may have important therapeutic implications. AT demonstrates a significantly greater specificity with a marginally better sensitivity than MRS, possibly because MRS reflects multiple metabolic pathways other than fibrosis. Biopsy sampling error may account for the cases where both AT and MRS were in agreement, but not with histology. A larger cohort is required to further delineate these discrepancies.

\section{ANTIBODIES AGAINST HOMOLOGOUS MICROBIAL CASEINOLYTIC PROTEASES P (CLPP) CHARACTERISE PRIMARY BILIARY CIRRHOSIS}

D.P. Bogdanos', H. Baum², U.C. Sharma', R. Williams', A.K. Burroughs ${ }^{3}$, D. Vergani'. 'Institute of Hepatology, University College London, UK; ${ }^{2}$ King's College, London, UK; ${ }^{3}$ Royal Free Hospital, London, UK

Antibodies directed to an 18aa (177-194) microbial sequence within the Clp protease (ClpP) complex of $E$ coli are uniquely present in patients with primary biliary cirrhosis (PBC) U Hepatol 2000;33:52836 ) and molecular mimicry between the regulatory subunit ClpX (aa 280-294) of E coli and PDC-E2 (aa 213-227), the principal target of antimitochondrial antibody (AMA) has been proposed to account for their emergence (J Hepatol 2001;34:785-7). Since the structure of Clp protease complex is highly conserved among bacteria we decided to investigate whether the microbial trigger of the production of PBC-specific anti-ClpP antibodies may be an infection by organisms other than E coli. E coli $\mathrm{ClpP}_{177.194}$ is identical to the corresponding ClpP of Salmonella typhimurium and also has a high degree of homology with ClpP of Yersinia enterocolitica (YEREN) and, to a lesser extent, to ClpP of Haemophilus influenzae (HAEIN). (Corresponding 
degrees of homology exist for the sequences in the respective ClpX peptides mimicking the PBC-specific epitope of E2.) We have tested the specificity of PBC-related reactivity to the ECOLI ClpP ${ }_{177124}$ as compared to YEREN and HAEIN homologous sequences by constructing the corresponding peptides and testing them by ELISA in 45 patients with PBC, 44 pathological and 32 healthy, demographically matched, subjects. Reactivity to at least one of the relevant ClpP peptides was observed in 21 (47\%) PBC patients as compared to $5.8 \%$ pathological and $3.1 \%$ healthy subjects ( $<<0.01$ for all). Among these 21 seropositive $\mathrm{PBC}, 15(71 \%)$ reacted to $\mathrm{ECOLI} \mathrm{ClpP}_{177.194}$ in isolation or in association with YEREN ClpP $\mathrm{P}_{177.194}$ and/or HAEIN $\mathrm{ClpP}_{164181}$ compared to $3(14.2 \%)$ patients reactive only with YEREN $\mathrm{ClpP}_{177.194,} 2$ (9.5\%) with YEREN ClpP 177.194 and HAEIN ClpP ${ }_{164.181}$ and 1 (4.7\%) patient reactive with HAEIN ClpP ${ }_{164181}$ only. The simultaneous reactivity to $\mathrm{ECOLI} \mathrm{ClpP}{ }_{177.194}$ and homologous sequences was due to cross-reactivity as confirmed by competition ELISAs. Of the 9 PBC patients positive for antibodies to virulence factors of Yersinia enterocolitica (Eurolmmun, UK), 8 (82\%) reacted with YEREN ClpP ${ }_{177.194}$ of which 3 were not reactive against the homologous peptide of ECOLI. Our data confirm the specificity of anti-microbial ClpP reactivity for PBC, but leave open the question as to the primary trigger of this reactivity and its relevance to the pathogenesis of PBC.

\section{IT IS JUSTIFIED TO BIOPSY PRESUMED HEPATOCELLULAR CARCINOMA (HCC) WHEN THE ALFA FETOPROTEIN (AFP) IS NORMAL}

D. Shawcross', A. Gillams², N. Naoumov', W. Lees², R. Williams, ${ }^{1}$ R. Jalan'. 'Institute of Hepatology and 'Radiology, University College London Hospitals, UK

Aims: Our study was designed to ask (1) when should a presumed $\mathrm{HCC}$ be biopsied and (2) what are the risks of tumour seeding with percutaneous treatment of HCCs.

Methods: Over 2 years, 36 consecutive patients with a presumed diagnosis of HCC were studied.

Patients: mean age 61.6 years; $(2.3), 8 \mathrm{~F} ; 35$ cirrhotic; [alcohol-17, Hepatitis virus-8], Child A-18, B-7, C-1 1. 6 lesions were identified on a screening programme (US-5, AFP-1). 31 had focal lesions, mean size $5.5 \mathrm{~cm}$ (range 1-14). The presumed diagnosis of HCC was based upon Triphasic multislice CT scan. If the AFP was normal and the imaging suggested a diagnosis of HCC, a targeted biopsy was performed using US guidance and a 18G tru-cut needle. If the patients were thought to be unsuitable for transplantation (OLT) or curative resection, they were treated with radiofrequency (RF), transarterial chemoembolisation (TACE) or percutaneous ethanol injection. All patients were followed up with 3 monthly CT scanning.

Results: Median AFP was $57 \mathrm{IU} / \mathrm{l}$ (range 2-1314000). In 13 patients AFP was normal (<12 IU/I) and a biopsy was performed. Of these, HCC was not confirmed in 5 patients and during follow up [5.2 months (1-14)], no radiological progression of the lesion has been observed. No tumour seeding has been observed in the other 8 patients that were biopsied with HCC [mean follow up 7 months (1-18)]. No other clinical variable distinguished those that were unlikely to have a HCC. In the 16 patients that had percutaneous intervention or biopsy, there was no evidence of needle track seeding during follow up.

Conclusions: Our results suggest that although the newer imaging modalities with multislice CT scanning allow better definition of HCCs, they have a false positive rate of $14 \%$ which will need to be addressed in developing algorithms for the diagnosis of presumed HCC. In patients with elevated AFP and imaging suggestive of HCC, a biopsy is not essential. However, a small proportion of patients with focal liver lesions suggestive of HCC and normal AFP should to be biopsied for confirmation of the diagnosis.

\section{IMPAIRED MIXED LEUCOCYTE REACTION AND ALTERED PHENOTYPE OF DENDRITIC CELLS IN CHRONIC HEPATITIS C}

E.A. Sanders', L.A. Fowkes', J. Holloway', C.L. Brooks', W.M. Rosenberg' 'Infection, Inflammation and Repair, ${ }^{2}$ Child Health, University of Southampton, Southampton General Hospital, Tremona Road, Southampton, UK

Introduction: In comparison with acute hepatitis $C$ infection, chronic hepatitis $\mathrm{C}(\mathrm{CHC})$ is characterised by weak cellular immune responses with both HCV-specific CD4+T lymphocyte proliferative responses and CD8+ T lymphocyte cytotoxicity being weak and oligospecific. We have studied the role of antigen presentation by dendritic cells (DCs) which are the most potent antigen presenting cells. We investigated the allogeneic stimulatory capacity of cultured DCs and the phenotype of ex vivo peripheral blood DCs (PBDCs) which had not been manipulated in culture or exposed to exogenous cytokines

Materials and Methods: Mixed leucocyte reactions (MLR) were compared in 6 normal healthy donors and $7 \mathrm{HCV}$ infected individuals using 7-14 day old monocyte derived DCs propagated in culture medium containing IL-4 and GM-CSF. The phenotype of ex vivo PBDCs was ascertained by 3 colour flow cytometry. Markers of antigen uptake (CD32, CD64, and mannose receptor), DC maturation (CD54, CD4 and CD8alpha) and costimulation (CD40, CD54, $\mathrm{CD} 80$, and $\mathrm{CD} 86$ ) were assessed in $13 \mathrm{CHC}$ and 8 uninfected individuals.

Results: MLR was impaired in CHC compared to uninfected individuals $(p<0.05)$. The altered function was less pronounced at day 14 compared to day 7 . The phenotype of ex vivo DCs was altered in patients with $\mathrm{CHC}$ compared to uninfected individuals. The expression of the costimulatory molecules CD40 and CD86 on DCs was reduced in $\mathrm{CHC}$ compared to uninfected individuals $(p<0.0001$ and $p<0.05$ respectively). Comparable levels of expression of markers of antigen uptake and DC maturation were observed between the two groups.

Conclusion: Mixed leucocyte reaction of CHC DCs is impaired compared with uninfected individuals. Our study is the first to report an altered phenotype of ex vivo DCs which reflect the phenotype of circulating $D C s$ in the body. The reduced levels of costimulatory markers CD40 and CD80 observed on the surface of the DCs from individuals with $\mathrm{CHC}$ may lead to the impaired $\mathrm{T}$ cell responses that are characteristic of chronic HCV infection.

\section{GLIOTOXIN INITIATES THE APOPTOSIS OF RAT AND HUMAN HEPATIC STELLATE CELLS-A MECHANISM FOR MODULATING THE PROGRESSION AND RESOLUTION OF LIVER FIBROSIS}

M.C. Wright', R. Issa², D. Smart², N. Trim², G. Murray', J. Primrose'2 , M. Arthur', J. Iredale', D. Mann'2. 'Depts of Molecular and Cell Biology and Pathology, University of Aberdeen, Aberdeen, UK; ' 2 Liver Group, Southampton General Hospital, Southampton, UK

Hepatic stellate cells play a pivotal role in the promotion of liver fibrosis and stimulating the specific apoptosis of these cells could be effective in treatments for liver fibrosis. Addition of the fungal metabolite gliotoxin at concentrations as low as $300 \mathrm{nM}$ to the culture medium of activated (a-smooth muscle actin\{a-SMA\} positive) rat and human hepatic stellate cells in vitro resulted in significant sub-stratum detachment and in morphological alterations typical of apoptosis within 1 hour. Within 2-3 hours of incubation, caspase 3 activity was markedly induced and caspase inhibitor-1 (Z-VAD-FMK) - sensitive oligonucleosome-length DNA fragments were detectable in rat hepatic stellate cells via gel electrophoresis of low molecular weight DNA. The level of DNA fragmentation was maximal by 4 hours and was widespread as judged by FACS analysis of propidium iodide stained cells and by TUNEL staining in both rat and human hepatic stellate cells. Gliotoxin failed to ellicit any effects on rat hepatocyte viability in vitro at the concentrations that stimulated hepatic stellate cell apoptosis. Only at significantly higher concentrations $(>50 \mathrm{mM})$ did gliotoxin affect hepatocytes, resulting in changes associated with necrosis. Rats treated with carbon tetrachloride to induce liver fibrosis were treated with a single injection of gliotoxin 24 hours after the final injection of carbon tetrachloride. Histological examination of livers 24 hours later indicated that gliotoxin significantly reduced the number of activated stellate cells by $57 \%$ as judged by a-SMA immunostaining and significantly reduced the mean intra-lobular thickness of fibrotic collagen bands stained using sirius red. These effects were observed without elliciting any hepatotoxic effects with gliotoxin. TUNEL/a-smooth muscle actin immunostaining indicated that activated hepatic stellate cell apoptosis in vivo was up-regulated in response to gliotoxin treatment. These data indicate that gliotoxin stimulates the apoptosis of activated hepatic stellate cells in vitro and effects a reduction in the number of activated stellate cells and a reduction in the extent of collagen in a rat model of liver fibrosis. These data demonstrate proof-of-concept that by up-regulating HSC apoptosis the extent of fibrosis can be decreased in inflammatory liver injury.

\section{AUTOANTIBODIES TO ALCOHOL DEHYDROGENASE ARE ASSOCIATED WITH ALCOHOL CONSUMPTION}

Y. Ma', M. Meregalli' ${ }^{2}$ S. Fargion', G. Fiorelli', D. Vergani' ${ }^{2}$. 'Institute of Hepatology, University College London Medical School, London, UK; ${ }^{2}$ Department of Internal Medicine, IRCCS Hospital, Milan, Italy 
Abstract 62

\begin{tabular}{|c|c|c|c|c|c|c|c|c|}
\hline H63D sub group & $\begin{array}{l}\text { Mean iron } \\
\text { (umol/l) }\end{array}$ & p value* & $\begin{array}{l}\text { Mean ferritin } \\
\text { (mcg/l) }\end{array}$ & p value* & $\begin{array}{l}\text { Mean TFS } \\
(\%)\end{array}$ & p value* & $\begin{array}{l}\text { Mean siderosis } \\
\text { score }\end{array}$ & $p$ value* \\
\hline Wild type $N=216$ & 19.5 & & 198 & & 30 & & 0.32 & \\
\hline Heterozygotes $N=80$ & 21 & $p=0.2$ & 298 & $p=0.05$ & 33.8 & $p=0.1$ & 0.57 & $p=0.23$ \\
\hline Homozygotes $\mathrm{N}=7$ & 22.4 & $P=0.4$ & 216 & $p=0.88$ & 35 & $p=0.35$ & 0.44 & $p=0.39$ \\
\hline
\end{tabular}

* $p$ values comparing to wild type genes

Background: Alcohol dehydrogenase (ADH) has been identified as an autoantibody target in patients with autoimmune (Gastroenterology, 1997) and alcoholic liver disease (J Hepatol, 1995).

Aims \& Methods: To investigate: (1) whether alcohol consumption is associated with the production of anti-ADH antibodies in patients with alcoholic liver disease (ALD) and in age and sex matched controls with well recorded history of alcohol intake; (2) the association between anti-ADH antibodies and the severity of liver disease. Anti-ADH antibodies were detected by immunoblot using recombinant human ADH $\beta 2$ subunit (kindly provided by Professor WF Bosron, Indiana University School of Medicine, Indianapolis, USA) as target antigen in the sera of four groups of subjects: (1) 83 ALD patients who were active alcohol abusers (AAAs) [alcohol intake $>60 \mathrm{~g} /$ day in males and $>40 \mathrm{~g} /$ day in female, 6 female, age range 22 to 82 yrs (median 50)]; (2) 48 hospital in-patients with non-alcohol related diseases of whom (2a) 39 had no history of alcohol intake and (2b) 9 were consuming alcohol $(40-60 \mathrm{~g} /$ day) and (3) 20 normal subjects.

Results: Anti-ADH antibodies were more frequently detected in AAAs $(43 / 83,52 \%)$ than in group $2 a(7 / 39,18 \%, p=0.0004)$, group $2 b(3 / 9,33 \%, p=0.3)$ and group $3(2 / 20,10 \%, p<0.001)$. Sequential sera were available on 9 AAAs with ALD from the time of active alcohol abuse to that of alcohol withdrawal for a median of 40 days into abstinence (range 30 to 100 days); 4 anti-ADH negative patients remained negative upon retesting, while of five positive patients, one remained positive without change in titre, 3 became negative during abstinence (median 45 days, range 40 to 100 days) and the antibody titre decreased from 1/3000 to $1 / 1000$ in the last patient. Anti-ADH antibodies were detected more frequently in patients with cirrhosis $(15 / 25(60 \%)$ than in those with steatosis.

Conclusions: The decline/disappearance of anti-ADH antibodies during abstinence suggests that alcohol ingestion renders ADH immunogenic. How alcohol imparts immunogenicity to $A D H$ remains to be defined.

\section{ENDOTHELIAL CELL DAMAGE IN ACUTE LIVER FAILURE DUE TO PARACETAMOL-INDUCED HEPATOTOXICITY}

A. Williams, P.G. Langley, J. Osei-Hwedieh, J. Wendon, R.D. Hughes. Institute of Liver Studies, Guy's, King's and St Thomas' School of Medicine, Denmark Hill Campus, London, UK

Damage to endothelial cells may be an important factor in the complications of acute liver failure, including alterations in platelets, haemostasis and haemodynamics, resulting in multi-organ failure. The aim of this study was to assess endothelial cell function in patients with acute liver failure (ALF) due to paracetamol ingestion.

Patients \& Methods: Fifty eight patients (median age 36y, range 15-68y; 25M:33F) with ALF due to paracetamol ingestion were studied. Blood samples were taken on admission and then daily for up to 7 days. Serum hyaluronic acid (HA), as a measure of hepatic sinusoidal endothelial cell function, was determined using an enzyme-linked binding assay (Chugai Diagnostics, Japan). Plasma von Willebrand Factor and thrombomodulin were also determined using sandwich ELISAs.

Results: Serum HA at the time of admission was significantly increased (median $6777 \mathrm{ng} / \mathrm{ml}$, range 24-50967 ng/ml) as compared to normal controls $(\mathrm{n}=10$, median $21 \mathrm{ng} / \mathrm{ml}$, range 0-50 $\mathrm{ng} / \mathrm{ml} ; \mathrm{p}<0.001)$. In non-survivors $(\mathrm{n}=21) \mathrm{HA}$ levels peaked on day 2 after admission $(p=0.0217)$, and then decreased. In the survivors $(n=$ 37 ) the levels of HA did not increase further after admission. HA rapidly decreased after liver transplantation $(n=7)$. Preliminary experiments using membrane ultrafiltration and gel electrophoresis demonstrated the presence of lower molecular weight fragments of HA $(<500 \mathrm{kDa})$, which have been shown to induce inflammatory cytokine gene expression. Plasma von Willebrand Factor on admission was significantly increased in the patients (median $241 \mathrm{U} / \mathrm{dl}$, range 97-474 $\mathrm{U} / \mathrm{dl}$ ) as compared to the normal controls (median $94 \mathrm{U} / \mathrm{dl}$, range $57-164 \mathrm{U} / \mathrm{dl} ; \mathrm{p}<0.001)$. Plasma thrombomodulin was also increased on admission in patients (median $26.9 \mathrm{ng} / \mathrm{ml}$, range 3-79 $\mathrm{ng} / \mathrm{ml}$ ) as compared to the normal controls (median $3.2 \mathrm{ng} / \mathrm{ml}$, range $1-19.4 \mathrm{ng} / \mathrm{ml} ; \mathrm{p}<0.001)$. There were no significant changes in either plasma von Willebrand Factor or thrombomodulin levels over 3 days, or difference between survivors and non-survivors.

Conclusions: Endothelial function is abnormal in ALF due to paracetamol ingestion. Damage to hepatic sinusoidal endothelial cells assessed by serum HA was greater in non-survivors than survivors.

\section{H63D GENE MUTATION IS NOT ASSOCIATED WITH BIOCHEMICAL OR HEPATIC IRON OVERLOAD IN C282Y WILD TYPE GENE CARRIERS}

A. Poullis, S. Moodie, L. Ang, C.J. Finlayson, J.D. Maxwell. St. George's Hospital and Medical School, London SWI7 ORE,UK

The C282Y gene mutation is the most important in cases of hereditary haemochromatosis. The H63D gene mutation appears to be important only in compound heterozygotes in whom a small proportion develops clinically significant iron overload.

Aims: To investigate the relationship between H63D gene mutations and serum iron markers and hepatic siderosis scores in C282Y wild type gene carriers in unselected liver patients with a variety of liver diseases.

Methods: Genomic DNA was prepared from EDTA blood, DNA fragments were amplified by restriction fragment length analysis and HFE mutations determined in 438 patients attending a liver clinic. C282Y homozygotes and heterozygotes were excluded from this study (55 patients). Iron, ferritin, and transferrin saturation (TFS) were measured using standard assays. Liver biopsies were performed on 303 subjects.

Results: See table above.

Conclusions: In our population studied the iron and transferrin saturation did not significantly differ in the different H63D populations studied. The serum ferritin reached statistical significance in heterozygotes compared to wild type carriers but as the homozygotes were not significantly different from wild type carriers this result should be interpreted with caution. The mean hepatic siderosis score did not differ significantly in the different H63D subgroups.

\section{OPTIMISED PROTOCOL FOR INTRAHEPATIC LYMPHOCYTES ISOLATION AND FACS ANALYSIS}

M.A. Morsy', P.J. Norman², M. Rela', N.D. Heaton', R.W. Vaughan ${ }^{2}$ 1 Liver Transplant Surgical Service, King's College Hospital, London SE5 9RS, '2South Thames Tissue Typing Unit, Guy's Hospital, London SEI 9RT, UK

Introduction: The quantitative and qualitative study of intrahepatic lymphocytes $(\mathrm{IHL})$ needs special protocols to ensure there are sufficient cell yields with acceptable viability satisfactory for FACS analysis. We have developed a modified protocol for $\mathrm{IHL}$ isolation and FACS analysis.

Methods: Viability of $\mathrm{IHL}$ was evaluated after isolation from 23 fresh liver biopsies (about $10 \mathrm{~g}$ ) collected from donor livers, using mechanical, enzymatic digestion' and modified enzymatic dispersal. Ten samples from the modified protocol were prepared for 3-colour FACS analysis, using anti-CD2 and anti-CD56 immunomagnetic microbeads for $\mathrm{T}$ and NK cell populations respectively. IHL populations were gated using side scatter parameters and CD45 CY5 monoclonal antibodies (mAb). CD3, CD19, CD14, CD4, CD8, CD161 mAb were used to compare purity in different protocols.

Results: The mechanical method yielded low cell numbers $0.8 \times 10^{6}$ $\left(0.2-1.2 \times 10^{6}\right) / 100 \mathrm{mg}$ with $39 \%$ viability. The modified enzymatic digestion protocol gave lower cell numbers but a higher viability $\left(1.16 \times 10^{6} / 100 \mathrm{mg}, 92.6 \%\right.$ viable) than the original enzymatic digestion protocol $\left(1.3 \times 10^{6} / 100 \mathrm{mg}, 86.4 \%\right.$ viable). The use of anti-CD2 
and anti-CD56 immunomagnetic microbeads has purified the $\mathrm{HL}$ population with less than $5 \%$ dead cells compared with $12 \%$ without beads, and less contamination with $\mathrm{CDI} 4$ positive cells, $4 \%$ and $1.3 \%$ respectively compared to $15.2 \%$ without beads. Using anti-CD45 CY5 to gate IHL in addition to immunomagnetic microbead isolation resulted in higher estimates of CD3, CD4, CD8 and CD161 positive cells and less contamination with other non-IHL cells.

Conclusion: We have devised a modified IHL isolation protocol that decreased the time of exposure of cells to collagenase, which resulted in increased cell viability. Our modifications increase the accuracy of IHL subset assessment and are more suitable for analysing intrahepatic T and NK cell populations.

1. Michael PC, et al. J Immunol Methods 2000;242:21-31.

\section{IMPROVEMENT IN CLINICAL PARAMETERS OF ACUTE LIVER FAILURE IN RABBITS BY EXTRACORPOREAL PERFUSION THROUGH A BIOREACTOR CONTAINING ALGINATE-ENCAPSULATED HEPG2 CELLS}

T.M. Rahman, C. Selden, I. Diakanov, M. Khalil, H.J.F. Hodgson. Imperial College School of Medicine and Centre for Hepatology, Royal Free Campus-UCL, Rowland Hill St., London, NW3 2PF, UK

Introduction and Aims: Bioartificial liver support depends on provision of functioning liver cells in an extracorporeal device. We have previously demonstrated that human hepatocyte cell lines maintain a panel of differentiated hepatocyte functions for up to 20 days when maintained in a novel alginate capsule which encourages cell-to-cell contact in a 3D environment. Here we used a device containing $10^{8}$ Hep G2 cells in an extracorporeal circuit, and investigated changes in parameters of liver failure in rabbits with acute liver failure induced by a combination of glutathione depletion and acetaminophen administration.

Methods: Pilot experiments demonstrated that administration of acetaminophen to glutathione-depleted animals induces liver failure with progressive hepatic encephalopathy. New Zealand White rabbits with $(n=13)$ and without $(n=9)$ acetaminophen-induced liver failure were anaesthetised, and a continuous plasmapheresis system (2-4 $\mathrm{ml} / \mathrm{min}$ ) established. Plasma was then rapidly recirculated over $50 \mathrm{ml}$ alginate containing either HepG2 cells, or similar beads without cells, and physiological and biochemical parameters assessed over the ensuing $12 \mathrm{~h}$ at which time experiments were terminated still under anaesthesia without recovery.

Results: All acetaminophen treated animals developed acute liver failure with high transaminases and progressive elevations of lactate, ammonia, and prothrombin times. Passage of plasma over beads containing HepG2s compared with empty beads resulted in significant rises in diastolic blood pressure $(p<0.025)$, and falls in plasma ammonia $(p<0.001)$. Measurement of transjugular venous saturations confirmed a fall in oxygen extraction on induction of liver failure, but the use of HepG2 containing beads of. empty beads restored extraction to normal by 10 hours.

Conclusion: Encapsulated HepG2 cells have the potential to provide short term support in liver failure.

\section{EPIDEMIOLOGY OF PRIMARY BILIARY CIRHOSIS (PBC) IN SHEFFIELD UPDATED: DEMOGRAPHICS AND RELATIONSHIP TO WATER SUPPLY}

D.S. Ray-Chaudhuri, E. Rigney, K. McCormack, N. Trudgill, A. Dube', A. Milford-Ward', D. Gleeson. Liver Unit and 'Depts of Pathology and ${ }^{2}$ Immunology, Sheffield Teaching Hospitals, Sheffield, UK

Background: Triger (BM 1980;281:772) observed that PBC prevalence over 1977-79 in areas of Sheffield supplied by one water reservoir (Rivelin) was 10-fold higher than in other areas.

Aim: Report on diagnosed cases of PBC in Sheffield between $1 / 1 / 87$ and 31/12/99. Definite PBC was defined as all of: (1) alkaline phosphatase or ALT abnormality over > 1 month, (2) serum positive for antimitochondrial antibody (AMA) and (3) consistent liver biopsy. Probable PBC was any two out of three.

Methods: Case-finding strategy was similar to that described by Metcalf (Int J Epidemiol 1997;26:830). AMA records were available from 1992 and did not include titres. Hospital notes were reviewed and when possible, liver tests repeated. Date of diagnosis was the earliest date when tests indicated probable PBC. Disease incidence was correlated with source of water supply using patient address at time of diagnosis.
Results: We found 31 cases of PBC in Sheffield on 1/1/87 and a further 141 incident cases between 1987 and 1999 (74 definite, 67 probable; 12 men, and 129 women;12 AMA negative), giving a cumulative incidence in Sheffield (population $529 \times 10^{3}$ in 1991) of $267 / 10^{6}$ and $969 / 10^{6}$ in women over 40 . PBC incidence did not change over 1987-99 but prevalence increased: $57 / 10^{6}$ in 1987 $136 / 10^{6}$ in 1993, and $238 / 10^{6}$ in 1999. Age at diagnosis was 65 (28-87)yr (median (range)); 102 of the 141 cases had symptoms at diagnosis. 32 incident cases have died: 11 of liver disease aged 69 (52-78), 13 of unrelated causes aged 77 (62-89) and 8 of, as yet, unknown causes aged 75 (59-87). Two other patients have undergone liver transplantation. Cumulative PBC incidence in an area (population $157 \times 10^{3}$ ) supplied $\geqslant 95 \%$ of the time by water from the Rivelin reservoir was $280 / 10^{6}$ and that in an area supplied $\leqslant 5 \%$ of the time by Rivelin water (population $135 \times 10^{6}$ ) was $325 / 10^{3}$ (OR $0.88,95 \% \mathrm{Cl} 0.57-1.31)$.

Summary: The prevalence of PBC in Sheffield between 1987-99 is similar to that recently reported from elsewhere in the UK The association between PBC and areas supplied by the Rivelin water reservoir does not hold over this period.

\section{ACUTE CHANGES IN CEREBRAL BLOOD FLOW WITH CHANGE IN PORTAL PRESSURE: EVIDENCE FOR THE EXISTENCE OF A HEPATOCEREBRAL REFLEX IN MAN?}

R. Jalan', S. Olde Damink², D.N. Redhead ${ }^{3}$, P.C. Hayes ${ }^{3}$, A. Lee ${ }^{3}$. 'Institute of Hepatology, University College London, UK; ${ }^{2}$ Liver Unit, Dept of Surgery, Maastricht University, the Netherlands; ${ }^{3}$ Royal Infirmary, Edinburgh

Hypothesis and Aims: Following insertion of a transjugular intrahepatic portosystemic stent shunt (TIPSS), some patients develop increases in intracranial pressure. This study tests the hypothesis that acute changes in portal pressure may be important in regulating CBF which has been suggested as important in the pathogenesis of cerebral ordema.

Methods: Part 1. Patients [n=7, age $53.2( \pm 7.1)$, males:4, Child class A:2, B:5; TIPSS inserted 15.3 ( \pm 16.1 ) months] who were attending for routine portography were studied before, during shunt occlusion with an angioplasty balloon for 20 minutes and following deflation of the balloon. Part 2. Patients $[n=12$, age $54.5( \pm 3.5)$ males:8, Child class A: 1, B:4, C:7]; undergoing a TIPSS procedure for variceal bleeding. Measurements were made immediately before and 30 minutes after insertion of TIPSS. Heart rate (HR), mean arterial pressure (MAP) and cardiac output $(C O)(p<0.05)$ and systemic vascular resistance (SVR) $(p<0.05)$ were measured using a Swan Ganz catheter. CBF was measured using the Kety-Schmidt method. Blood was collected from an artery and the jugular vein to measure oxygen. All the patients were electively mechanically ventilated for the studies.

Results: Shunt occlusion resulted in a reduction in $\mathrm{HR}(p<0.05)$ and CO $(p<0.05)$ with significant increase in SVR $(p<0.05)$ which was restored after balloon deflation. CBF decreased in all patients, from $52( \pm 4.7)$ to $34( \pm 5.4)(\mathrm{p}<0.05) \mathrm{ml} / 100 \mathrm{~g} / \mathrm{min}$ and was restored after balloon deflation to $47( \pm 4.9) \mathrm{ml} / 100 \mathrm{~g} / \mathrm{min}[\mathrm{p}=0.28$, from baseline]. Insertion of TIPSS was followed by an increase in $\mathrm{CO}(\mathrm{p}<0.05)$ and a reduction in SVR $(p<0.05)$ with no significant changes in HR. CBF increased in all patients from $53.9( \pm 3.4)$ to $68.3( \pm 3.5) \mathrm{ml} / 100$ $\mathrm{g} / \mathrm{min}(\mathrm{p}<0.05)$. No significant changes were observed in brain oxygen kinetics.

Conclusions: Our data are consistent existence of a hepatocerebral reflex in cirrhosis. This may be responsible for some of the cerebral haemodynamic changes observed in the TIPSS patients.

\section{FUNCTIONAL INTERPLAY OF FACTORS BINDING TO THE UTE-1 AND SERUM RESPONSE ELEMENT (SRE) OF THE TIMP-1 PROMOTER DIRECTS HIGH-LEVEL GENE TRANSCRIPTION}

J.D. Thomas, M. Bertrand, M.J.P. Arthur, D.A. Mann. Liver Research Group, Division of Infection, Inflammation and Repair, University of Southampton, Level D, Southampton General Hospital, Southampton, SO16 6YD, UK

The de novo expression of high levels of TIMP-1 by activated hepatic stellate cells (HSC) is a strong contributory factor to the deposition of extracellular matrix (ECM) in the fibrotic liver. We have previously described the requirement for two essential cis-acting DNA sequences (UTE-1 ' and SRE') in the human TIMP-1 promoter in order to direct high level transcription of the TIMP-1 gene in activated HSC. In this study we used a mutagenesis approach in order to determine if there are functional interactions between the UTE- 1 and SRE sequences that 
influence transcription. First of all we established that the UTE- 1 site is unable to operate as a transcriptional activator in isolation but can activate transcription when present as multiple copies in a reporter gene. This result indicated that UTE-1 acts via interactions with neighbouring cis-acting DNA elements. As UTE-1 is located downstream of the SRE in the human TIMP-1 promoter it was of interest to determine if UTE-1 can influence function of the SRE. Chloramphenicol Acetyl Transferase (CAT) reporters were constructed in which the SRE was placed upstream of a minimal active thymidine kinase promoter and in either the presence or absence of adjacent wild type or mutant UTE-1 sequences. Transfection of these reporters showed presence of a wild type UTE-1 site either $5^{\prime}$ or $3^{\prime}$ of the SRE increases activity of the reporter gene by greater than 2-fold. In contrast inclusion of a mutant UTE-1 site that is unable to interact with UTE-1 binding proteins had no influence on SRE activity. We therefore now propose a model for transcriptional regulation of TIMP-1 expression in HSC that involves the interplay of factors binding to the UTE-1 (UTE- 1 binding proteins) and the SRE (JunD, Ets and STAT factors). Further detailed analysis of the interactions that occur between these factors will help improve our understanding of the molecular regulation of ECM turnover in the injured liver.

1. Trim JE, et al. J Biol Chem 2000;275:6657-63.

2. Bahr MJ, et al. Hepatology 1999;29:839-48.

\section{HUMAN HEPATOCYTES ENCAPSULATED IN ALGINATE MAINTAIN DIFFERENTIATED FUNCTION AND CAPACITY FOR DNA SYNTHESIS}

N. Mellor, S. Choudhury, C. Selden, H.J.F. Hodgson. Centre for Hepatology, Royal Free Campus-UCL, Rowland Hill St., London, NW3 2PF, UK

Introduction and Aims: Hepatocytes rapidly lose specific function in monolayer culture. To maintain function of primary human hepatocytes in culture, we have utilised a novel form of alginate encapsulation previously successfully applied to enhancing differentiated function of hepatocyte cell lines, by providing a 3D dimensional environment.

Methods: Human hepatocytes from surgical specimens were obtained by collagenase perfusion and encapsulated at $1.5 \times 10^{6}$ cells $/ \mathrm{ml}$ in $1 \%$ medium-viscosity alginate $400 \mu \mathrm{m}$ beads, without polyL-lysine coating. Beads were maintained in 6-well plates in cell strainers with $5 \mathrm{ml}$ medium. Conditioned medium (CM) was collected on days 2,3 , and 6 following encapsulation, and analysed for albumin, alpha-1-antitrypsin by ELISA. Total intracellular and secreted protein synthesis was assessed by incorporation of tritiated aminoacids. Hepatocyte DNA synthesis in response to EGF was estimated by incorporation of tritiated thymidine into DNA.

Results: Hepatocyte responsiveness to EGF was maintained in algiinate, with peak DNA synthesis at 31 hours following EGF. DNA synthesis was similar in alginate to that in monolayer cultures-though intriguingly the kinetics of EGF response of human hepatocytes differs from rat hepatocytes with a more prolonged time course. Cells were viable throughout the 6-day incubation with total recovered cell protein per sample, reflecting cell mass, remaining constant $(108 \pm 30 \mu g, 117 \pm 29$ and $113 \pm 32 \mu g$ at days 2, 3, and 6 respectively). Alpha-1-antitrypsin secretion remained at in vivo levels throughout $\left(0.974 \mathrm{~g} / 10^{12}\right.$ cells/day cf. 0.9 for human liver in vivo). Albumin secretion at day 1 was $5.9 \pm 1.7 \mu \mathrm{g}$ albumin/mg protein. Intracellular protein synthesis peaked at day 2 and was maintained at day 6 at $33 \%$ of that at day 2 . Total protein synthesis of secreted proteins peaked at day 2 and was maintained at day 6 at $55 \%$ day 2 .

Conclusion: Encapsulation of human hepatocytes offers a promising strategy to promoting survival and proliferation in culture, whilst maintaining the hepatocyte differentiated phenotype.

\section{THE NATURAL HISTORY OF NONALCOHOLIC} STEATOHEPATITIS

C.D.J. Evans, K. Oien', R.N.M. MacSween', P.R. Mills. Gastroenterology Unit and 'University Department of Pathology, Western Infirmary, Glasgow, UK

Background: Nonalcoholic steatohepatitis (NASH) was first described in 1980 and is now thought to be a common cause of chronic liver disease. The diagnosis is made on liver biopsy after clinical exclusion of several conditions. Histological features include steatosis, steatohepatitis and cirrhosis. The prevalence, disease associations and natural history of this condition remain poorly understood.

Aim: To study the natural history in a retrospective sequential series of patients with NASH identified by liver biopsy at the Western Infirmary over the 10 year period 1985-94.
Methods: 1571 patients underwent liver biopsy over the period. All were reported by a single pathologist (RNMMcS). 152 (9.7\%) patients had histological features of NASH and no other condition identified. After case note review, GP contact and review of these biopsies (KO), 62 (3.9\%) patients were confirmed to have NASH and the biopsy scored for severity. These patients were prospectively studied.

Results: Of the 62 patients (mean age at biopsy 51, 21 male), 16 were diabetic, 16 obese $(B M I>30)$ and biopsy scores showed a mean of $1.86,1.46$, and 0.48 for inflammation, fibrosis and iron respectively, (Brunt et al, 1999). 9 had died but in none was liver disease thought to be responsible. 11 were untraceable, 3 had moved outwith the area and 2 were unfit for recall. The remaining 37 patients were invited for review: 26 have attended at a mean 8.7 years post biopsy (mean age 49, 9 diabetic, 13 obese, and 6 male). All showed normal serum bilirubin, albumin and alkaline phosphatase, a mean gammaGT of 104, AST 38 and ALT 49. 6 patients had normal LFTs; the remaining 20 were invited to have a repeat liver biopsy. Only 5 patients agreed (mean 7.2 years after initial biopsy) and biopsy scores showed a mean of 1.6, 1.4, and 0.2. (2.2, 1.0 and 0 for these 5 patients at initial biopsy).

Conclusions: NASH is a common cause of abnormal liver function tests. It is associated with diabetes and obesity and is more common in females. In our series, with a mean follow-up of almost nine years, this condition showed little evidence of causing progressive chronic liver disease.

\section{ISOLATION AND CHARACTERISATION OF BILIARY EPITHELIAL CELLS FROM DIAGNOSTIC AND STAGING BIOPSIES IN EXTRAHEPATIC BILIARY ATRESIA}

D.M. Flynn, J. de Ville, S. Nijaar, D.A. Kelly, A.J. Strain, H.A. Crosby. Liver Research Laboratories, Queen Elizabeth Hospital Birmingham and Birmingham Children's Hospital, Birmingham, UK

Introduction: Extrahepatic biliary atresia (EHBA) is the commonest paediatric liver disorder leading to transplantation, but is of unknown aetiology. Study of pathgenesis is limited by lack of an animal model and availability of human tissue. Our previous work has shown that end stage liver is a poor source of biliary epithelial cells in EHBA and that cell isolation from liver biopsies has not been possible in children under the age of 7 years.

Aim: To isolate and culture biliary epithelial cells from paediatric EHBA liver biopsy specimens for cell culture and molecular studies of pathogenesis.

Method: Liver biopsies were obtained by Menghini or wedge biopsy when clinically indicated, or at transplantation. 1-2mm fragments were plated onto plastic or fibronectin-coated wells, allowed to adhere, then fed with medium containing $10 \%$ fetal calf serum and HGF. Phenotype was determined by immunohistochemistry and RT-PCR.

Results: 33 biopsies were taken from 31 patients with EHBA (15 at diagnosis and/or Kasai procedure; 11 staging biopsies and 5 at time of transplantation) with median age $0.5 y$ rs (range 4 weeks to 18 years); $M: F \quad 1: 1$. Normal $(n=7)$ and diseased $(n=30)$ controls had median age 3 years (range 5 weeks to 18 years) and M:F 3:1. Adhesion of biopsy fragments was associated with prior coating of wells with fibronectin. In EHBA biliary epithelial cells were isolated from all ages in $44 \%$ of Menghini biopsies and $75 \%$ of wedge biopsies, compared to $70 \%$ and $72 \%$ of disease controls. All normal biopsies grew. Poorer growth was seen from female patients in EHBA $(\mathrm{F}=30 \% ; \mathrm{M}=80 \%)$ but not in controls $(\mathrm{F}=75 \% ; \mathrm{M}=73 \%)$. Cells stained positive for the biliary cell markers CK19 up to passage 3 but lost HEA 125 following one passage. RT-PCR showed that cells expressed Jagged 1 mRNA, and those isolated from EHBA expressed Notch 3 mRNA, comparable to immunostaining of frozen sections with Jagged 1 and Notch3 in EHBA.

Conclusion: Biliary epithelial cells can be successfully isolated and cultured from paediatric liver biopsies at all ages. This is a novel and useful tool for comparing cell populations from different stages in disease, where access to biliary epithelial cells has so far been limited.

\section{CHARACTERISING THE SYNERGY BETWEEN TRI-IODOTHYRONINE AND PARTIAL HEPATECTOMY ON THE REGENERATIVE RESPONSE OF THE LIVER}

R. Malik, N. Mellor, C. Selden, H. Hodgson. Department of Medicine, Royal Free Campus, Royal Free and University College Medical School, Rowland Hill Street, London NW3 2PF, UK

Background \& Aim: We have previously demonstrated that tri-iodothyronine (T3) induces liver cell growth by the process of direct 
hyperplasia acting as a primary mitogen. The aim of the study was to investigate the effects of combining the distinct pathways of direct hyperplasia and compensatory regeneration.

Method: Rats $(\mathrm{n}=5)$ were injected $(4 \mathrm{mg} / \mathrm{kg})$ with T3 1 day prior to and at the time of $70 \%$ partial hepatectomy (PH). There were control groups that received vehicle only at PH. Animals were sacrificed 24 hours and 4 days after surgery. Cell proliferation was assessed by bromo-deoxyuridine (BrdU) incorporation into nuclei and immunohistochemistry.

Results: There was no significant difference in liver mass, total DNA, or liver protein when T3 was administered at surgery compared to controls at the 24-hour time point. Effect of T3 and PH on hepatocyte proliferation-Flash BrdU labelling showed cells in S-phase 24 hrs after partial hepatectomy alone $26+1 \%$ SEM; when T3 was administered at surgery $39+1 \%$ (contribution from T3 alone at this time point $7+0.5 \%)$. Continuous BrdU labelling was performed every 6 hours between 15 and 51 hours following surgery and showed an index of $83+1.4 \%$ when T3 was administered at surgery as compared to $72+1.4 \%$ labelled hepatocytes with PH alone. The increase in proliferative response seen when $\mathrm{T} 3$ was administered at surgery translates into a larger liver segment at sacrifice at 4 days as compared to controls $(p<0.005)$. The difference in liver mass at 4 days when T3 is administered at $\mathrm{PH}$ is matched by corresponding increases in total DNA $(p<0.05)$ and total protein $(p<0.01)$ confirming an increased cell number.

Discussion: Thyroid hormone increases the regenerative response of the liver following $70 \%$ partial hepatectomy. Histological assessment of livers after T3 and partial hepatectomy, singly or together, provides an explanation for this phenomenon. The cells proliferating after partial hepatectomy are predominantly in the periportal area of the liver while those after T3 are predominantly in the midzonal area. The ability to enhance proliferation could be therapeutically valuable if applicable to man.

\section{STIMULATED LIVER AND MUSCLE PROTEIN SYNTHESIS BY ISOLEUCINE INFUSION DURING A SIMULATED BLEED IN PATIENTS WITH CIRRHOSIS OF THE LIVER}

S. Olde Damink ${ }^{1,2}$, R. Jalan ${ }^{3}$, D.N. Redhead ${ }^{4}$, C. Dejong ${ }^{2}$, P.C. Hayes' P. Soeters', N. Deutz'2. 'Liver Unit and 'Radiology, Royal Infirmary, Edinburgh, UK; ' Surgery, Maastricht University, the Netherlands; Institute of Hepatology, University College London, UK

Hypothesis and Aims: Upper gastrointestinal bleeding (UGIB) in cirrhosis has a high morbidity and mortality, which is not due to the blood loss but to the metabolic consequences of the bleed. This study was designed to test the hypothesis that isoleucine administration during the simulated bleed would increase organ protein synthesis.

Methods: 16 overnight fasted, cirrhotic patients $6 \mathrm{~F}, 10 \mathrm{M}$; age $48.0( \pm 2.9)$ yrs; mean Pugh $6.7( \pm 0.3)$ ) that underwent a portography of their transjugular intrahepatic portasystemic stent shunt were randomised to intravenous isoleucine or placebo. Blood was sampled at $\mathrm{t}=0,2,3$ and $4 \mathrm{hrs}$ from a catheter in the femoral artery, the right femoral, right renal, and the portal and hepatic veins. The UGIB was simulated by intragastric infusion of an amino acid solution that mimics haemoglobin. Organ protein synthesis was measured using infusion of stable isotopes (Tyrosine and Phenylalanine). Blood flow was measured using para-aminohippuric acid and indocyanine green.

Results: Arterial isoleucine concentrations decreased significantly in the placebo group, and increased in the isoleucine group. Renal protein kinetics did not change in both groups. Gut protein synthesis deceased during the simulated VB in the placebo group, but was unaltered in isoleucine controls. Isoleucine infusions significantly stimulated liver and muscle protein synthesis during a simulated VB, in contrast to placebo treatment.

Conclusions: This is the first study that quantifies protein kinetics across 4 organs in the same patients and demonstrates clearly that isoleucine infusion during a simulated VB stimulates liver protein synthesis. Increasing hepatic protein synthesis could be a valuable new therapy for cirrhotic patients with a VB, since hepatic decompensation is their major cause of death.

\section{FRACTURE RISK OF PATIENTS WITH PRIMARY BILIARY CIRRHOSIS}

J.R. Boulton-Jones, R. Fenn, J. West, R.F.A. Logan, S.D. Ryder. Department of Gastroenterology, Queens Medical Centre, Nottingham, NG7 2UH, UK

Introduction: Primary biliary cirrhosis (PBC) has a reported association with osteoporosis. Fracture is the important adverse clinical outcome of osteoporosis. The fracture risk of patients with PBC is unknown.
Aims: To assess the prevalence of fractures in patients with PBC compared to a control group.

Methods: Female PBC patients attending gastroenterology clinics were identified. Patients were included if they had 2 of the following 3 criteria-abnormal LFTs, liver histology compatible with PBC, and raised anti-mitochondrial antibodies. All cases were sent a postal questionnaire asking for a fracture history. A control group, identified from the control group of a study on myocardial infarction in women running in the same area, were sent the same questionnaire. High impact fractures were defined as those sustained in a road traffic accident or in a fall from above ground level and all others were defined as low impact fractures. Statistical differences were calculated by the Chi-squared test.

Results:

\begin{tabular}{lllll}
\hline Abstract 73 & & & \\
\hline & PBC group & $\begin{array}{l}\text { Control } \\
\text { group }\end{array}$ & $\begin{array}{l}p \\
\text { value }\end{array}$ \\
\hline Number in group & 91 & 116 & \\
Mean age (SD) & $62.1(10.6)$ & $59.7(7.8)$ & \\
Number reporting fracture (\%) & $36(39.6 \%)$ & $35(30.2 \%)$ & 0.16 \\
Number fracture aged $>30(\%)$ & $26(28.6 \%)$ & $27(23.3 \%)$ & 0.39 \\
Number low impact fracture of & & & \\
long bones/vertebrae aged $>30(\%)$ & $14(15.3 \%)$ & $14(12.1 \%)$ & 0.49 \\
\hline & & & \\
\hline
\end{tabular}

Conclusion: There was no evidence of excess fractures in the patients with PBC compared to a control group either for total number of fractures reported, fractures occurring in later adulthood or for low impact fractures. PBC is not associated with a significantly increased fracture risk.

\section{GENETIC SUSCEPTIBILITY TO LIVER FIBROSIS IN HEPATITIS C}

S. Earl' , S. Littleford', E. Sanders', G. Alexander ${ }^{2}$ M. Howell ${ }^{3}$, W. Rosenberg'. 'Mailpoint 811 , Liver Group, Division of Infection, Inflammation and Repair, University of Southampton, UK; ${ }^{2}$ University of Cambridge and Southampton General Hospital, UK

Background: The major cause of morbidity and mortality in chronic hepatitis $\mathrm{C}(\mathrm{CHC})$ is hepatic fibrosis. Increasing evidence supports the theory that the immune response to $\mathrm{HCV}$ leads to fibrogenesis that may in turn result in hepatic cirrhosis. The propensity to develop severe fibrosis in $\mathrm{CHC}$ varies considerably between individuals, suggesting that heterogeneity in genes involved in the immune response and fibrogenesis may contribute to this variation. Previous studies have suggested that polymorphisms in Transforming Growth Factor beta (TGF- $\beta$ ) gene and in the Angiotensinogen (AT) gene, associated with increased levels of protein are associated with worse fibrosis. The 5G_4G polymorphism at -675 in Plasminogen Activator Inhibitor 1 (PAI-1) gene is associated with high levels of PAl and is thus implicated as being profibrotic through inhibition of extracellular matrix degradation. It has been found to be associated with severe Bleomycin induced fibrosis in mice. We have investigated the association between severity of hepatic fibrosis with polymorphisms in TGF- $\beta$, AT and PAI-1 with hepatic fibrosis in $\mathrm{CHC}$.

Methods: In the largest study to date DNA was extracted from peripheral blood samples obtained from a cohort of 144 patients with $\mathrm{CHC}$ who had undergone liver biopsy. Polymorphisms were typed using Sequence Specific Polymerase Chain Reaction amplification. PCR products were resolved on agarose gels and genotypes assigned. Multiple Logistic Regression was used to analyses the data testing the hypothesis that the candidate genotypes conferred susceptibility to more severe fibrosis in patients matched for known confounding variables, age, sex, duration of infection, and alcohol consumption.

Results: None of the polymorphisms investigated were found to be associated with fibrosis or inflammation in chronic hepatitis C. PAl-1 $\mathrm{OR}=1.29 \quad(0.7-2.4) ; \quad$ AT $\quad \mathrm{OR}=1.07 \quad(0.6-1.8) ; \quad T G F-b \quad O R=1.0$ (0.5-2.1).

Conclusions: Polymorphisms in TGF- $\beta$ and AT previously thought to be associated with severe fibrosis were not found to be associated with a worse outcome in this study. Variation in PAI-1 does not appear to be associated with severity of fibrosis in this study cohort. The close similarity between the frequency of the polymorphisms detected in this study and other populations suggests that these data are valid. 


\section{CAN HEPATIC VEIN TRANSIT TIMES USING MICROBUBBLE-ENHANCED ULTRASOUND DIFFERENTIATE SEVERITY OF LIVER DISEASE IN PATIENTS WITH HEPATITIS C?}

A.K.P. Lim 1,2, N. Patel', G. Hamilton', M.J.K. Blomley², H.C. Thomas, D.O. Cosgrove', S.D. Taylor-Robinson. 'Robert Steiner MRI Unit, ${ }^{2}$ Divisions of Imaging, and Medicine, Imperial College School of Medicine, London, UK

Purpose: We have shown that hepatic vein arrival times (AT) of a microbubble can distinguish between normal, fibrotic and cirrhotic livers in patients diffuse liver diseases. Our aim was to investigate whether this test and carotid-delay times (CDT) could be used to grade the severity of liver disease in patients with chronic hepatitis $\mathrm{C}(\mathrm{HCV})$.

Materials/method: 34 untreated and 7 interferon-treated patients with biopsy-proven HCV induced liver disease were studied prospectively. Based on their histological fibrosis (F) and necroinflammatory (NI) scores, untreated patients were divided into mild, $n=8(F \leqslant 2 / 6$, $\mathrm{NI} \leqslant 3 / 18) ; \quad$ moderate/severe, $\mathrm{n}=13 \quad(\mathrm{~F} \geqslant 3 / 6, \quad \mathrm{Nl} \geqslant 4 / 18)$ and cirrhotic, $n=13(\mathrm{~F}=6 / 6)$ disease. Each patient was fasted and microbubbles (Levovist $2 \mathrm{~g}$, Schering AG, Berlin) were injected into a median cubital fossa vein. Time-intensity curves of spectral Doppler signals were analysed from the right and middle hepatic veins. AT was calculated as the time from injection to a sustained rise in Doppler signal $10 \%$ greater than baseline. Audio intensity from the carotid artery was measured and CDT calculated as the difference between carotid and hepatic vein arrival times. The earliest AT for each patient was used for analysis. The data was analysed using a Kruskal Wallis test.

Results: The mean AT \pm s.d. for the mild, moderate and cirrhotic groups showed a monotonic progression of $43.4 \mathrm{~s} \pm 19.2,31.9 \mathrm{~s} \pm 28$ and $14.7 \mathrm{~s} \pm 4.5$ respectively. CDT were measured in 20 patients only. The mean values \pm s.d. for mild $(n=4)$, moderate $(n=7)$ and cirrhotic $(n=9)$ patients again showed progressive shortening $28.3 \mathrm{~s}$ $\pm 1.1,6.4 \mathrm{~s} \pm 4.8$ and $3.7 \mathrm{~s} \pm 3.1$ respectively. There was significant difference between the groups for AT $(p<0.001)$ and CDT ( $p=0.003)$. AT $<24$ s and CDT $<10$ s were $100 \%$ sensitive for cirrhosis but only $57 \%$ and $45 \%$ specific respectively. 7 further interferon-treated patients demonstrated arrival times later than expected for the severity of their disease.

Conclusion: AT and CDT measurement holds promise in characterising liver disease in HCV patients. Treatment with interferon appears to prolong AT. This is important for disease monitoring and may be useful in assessing the efficacy of treatment regimes non-invasively. A larger cohort needs to be investigated to validate our encouraging results.

\section{ORGANOTYPIC LIVER CULTURE IN A FLUID-AIR INTERFACE USING SLICES OF NEONATAL RAT AND ADULT HUMAN TISSUE-A MODEL OF FIBROSIS OCCURRING INVITRO?}

C. Verrill, H. Millward-Sadler, L. Sundstrom, N. Sheron. Liver Inflammation; Division of Infection, Inflammation and Repair; University of Southampton, Southampton General Hospital, SO16 6YD, UK

Background: There are few in vitro models with which to study the process of liver fibrosis. We used a slice culture technique first developed for use with neural tissue to develop organotypic cultures of liver in which we could induce fibrosis.

Methods: $200 \mu \mathrm{m}$ thick slices of neonatal rat or adult human liver were cut by vibrotome and cultured on nitrocellulose inserts at the air/ fluid interface for up to 28 days.

Results: Hepatocytes were viable for up to 21 days, during which time new structures appeared including ductular structures and bands of smooth muscle actin positive stellate cells associated with new matrix. Stellate cell activation could be pharmcologically inhibited suggesting possible uses for this model in the screening of anti-fibrotic drugs.

\section{ACTIVATED HUMAN HEPATIC STELLATE CELLS EXPRESS ICAM-1 WHICH CAN BE CONDITIONALLY UP-REGULATED BY TNF- $\alpha$ AND IFN- $\gamma$}

C.L. Brooks, E.A. Sanders, M. Wright, J. Trim, W.M. Rosenberg. Infection, Inflammation and Repair, University of Southampton, Southampton General Hospital, Tremona Road, Southampton, UK

Introduction: In the normal liver, quiescent hepatic stellate cells (HSC) are vitamin A rich, fat storing cells found in the space of Disse.
Liver insult may result in activation of these cells to a myofibroblast phenotype. Activated HSC actively secrete fibrillar collagens, collagenases and tissue inhibitors of metalloproteinases. A marker of HSC activation is ?-smooth muscle actin. Rat HSC have been shown to express ICAM-1 upon activation, and this can be further up-regulated by TNF- $\alpha$. ICAM- 1 expression is mediated by the transcription factor NFK.

Methods: Human HSC were isolated from normal liver tissue by standard methods. Passage 1-3 cells were grown to confluence, then cultured for 16 hours with control medium (RPMI containing 5\% human $A B$ serum), or medium supplemented with TNF- $\alpha$, IFN- $\gamma$, or IL-12. Cells were washed, fixed, and blocked to avoid non-specific binding. The cells were then stained with a biotinylated monoclonal antibody to human ICAM-1, followed by streptavidin Horse Radish Peroxidase and a standard ELISA colour reaction. FACS analysis was undertaken following trypsinisation of cells and staining with a FITC labelled anti-human ICAM-1 antibody.

Results: Using cellular ELISA, ICAM-1 expression in activated HSC was increased by TNF- $\alpha$ and IFN- $\gamma$ in doses as low as $0.1 \mathrm{ng} / \mathrm{ml}$. The increase in OD reading in the presence of $10 \mathrm{ng} / \mathrm{ml}$ of either TNF- $\alpha$ or IFN- $\gamma$ was up to three times control. This increase in ICAM-1 expression was reproduced by FACS analysis, where it was possible to demonstrate a 2-3 fold increase in ICAM-1 positive staining cells. There was no effect on ICAM-1 expression with IL-12

Conclusions: Primary HSC are difficult to isolate and begin to activate as soon as they are placed in culture on plastic. This study shows that activated, human HSC also express ICAM-1 which can be up-regulated by TNF- $\alpha$ and IFN- $\gamma$ but not IL-12. This may be a useful preliminary tool for examining the differential effects of cytokines, conditioned supernatants and drugs upon activated, passaged human HSC. The ability to simultaneously screen large numbers of potentially active compounds in 96 well format will be invaluable.

\section{A NOVEL SYNDROME: PROGRESSIVE FAMILIAL INTRAHEPATIC CHOLESTASIS ASSOCIATED WITH SHORT STATURE, COLOBOMA, AND CLEFT PALATE}

S. Strautnieks', E. Soler', J.Byrne', A. Baker², G. Mieli-Vergani, ${ }^{1,2}$, R Thompson',2. 'Department of Child Health, Guy's, King's and St Thomas' School of Medicine', London, UK; ${ }^{2}$ Paediatric Liver Service, King's College Hospital, London, UK

The progressive familial intrahepatic cholestases (PFIC) are a heterogeneous group of autosomal recessive conditions. The common features are presentation in early childhood of a subsequently progressive cholestasis leading to end stage liver disease by the second decade. The two most common forms are caused by mutations in $A B C B 11$ and $A T P 8 B 1$, the genes encoding the bile salt export pump (BSEP) and FIC proteins on chromosomes 2q24-31 and 18q21 respectively.

We have identified a patient with PFIC and number of extrahepatic features. This combination has not been described previously. Furthermore we have a genetic explanation for this combination. The patient had progressive familial intrahepatic cholestasis, which presented with severe giant cell hepatitis and required liver transplantation at 16 months. She had features suggestive of the Robin sequence, including microagnathia and a cleft palate, which was repaired at 12 months. In addition she has a unilateral coloboma involving the iris, retina and choroid. She has very poor growth despite intensive nutritional support.

Sequence analysis of the $A B C B 11$ gene identified an apparently homozygous mutation: an $A$ to $G$ change at the invariant -2 position of the 3' splice site of intron 18. The same heterozygous change was detected in the mother but not the father. A de novo deletion was confirmed by haplotype construction across chromosome 2q24-31. Four flanking microsatellite marker loci (D2S2380, D2S354, D2S2395, and D2S 1 1 l) and 3 intragenic loci (BSEP1, BSEP2, BSEP1) were typed. Mendelian inheritance was seen at loci D2S354, D2S 111 however all 3 intragenic loci lacked a paternal allele. The remaining markers proved uninformative. Paternity was confirmed by typing on 5 other chromosomes.

We believe the combined loss of one copy of $A B C B 11$ and one or more adjacent genes is the basis of this syndrome. These features, in the absence of liver disease, have been previously reported to be associated with heterozygous deletions of the adjacent chromosomal region: $2 q 32$. The presence of a point mutation in the remaining copy of $A B C B 11$ caused PFIC.

\section{ADRENAL DYSFUNCTION IS ASSOCIATED WITH LIVER DISEASE}

R. Harry, G. Auzinger, J. Wendon. Institute of Liver Studies, Kings College Hospital, London, SE 13 5DD, UK 
Abstract 79

\begin{tabular}{|c|c|c|c|c|c|c|}
\hline & \multicolumn{2}{|c|}{ AHN/ITU } & \multicolumn{2}{|c|}{ CLD/ITU } & \multicolumn{2}{|c|}{ CLD/Ward } \\
\hline & Median & $\%$ BNR & Median & $\% B N R$ & Median & $\%$ BNR \\
\hline APIII/CP & $78 /-$ & & $78 / 13$ & & $21 / 11$ & \\
\hline Baseline & 286 & 38 & 401 & 20 & 347 & 14 \\
\hline Increment & 307 & 37 & 196 & 62 & 228 & 57 \\
\hline Peak & 679 & 37 & 655 & 30 & 608 & 29 \\
\hline$I+P$ & & 30 & & 30 & & 29 \\
\hline
\end{tabular}

Introduction: Liver failure is associated with vasodilatation and a hyperdynamic circulation. Adrenal insufficiency may result in the same pattern of cardiovascular collapse and contribute to the pathophysiology of liver failure. We used the short synacthen test (SST) to study the incidence of adrenal dysfunction in patients with liver disease in different clinical settings.

Methods: We performed 9am SSTs in 15 patients admitted for routine investigation of stable chronic liver disease (CLD/Ward), 30 with complications of CLD requiring ITU (CLD/ITU) and 45 with acute hepatic necrosis requiring ITU (AHN/ITU). Normal ranges for baseline, increment and peak were defined as for the general population as $>250,250$, and $500 \mathrm{nmol} / \mathrm{L}$.

Results: $(B N R=$ below normal range; $A P=A P A C H E ; C P=C h i l d$ Pugh score)

The absolute values were not significantly different. Baseline is more commonly BNR in AHN $(p<0.005)$ but increment is more commonly $B N R$ in CLD groups $(p<0.001)$. Similar proportions in the 3 groups have inadequate increment and peak $(I+P)$ and thus have an inadequate adrenal response to synacthen. Haemodynamic instability is associated with an increased proportion of patients with reduced adrenal response in $A H N(p<0.001)$ not CLD. More ITU survivors have normal adrenal response (AHN/CLD; $p<0.01$ ).

Conclusion: Adrenal dysfunction in liver disease differs in different clinical settings. Differences in severity of illness and of liver disease may account for this. The presence of decreased response in all groups may suggest that adrenal dysfunction is an inherent feature of liver disease and the association with outcome and haemodynamics suggests it may contribute to pathophysiology.

\section{SERUM IRON INDICES IN BLOOD DONORS: RELATIONSHIP TO HAEMOCHROMATOSIS (GH) GENOTYPE, AGE AND NUMBER OF BLOOD DONATIONS}

K. Palmer, V. Chambers, A. Dalton, R. Sokol, R.J. Pollitt, M.S. Tanner, D. Gleeson. Dept of Child Health, University of Sheffield, Trent Regional Blood Transfusion Service and Liver Unit, Sheffield Teaching Hospitals, Sheffield, UK

Background: There are limited data on phenotypic expression of the GH-associated mutations $\mathrm{C} 282 \mathrm{Y}$ and H63D in healthy populations, especially in regard to the heterozygous state.

Methods: We studied randomly selected male blood donors $(\leqslant 4$ units previously donated) from the Trent Region aged 18-60 yrs. HFE genotyping was performed using a PCR-based BIPASA system. Associations were examined between serum ferritin, iron, unsaturated iron binding capacity (UIBC), \% iron saturation (\%sat)) and HFE genotype, age and no of units donated.

Results: See table:mean+SD

Abstract 80

\begin{tabular}{|c|c|c|c|c|}
\hline Genotype & $\begin{array}{l}\text { Iron } \\
\mu \mathrm{mol} / \mathrm{L}\end{array}$ & $\begin{array}{l}\text { UIBC } \\
\mu \mathrm{mol} / \mathrm{L}\end{array}$ & $\%$ sat & $\begin{array}{l}\text { Ferretin } \\
\mu \mathrm{mol} / \mathrm{L}\end{array}$ \\
\hline Wild/Wild $(n=405)$ & $18.2+9.6$ & $42.7+8.4$ & $30+10$ & $74+76$ \\
\hline Wild/H63D ( $n=724)$ & $18.9+6.3$ & $39.4+7.7$ & $32+10$ & $75+71$ \\
\hline Wild/C282Y (n=552) & $19.7+7.0$ & $37.8+8.4$ & $34+11$ & $80+63$ \\
\hline H63D/H63D $(n=117)$ & $21.6+11.3$ & $37.0+9$ & $37+12$ & $75+57$ \\
\hline C282Y/H63D $(n=100)$ & $23.5+11.3$ & $33.1+7.4$ & $41+11$ & $95+76$ \\
\hline$C 282 Y / C 282 Y(n=16)$ & $30.2+7.8$ & $19.8+10.7$ & $61+16$ & $389+567$ \\
\hline
\end{tabular}

Overall, serum iron and \% sat values followed the patterns: homozygous $>$ heterozygote $>$ wild/wild $(p<0.01$ for both $\mathrm{C} 282 \mathrm{Y}$ and
H63D by ANOVA) and: C282Y > H63D (p<0.05-0.01). UIBC showed a reciprocal relationship with genotype $(p<0.01$ by ANOVA). There was no clear relationship between these indices and age or donation number. Serum ferritin showed a similar (to iron and \%sat) relationship with genotype for $\mathrm{C} 282 \mathrm{Y}(<0.01$ by ANOVA) but not for H63D. For all genotypes except C282Y/C282Y, serum ferritin rose with increasing age and fell with increasing donation number.

Conclusions: In UK blood donors, C282Y and H63D heterozygosity is associated with changes in serum iron indices but these are small compared to those associated with $\mathrm{C} 282 \mathrm{Y} / \mathrm{C} 282 \mathrm{Y}$ homozygosity. For all genotypes except C282Y/C282Y homozygosity, serum ferretin rises with age and falls following donation of $1-4$ units of blood.

\section{USING THE JOINT BRITISH SOCIETIES CORONARY RISK PREDICTION CHART TO CALCULATE CORONARY HEART DISEASE RISK AFTER LIVER TRANSPLANTATION}

D.A.J. Neal', P. Flynn', A.E.S. Gimson', P. Gibbs'², G.J.M. Alexander'. ' Department of Medicine and ${ }^{2}$ Department of Surgery, University of Cambridge School of Clinical Medicine, Addenbrooke's NHS Trust, Cambridge, UK

Background: Hypertension, hypercholesterolaemia, and weight gain are common after liver transplantation. It has not been established whether the development of these complications alters the cardiovascular risk profile after liver transplant.

Methods: The case notes of 108 consecutive adult liver transplant recipients surviving greater than 6 months were reviewed.

Results: Median follow up was 35 months (range 6-76 months). Hypertension developed in $74 \%$ of patients with only $3 \%$ having a history of hypertension prior to transplant $(p<0.001)$. Hypercholesterolaemia was present in $16 \%$ before and $60 \%$ after transplant $(p<0.001) .29 \%$ had a body mass index greater than $25 \mathrm{~kg} / \mathrm{m}^{2}$ at the time of transplant compared with $58 \%$ after transplant $(\mathrm{p}<0.001)$. Diabetes mellitus was present in $8 \%$ before and $12 \%$ of patients after transplant. Cardiovascular events comprised 2 cerebrovascular accidents and 2 cardiac arrhythmias. The Joint British Societies Coronary Risk Prediction Chart incorporates cholesterol:HDL ratios, blood pressure, smoking history, diabetes mellitus, age, and sex. Using these charts we calculated that the 10-year risk of coronary heart disease increased from less than 15\% before transplant to more than $30 \%$ after transplant in $30 \%$ of patients. Overall, risk increased in $34 \%$ and decreased in $4 \%$ whilst in $62 \%$ risk remained unchanged.

Conclusions: Coronary heart disease risk increases after liver transplant. The number of observed cardiovascular events however is low. We would expect more events than we have seen.

\section{DEVELOPMENT OF TETRACYCLINE REGULATED BACULOVIRUS VECTORS FOR HIGH EFFICIENCY GENE DELIVERY AND CONTROLLED PROTEIN EXPRESSION IN HUMAN AND RAT HEPATIC STELLATE CELLS}

C. McCormick², R. Ruddell', M.J.P. Arthur', R.Gao', F. Oakley', M.P.G Harris ${ }^{2}$ and D.A. Mann'. 'Liver Research Group, Division of Infection, Inflammation and Repair, University of Southampton, Level D, Southampton General Hospital, Southampton, SO16 6YD, UK; ${ }^{2}$ Division of Microbiology, School of Biochemistry and Molecular Biology, University of Leeds, Leeds, LS2 9JT, UK

In order to gain a detailed understanding of the biology of the HSC and its role in fibrosis it is adventitious to have the facility to deliver exogenous genes to these cells in culture. Standard DNA transfection protocols deliver DNA to at best $10 \%$ of HSC in culture which is not suitable for studying the phenotypic consequences of introducing 
exogenous genes. There is therefore a specific requirement for development of viral-based vector systems that deliver high efficiency gene transfer to human and rat HSC. We have used a baculovirus vector (AcCALacZ) incorporating a eukaryotic promoter to deliver expression of LacZ to culture activated rat and human HSC at levels approaching $100 \%$ '. The main aim of the current study was to further develop this gene delivery system to enable regulated expression of the gene product being delivered to HSC. To this end two baculovirus vectors were constructed that in combination provide tetracycline regulated gene expression. One virus (BactTA) utilises the CMV promoter to drive expression of the tetracycline activator $\left(\right.$ tet $_{A}$ ), the other virus (BACINDLacZ) carries a LacZ gene under control of the tetracycline operator $\left(t_{0} t_{0}\right)$. When HSC were co-infected with the two viruses tet $t_{A}$ produced from BactTA directed expression of LacZ from BACINDLacZ in a high percentage of cells $(>95 \%)$. Introduction of tetracycline into the cell culture media caused a complete repression of LacZ gene expression demonstrating the ability of the system to deliver regulated expression of an exogenous gene in activated HSC. Ongoing studies will use this tetracycline regulated baculovirus system to deliver regulated expression of wild type and dominant negative transcription factors implicated in HSC activation and fibrogenesis.

1. Mann DA, et al. J Hepatol 2001;34(suppl 1):A1597.

\section{IN VIVO GENE DELIVERY VIA PORTAL VEIN AND BILE DUCT TO INDIVIDUAL LOBES OF THE RAT LIVER USING AN INTEGRIN-TARGETED NON-VIRAL DNA VECTOR IN COMBINATION WITH CHLOROQUINE}

X. Zhang, L. Collins, G.J. Sawyer, X. Dong, Y. Qiu, J.W. Fabre. Department of Clinical Sciences, Institute of Liver Studies, Guy's, King's and St Thomas' School of Medicine, King's College Hospital, Bessemer Road, London, UK

The objective of this study was to evaluate a bifunctional synthetic peptide as a DNA vector for receptor-targeted gene delivery to the rat liver by the portal vein and bile duct routes. The 31 amino acid peptide (polylysine-molossin) comprises an amino terminal chain of 16 lysines for electrostatic binding of DNA, and the 15 amino acid integrin-binding domain of the venom of the American pit viper, Crotalus molossus molossus. Initial in vitro evaluation demonstrated that polylysine-molossin/DNA complexes were much smaller ( 50-100nm versus $500-1300 \mathrm{~nm})$, more positively charged and more stable in isotonic dextrose in comparisons with salt-containing solutions. Vector localisation studies demonstrated that both the portal vein and bile duct routes provided excellent access of polylysine-molossin/DNA complexes to the liver. However, complexes delivered by the portal vein were rapidly lost $(<15 \mathrm{~min})$ following re-establishment of the portal circulation, whereas complexes delivered by the bile duct persisted much longer. Polylysine-molossin/DNA complexes in various isotonic solutions were delivered to the right lateral lobes either by perfusion through a branch of the portal vein, or by infusion into appropriate branches of the bile duct. Two or three hours before gene delivery, rats were given a single injection of chloroquine. We report that the polylysine-molossin vector is much more effective (>10 fold) when delivered by the bile duct route with all isotonic solutions evaluated, and that polylysine-molossin/DNA complexes in isotonic dextrose are much more effective (>10 fold) than complexes in salt-containing solutions.

\section{COMPARISON OF ANTI-CYTOCHROME REACTIVITY IN AUTOIMMUNE HEPATITIS OF AUTOIMMUNE POLYENDOCRINOPATHY-CANDIDIASIS-ECTODERMAL DYSTROPHY AND AUTOIMMUNE HEPATITIS TYPE 2}

U.C. Sharma', D.P. Bogdanos', Y. Ma, P. McClean', S. Tanner ${ }^{3}$, R. Williams', G. Mieli-Vergani ${ }^{4}$, D. Vergani'. 'Institute of Hepatology, Royal Free and University University College London Medical School, London, UK; ${ }^{2}$ Paediatric Liver Unit, St James' University Hospital, Leeds, UK; ${ }^{3}$ Department of Paediatrics, Sheffield Children's Hospital, Sheffield, UK; ${ }^{4}$ Department of Child Health, King's College School of Medicine and Dentistry, London, UK

Autoimmune hepatitis $(\mathrm{AlH})$ of autoimmune polyendocrinopathycandidiasis-ectodermal dystrophy (APECED), a rare condition due to the mutation of the Autoimmune Regulator (AIRE) gene, is similar to AlH type 2 (AlH-2) in terms of seropositivity for liver kidney microsomal antibody (LKM), clinical manifestations, histological appearance and response to immunosuppression. Patients with AlH-2 often develop endocrine autoimmunity, suggesting that the two hepatitides may lie within the same disease spectrum. Cytochrome P4501A2 (CYP1A2) and CYP2A6 have been described as the LKM targets of APECED-AlH while other studies indicate the target to be CYP2D6, the same as in AlH-2. We established enzyme-linked immunosorbent assays (ELISA) measuring reactivity against 11 eukaryotically expressed (CYP1A2, CYP2A6, CYP2D6, CYP3A4, CYP2C8, CYP2C19, CYP1B1, CYP2B6, CYP4A11, CYP2E1, and CYP2C9) and 2 baculovirus expressed cytochromes (CYP3A5 and CYP3A7) and tested sera from 8 patients with $\mathrm{AlH}-2$ and from 3 patients with APECED-AlH, one of whom on 10 occasions. As expected, all sera from AlH-2 patients reacted against CYP2D6; two of the APECED-AlH patients reacted with no cytochrome. In the third patient reactivity to CYP1A2 and CYP2D6 was present on all 10 occasions by ELISA and immunoblotting. Additional reactivity to CYP3A4, CYP4A 11 and CYP3A7 was observed in all 8 sera from this patient tested. No reactivity was detected against CYP2A6. The cytochrome primarily targeted in APECED-AIH remains to be defined. The observed multiple anti-cytochrome reactivity suggests mechanisms of cross-reactivity or epitope spreading among these highly conserved enzymes. APECED-AlH may also be negative for humoral anticytochrome reactivity.

\section{A COST EFFECTIVENESS STUDY OF 3 MONTHS THERAPY WITH PEGYLATED INTERFERON AND RIBAVIRIN IN CHRONIC HEPATITIS C INFECTION}

P. Paine, C. Hobday, C. Brown, A. Higham, J. Morris, T. Rigby, S. Daunt, J. Keating. Depts of Medicine, Morcambe Bay NHS Trust, Barrow and Lancaster, UK

Combination therapy with pegylated interferon and ribavirin is rapidly becoming the gold standard treatment for chronic hepatitis $\mathrm{C}$ infection. The duration of therapy, however, has not been clearly defined. A prospective study was conducted of 30 patients who were PCR positive for hepatitis C $(60 \%$ genotype 1$)$. The majority of patients had mild to moderate disease as assessed by percutaneous liver biopsy using an Ishak scoring system. All patients initially received 3 months therapy with 1.5 micrograms per kilogram of pegylated interferon weekly and 400 milligrams twice daily of ribavirin. Patients' responses were assessed by PCR at monthly intervals following commencement of treatment. Those who remained PCR positive at 3 months were continued on treatment. To maximize compliance, pegylated interferon injection therapy was administered either at the hepatology clinic or by the general practice nursing staff. By not allowing patients to self-administer interferon injections we achieved $100 \%$ treatment compliance. On an intention to treat basis, of the first 20 patients completing 3 months' therapy, 18 patients $(90 \%)$ seroconverted. The 2 non-responders (1 cirrhotic, 1 alcohol abuse) are continuing a further 3 months treatment. Side effects noted were flu-like symptoms in the majority of patients, hair thinning in 2 patients, a Stevens-Johnson like rash in 1 patient, and leucopenia requiring temporary interruption of treatment in one further patient with a subsequent dose reduction. The other 10 patients are either beginning or midway through their treatment course. Sustained virological response is being assessed in the patient group. We conclude that 3 months therapy may be adequate in the majority of patients, with mild to moderate hepatitis $C$, with a consequent financial saving.

\section{HFE MUTATIONS PROTECT AGAINST IRON DEFICIENCY}

M. Purkiss', A. Field-Smith', M. Howell, W.M. Rosenberg'. 'Mailpoint 811 Liver Group, Division of Infection, Inflammation and Repair, University of Southampton, UK; ${ }^{2}$ Southampton General Hospital, Southampton, UK

Background: Hereditary haemochromatosis $(\mathrm{HHC})$ is associated with two mutations in the HFE gene located on chromosome 6, C282Y and H63D which are carried by 1 in 10 and 1 in 5 of the UK population respectively. Homozygosity for C282Y is found in over $90 \%$ of patients with $\mathrm{HHC}$ which in its fully expressed form leads to iron overload and liver disease, arthropathy, diabetes, and cadiomyopathy. The very high prevalence of mutations in HFE raises two questions. Why are clinical presentations of $\mathrm{HHC}$ thought to be rare, and why are mutations in HFE so prevalent? The low detection rate of HHC could be due to a failure of diagnosis of patients with end-organ damage. The high prevalence of HFE mutations suggests that they might be associated with an evolutionary survival advantage. We have explored these hypotheses by investigating the prevalence of HFE mutations in patients coming to joint replacement for non-inflammatory arthritis; and by investigating the iron levels and prevalence of HFE 
mutations in patients confronted by "iron stress" due to non-steroidal anti-inflammatory (NSAID) use and coeliac disease(CD).

Methods: In a case-control study the prevalence of HFE mutations, transferrin saturation (TS) and serum ferritin were ascertained in 31 patients undergoing joint replacement for non-inflammatory joint disease, and 101 age and sex matched controls. In a separate casecontrol study HFE was determined in 81 patients with coeliac disease and 462 ethnically matched controls and genotype and iron levels were ascertained in 66 controls and 47 coeliacs.

Results: Joint disease was associated with $\mathrm{C} 282 \mathrm{Y}$ heterozygosity (16.7\% $\vee 5.9 \%$; not significant), and HFE mutations in this group were associated with significantly higher TS $(p=0.041)$. Amongst the CD patients $9 \%$ carried iron loading genotypes compared with $1.5 \%$ controls ( $p<0.02$ Fisher's exact test). 4 CD patients presenting with normal ferritin carried mutations in HFE while 6 with HFE mutations were iron deficient ( $p=0.02$ Fisher's exact). Conclusions: All HFE mutations appear to protect against iron deficiency in the face of iron depleting "stresses" such as NSAID ingestion or CD. Protection against iron deficiency is likely to be the "survival advantage" attributable to HFE mutations accounting for their high prevalence in Northern Europeans. Our findings also support the hypothesis that patients with occult $\mathrm{HHC}$ may present with end-stage joint disease requiring joint replacement.

\section{APPLYING EASL GUIDELINES ON ROUTINE TRANSFERRIN SATURATION (TFS) TESTING TO IDENTIFY NEW CASES OF HAEMOCHROMATOSIS IN LIVER CLINIC PATIENTS}

A. Poullis, S. Moodie, L. Ang, C.J. Finlayson, J.D. Maxwell. St. George's Hospital and Medical School, London SWI7 ORE, UK

$90 \%$ of patients with hereditary haemochromatosis in European populations are homozygous for the $\mathrm{C} 282 \mathrm{Y}$ mutation. Compound heterozygotes (C282Y/H63D) are at a lower risk of developing significant iron overload. The recent EASL consensus suggested using TFS $>45 \%$ as a phenotypic screening test for the HFE genotype in various high risk populations, including those with chronic liver disease.

Aims: To investigate the effect of routine TFS measurements in detecting new HFE cases in unselected patients presenting to a liver clinic.

Methods: Non-fasting TFS was measured in all patients referred to a liver clinic for investigation of abnormal liver function tests. Genomic DNA was prepared from EDTA blood, DNA fragments were amplified by restriction fragment length analysis and HFE genotyping (C282Y and H63D) was undertaken in all those with elevated TFS and in patients requiring a liver biopsy for other reasons. Patients with previously diagnosed haemochromatosis were excluded.

Results: Liver biopsy and genotype data was available for 248 patients.

(1) 11 new patients were identified as homozygous for the C282Y mutation. 10 of these were identified by elevated TFS, of whom 9 had elevated hepatic siderosis scores and 4 were cirrhotic. 1 with normal TFS had alcoholic cirrhosis. All were of Northern European (majority Celtic) origin. 3 had coexisting HCV and one had PBC.

(2) 6 new compound heterozygotes were detected but only $50 \%$ had tfs $>45 \%$. These subjects had hepatic siderosis but also abused alcohol.
Conclusions: Adopting the EASL strategy of testing at risk populations with TFS and HFE genotyping if this was $>45 \%$ we found C282Y homozygosity to be relatively common $(2-3 \%$ of an unselected ethnically mixed liver clinic population compared to reported European population prevalence of 1 in 188 to 1 in 400) with 45\% already cirrhotic. TFS screening was less effective in identifying compound heterozygotes, few of whom develop iron overload.

\section{INTERLEUKIN - 6 AND - 10 GENE POLYMORPHISMS IN DECOMPENSATED ALCOHOLIC LIVER DISEASE (ALD)}

D. Gleeson, M. Bradley, J. Sorrell², R.J. Peck RJ', G.W. Duff ${ }^{2}$. Liver Unit and 'Dept of Radiology, Sheffield Teaching Hospitals, UK; ' ${ }^{2}$ ivision of Molecular \& Genetic Medicine, University of Sheffield, Sheffield, UK

Background: Only a minority of heavy drinkers develop ALD; twin studies suggest some genetic predisposition. Candidate genes to explain the variable predisposition to ALD include those for the pro and antiinflammatory cytokines IL-6 and IL-10 respectively. Biallelic promoter-region polymorphisms exist at positions - 174 ( $G$ to C) in IL-6 and at -1082 ( $G$ to $A$ ) in IL-10. Both these polymorphisms may be functionally significant but data on their allelic frequencies ALD are limited.

Methods: We studied 2 groups of Caucasian heavy drinkers (>60U/wk(M) or $40 U / w k(F)$ for $>5 y r)(1)$ : Patients $(n=162 ; 110 M$,

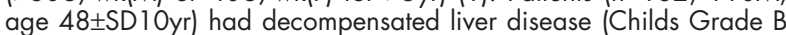
or C; Maddreys DF $31 \pm 311$, a more severe phenotype than in other studies; other liver diseases were excluded by serum testing and, in 56 cases, by liver histology (2): Controls ( $n=102,80 M$, age $49 \pm 9 y$ ) had no clinical liver disease, normal serum bilirubin, albumin and prothrombin time, no abnormality or fatty infiltration on ultrasound, and in 87 cases, a PGA index of $\leqslant 5190 \%$ exclusive of cirrhosis; Gastroenterology $1991 ; 100: 1397)$. Subjects were genotyped at the IL-6 and IL-10 loci using the Taqman system.

\begin{tabular}{|c|c|c|c|c|}
\hline Abstract 88 & & & & \\
\hline Polymorphism & G:G n (\%) & G:A n (\%) & $A: A \cap(\%)$ & $3 \times 2 \mathrm{chi}^{2}$ \\
\hline \multicolumn{5}{|l|}{ IL-10 -1082 } \\
\hline Patients & 38 (23) & 80 (49) & 44 (27) & 1.76 \\
\hline Controls & $28(37)$ & 44 (43) & 30 (29) & (ns) \\
\hline IL-6 -174 & $\mathrm{G}: \mathrm{G}$ n (\%) & GC n $(\%)$ & $\operatorname{CC} \mathrm{n}(\%)$ & \\
\hline Patients & $45(28)$ & $87(54)$ & 30 (19) & 0.99 \\
\hline Controls & 34 (33) & $56(55)$ & 12 (12) & (Ns) \\
\hline
\end{tabular}

Results: see table. In patients with ALD, there were no significant differences with regard to age at presentation, severity of liver disease or lifetime alcohol intake between the three genotypes for either polymorphism.

Conclusion: These data do not support roles for these IL-6 and II-10 polymorphisms in determining genetic susceptibility to ALD. 